\title{
ON THE ACTIVITY OF THE SPERMATOZOA \\ OF PERIPLANETA
}

\author{
by \\ MALCOLM HUGHES B.Sc.(Edin.)
}

Submitted in partial fulfilment for the degree of Master of Science in McGill University, Montreal.

Apri], 1968

(C) Malcolm Hughes 1969 


\section{ABSTRACT}

MALCOLM HUGHES

Department of Zoology

M.Sc. Thesis

On the Activity of the Spermatozoa of Periplaneta

The spermatozoa of the cockroach, $\underline{P}$.americana, are physiologically different in the male and female.

In Gouldin's solution ( $\mathrm{pH} 7$ ) the tail-beat frequency of sperms from the seminal vesicles is about 400 - 700 beats/min; those from the spermatheca beat about 800 - 1200 beats/min. Also the large leaf-shaped acrosome is smaller and simpler in the latter sperms. These differences are reminiscent of sperm capacitation in mammals. They were not duplicated in vitro by tissue extracts, chemicals or modifications to the Ringer.

Sperms are always quiescent in situ, except, perhaps, during sperm transfer to the female. Activity in vitro is remarkably independent of tissue extracts, added substrates, variations in ions, and of glucosamine, seratonin, adrenaline, ATP; but dopamine inhibits strongly at $10-2 \mathrm{M}$ and less so down to about $10^{-6} \mathrm{M}$. Inhibition is reversible to some extent. 
"Considering how intimate some of the cockroaches are with us, it is disconcerting to find how little we know of their private lives."

\section{R.E.Snodgrass, 1937}

Smithsonian misc. Coll., 96, (5)

"A suspension of spermatozoa is one of the nicest assemblages of cells with which one could work."

Lord Rothschild, Sperm Movement: Problems and Observations, in 'Spermatozoan Motility', 1962, D.W.Bishop, editor (ref, cited). 


\section{LIST OF CONTENTS}

$\underline{\text { Page }}$

Preface - - - - - - - - - - - - - - - - iv

List of Illustrations and Abbreviations - - - - - - - - - v

List of Tables - - - - - - - - - - - - - - vii

Chapter One - Introduction - - - - - - - - - 1

" Two - Setting out the Problems - - - - - - - 5

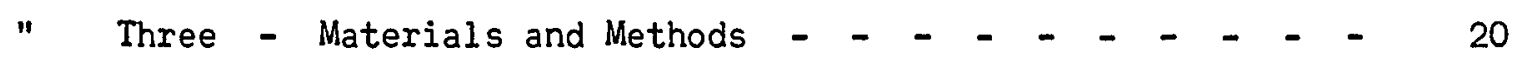

" Four - The Transfer and Maintenance of Sperms - - - 26

" Five - Spermatozoan Activity - - - - - - - 34

" Six - Substrates, Ions and Pharmacology - - - - - 45

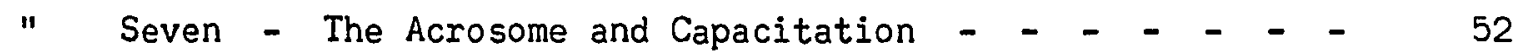

" Eight - An Assessment - - - - - - - - - - - 55

Summary - - - - - - - - - - - - - - -

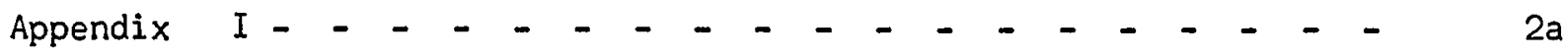

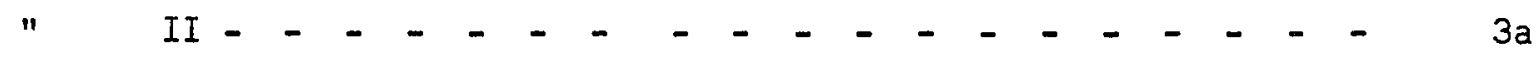

References - - - - - - - - - - - - - - - $5 a$ 


\section{LIST OF ILLUSTRATIONS}

Fiqure

Preceding page

1. Spermatozoa of Periplaneta from the seminal vesicles - - 4

2. Tail of a dead spermatozoon - - - - - - - - 4

3. Diagram of the male and female reproductive organs

during copulation - - - $-\quad-\quad-\quad-25$

4. Terminal capsule of the spermatheca - - $-{ }_{-}-{ }_{-}-33$

5. Spermatheca with an irregular-capsule and forked branch - - 33

6. Diagram of a spermatheca showing minor branches - $\quad$ - -33

7. Active spermatozoa within the spermatheca of a recently

mated cockroach - - - - - - - 33

8. Active spermatozoa within the plain branch of the

spermatheca $-\quad-\quad-\quad-\quad-\quad-\quad-\quad-\quad-33$

9. (a) Quiescent spermatozoa within the capsule of the

spermatheca - $-\quad-\quad-\quad-\quad-\quad-\quad-\quad 33$

(b) The neck region of the capsule - - - - - 33

10. Disoriented sperms in the capsule; quiescent after violent

activity - - - - - - - - - - 33

11. Oriented sperms; quiescent after synchronous beating - - 33

12. Diagram of the sperm release mechanism at fertilization - - 33

13. The activity of spermatozoa from the male seminal vesicles

in Gouldin's solution - - - $\quad$ - $\quad$ - 44

14. Diagram of the spermatheca - - - - - - - - 35

15. The activity of spermatozoa from the spermatheca in

Gouldin's solution - - - - - - - -44

16. The effect of dopamine on sperms from the male and the

female $-\quad-\quad-\quad-\quad-\quad-\quad-\quad-51$ 
17. The acrosome of a spermatozoon from the seminal vesicles - -54

18.

19. Smears of spermatozoa from the spermatheca $-{ }_{-}-{ }_{-}-54$

20. Pathological changes in the sperm acrosome $-{ }_{-}-{ }_{-}-54$

21. Disintegrating sperms from the male $-{ }_{-}-{ }_{-}-{ }_{-} 54$

22. Micropyles in the chorion of the egg $-{ }_{-}-{ }_{-}-{ }_{-} 54$

23. Diagrams of the position of the sperm acrosome during swimming - $-\quad-\quad-\quad-\quad-\quad-\quad-\quad-58$

\section{ABBREVIATIONS USED IN FIGURES}

a.
b. bacterium acrosome
b.c. bursa copulatrix
c. capsule of spermatheca
c.m. cell membrane
cnl. canaliculi of secretory cells
co.g. colleterial gland
c.ov. common oviduct
e.d. ejaculatory duct
m.b. mushroom body (male accessory glands)
m.l. muscle layer
mp. micropyle
m.s. mitochondrial strand of nebenkern
n. nucleus
ph.g. phallic gland

r. rectum

s.c. secretory cells

s.h. sensory hairs

s.v. seminal vesicle(s)

sp. spermora

sph. spermatophore

sth. spermatheca

sth.d. spermathecal duct

sth.s.

"

sclerite

sz. spermatozoon

sz.t. sperm tail

t. testis

v. vestibule

v.g. vestibular gland

v.d. vas deferens 


\section{LIST OF TABLES}

Preceding page

1. Minor branches of the spermatheca of Periplaneta $-\quad-\quad-33$

2. Copulation and the transfer of semen $--_{-}+-{ }_{-}-33$

3. Activity of sperms from different parts of the spermatheca --- 35

4. Activity of sperms from the seminal vesicles with male accessory glands and muscle - - - - - - 44

5. Activity of sperms with spermathecae and insect leg muscle 44

6. Activity of sperms with spermathecae removed during copulation - $-\quad-\quad-\quad-\quad-\quad-\quad-44$

7. Activity of sperms removed during and after copulation - - -44

8. Modified Ringer solutions - - - - - - - - - 45

9. Activity of spermatozoa from the male and from the female with hexose - $--{ }_{-}-{ }_{-}-{ }_{-} 51$

10. Activity of spermatozoa with glucosamine - - - - - 51

11. Activity of spermatozoa with citrate $-{ }_{-}-{ }_{-}-{ }_{-} 51$

12. Activity of spermatozoa with variations in phosphate - - - 51

13. Activity of spermatozoa in solutions of simple salts - - $\quad 51$

14. The effect of ATP on spermatozoa from the seminal vesicles and from the spermatheca $-\quad-\quad-\quad-\quad-\quad-51$

15. The concentrations of adrenaline and seratonin tested on various preparations of spermatozoa - - - - 51

16. The inhibition of sperm motility by dopamine $-\quad$ - $-\quad$ - 51

17. The reduction in size of the sperm acrosome within the female cockroach - - - $-\quad-\quad-\quad-\quad-54$ 
INIRODUCIION

Since 1679, when Von Leeuwenhoek presented his observations on spermatozoa to the Royal Society, these unique, motile cells of the mature male have aroused the interest and imagination of both scientist and layman alike. The present day student of spermatozoa may simply echo the words of Charles Bonnet, writing some 200 years ago, "They are, of all animalculi of liquids, those which have most excited my curiosity...." (Mann, 1964).

Bonnet continued his letter by enumerating, with remarkable clarity, the numerous questions that their discovery provoked. Some of these questions we would today clearly recognise as those of spermatogenesis, sperm motility and metabolism, and the, then unknown, phenomenon of fertilization. Indeed this latter, most important function of the spermatazoon was the subject of keen controversy for some 200 years until the claims of the "ovists" and those of the "animalculists" were finally resolved by the work of Prévost and Dumas who in 1824, recognised the spermatozoon as the fertilising agent initiating normal development of the egg (Parkes, 1956). A classical case of biological compromise.

An interesting point raised by the proponents of "generation ex ovo" was that spermatozoa were merely some sort of infective microorganism. This was not then an unreasonable assumption, but it is surprising, as Thaddeus Mann clearly points out in his text on semen biochemistry, that there is a remarkable similarity between the penetration of an egg by a spermatozoon and the penetration of a bacterium by a phage particle (Mann, 1964).

The present study of an insect spermatozoon must be seen in the context 
of the process of reproduction as a whole. Reproduction forms the all-important link in the chain of events from one generation to the next. It is a particularly weak link, susceptible to external interference and therefore of greater interest from the human point of view.

Studies on insect reproduction have recently been reviewed in detail by Wigglesworth (1965) and in a more general way by Davey (1965a) and Imms (1957). The reproductive processes of the commoner cockroaches are relatively well known although much detail is still lacking, as is emphasised by Roth and Willis (1954) in their review. The American cockroach Periplaneta americana, is able to reproduce parthenogenetically for a number of daughter generations (Roth and Willis, 1954). But this does not detract from the significance and interesting problems associated with the spermatozoon and fertilization of the egg.

In insects generally, considerable diversity exists between spermatozoa of different species and even some polymorphism may occur within a species (Lee and Wilkes, 1965). The spermatozoon is typically very long, filiform, with no middle piece. Rather, the mitochondria fuse to form a 'nebenkern' consisting of one or more very long mitochondria wound around the length of the tail except for the terminal projection of the axial filament (Davey, 1965i) In the sense above, the sperm of Rhodnius is typical (Davey, 1958) as is that of the honey bee (Rothschild, 1955), some other hymenoptera (Flanders, 1920; Wilkes, 1965), and as is commonly the case in most groups studied. It has been suggested that the filamentous form is a necessary adaptation for entry of the spermatozoon into the egg through a narrow micropyle in the chorion, which is elsewhere a resistant coat specialised for water-retention within the egg. The non-filamentous spermatozoon of Periplaneta is an 
exception and this may relate to the larger egg micropyle diameter or to other, unknown factors (Davey, 1965a).

Remarkable are the filamentous spermatozoa of Notonecta each about $1 \mathrm{~cm}$ long (Pantel and De Sinety, 1906); those of Cicindela and Lepisma in which the proximal centriole appears to drag the axial filament and nebenkern anterior to the nucleus (Nath et al., 1960, but to be fair others do not accept this, Gatenby and Marthur, 1960); and those aflagellate, motile spermatozoa of a homopteran and a dipteran in which some 60 to 80 microtubules are believed to fulfill the function of the normal flagellum (Moses, 1966; Phillips, 1966).

The spermatozoon of Periplaneta has a clearly defined head with a distinct apical acrosome and is about $70 \mu$ long (Fig.1). The nebenkern consists of two mitochondrial elements in Periplaneta (Bradfield, 1955), Culex (Nunez, 1963), and Rhodnius (Davey, unpublished data). In Periplaneta these appear to run parallel to the tail axis, for the flagella of dead sperms may easily separate into 3 distinct elements after rupture of the tail membrane (Fig.2).

The spermatozoon is not unlike the mammalian type and swims in a similar way, that is by vigorous oscillations of the tail and usually these are nicely mono-planar, unlike the complex spirallations of filamentous spermatozoa. The movements of the spermatozoa of orientalis, in vitro, were described by Dewitz (1886). Recent workers have studied, in americana, sperm genesis and structure (Nath et al., 1957) and sperm activity in relation to temperature (Davey, 1958a; Richards, 1963), sperm density (Davey, 1958a) and hydrogen ion concentration (Davey, 1958a).

I know of no other works in which the activity of an insect sperm has been measured. Periplaneta was therefore an obvious choice for establishing a point of reference and for comparison with results obtained from spermatozoa 
of other groups.

Activity may be represented in terms of the percentage of sperms swimming, their velocity, metabolic activity, etc. But in the present study the tailbeat frequency of the fastest, freely swimming spermatozoa was measured and, in some cases, the results were supplemented with brief comments on the general level of activity.

The considerable literature on spermatozoan activity has been reviewed selectively by Sleigh(1962) and widely by Mann (1964). There has been an important symposium on spermatozoan motility (Bishop, ed., 1962). But there are few reports of the tailbeat frequency (Sleigh, 1962). These are given later for comparison with the results of this study.

In the following chapter some significant facts and problems concerning spermatozoa generally and insect sperms particularly are reviewed, and the aims of this investigation are set out. 


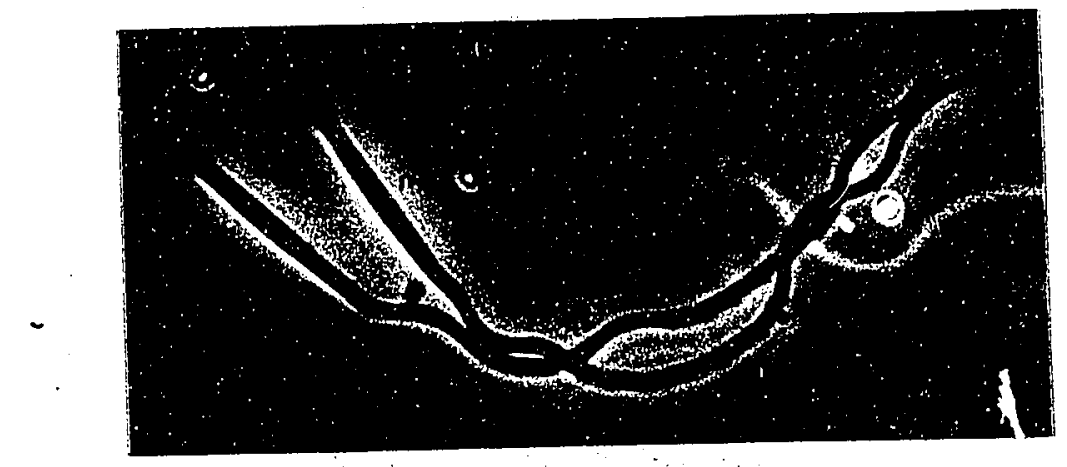

Figure 1. Spermatozoa of Pexiplaneta from the seminal vesicies. (x1250).

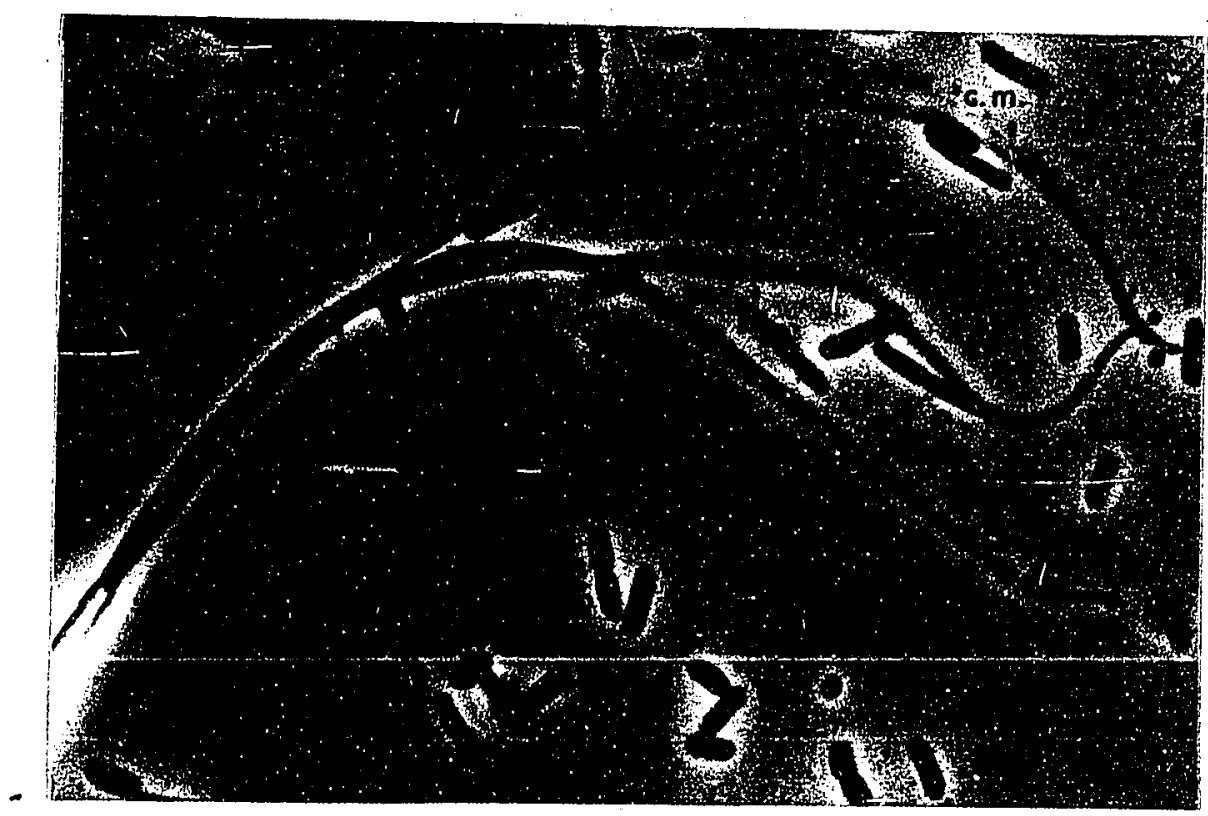

F1gure 2. Tail of a dead spermatozoon, apparently showing the two mitochondrial strands of the nebenkern. (x2500). 


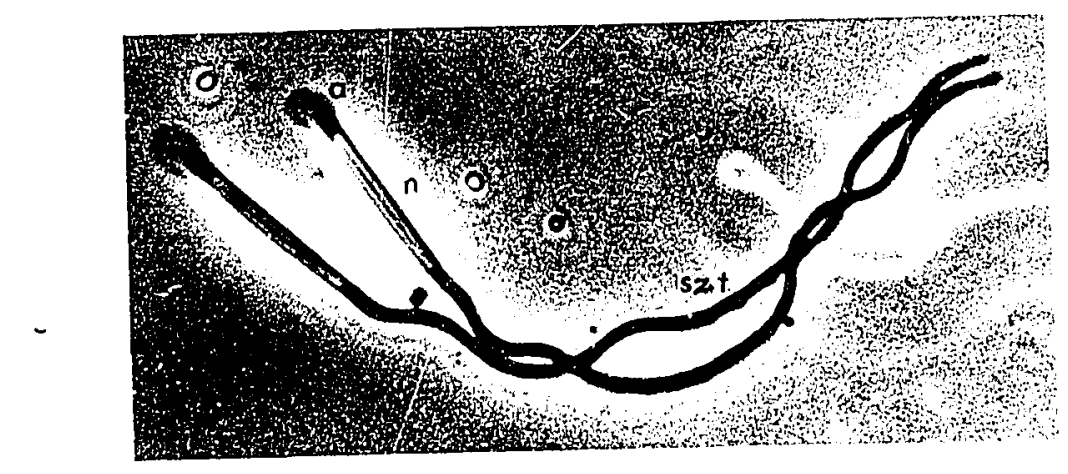

Figure 1. Spermatozoa of Periplaneta from the seminal vesicles. $(\mathrm{x} 1250)$.

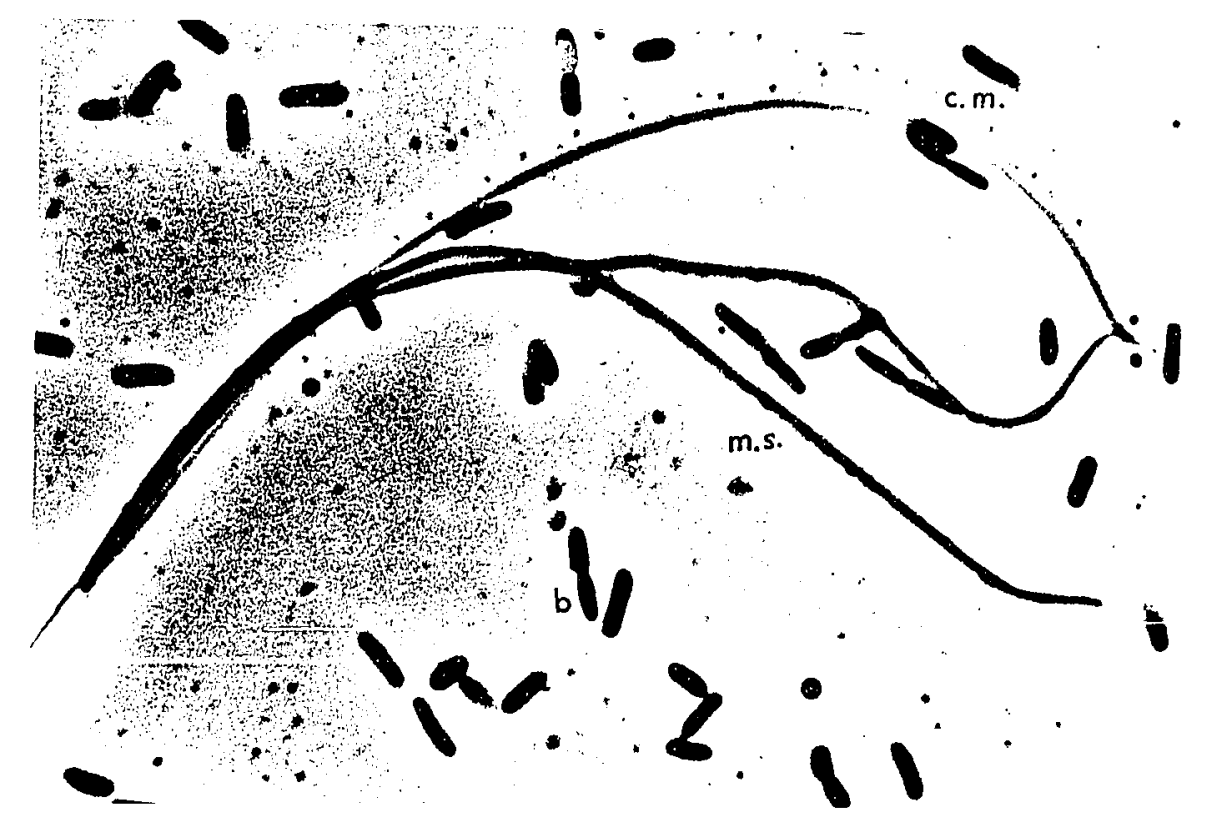

Wigure 2. l'ail of a dead spermatozoon, apparently showin the two ratochondrial strands of the nebenkern. $(x 2500)$ 


\title{
Chapter Two
}

\section{SETTING OUT THE PROBLEMS}

\begin{abstract}
"But it is necessary to emphasize that problems relating to spermatozoa and fertilization must be seen in the widest possible context ...."

Thaddeus Mann,

The Biochemistry of Semen and of the Male Reproductive Tract, 1964.
\end{abstract}

The activiation of frog spermatozoa that was observed by Koelliker in 1856 when he added saline to them has long been known as the 'dilution effect'. In sea urchin sperms this is mainly due to an increased availability of oxygen for sperm respiration (Rothschild, 1950). A similar conclusion was reached for ram sperms by Amir and Schindler (1967), who showed that neither respiration nor fructolysis were directly related to sperm density but that at greater concentrations than $10^{9}$ sperms/ml. oxygen diffusion was retarded. Excessive dilution or repeated washing of sperms produces permanent inactivation which Mann considers due to degenerative processes similar to those of senescence. In mammalian spermatozoa these result in breakdown of the lipoprotein cell coat, oxidation of intracellular sulphydryl groups essential for normal motility, loss of vital coenzymes such as ATP, increased sperm permeability leading to loss of sperm proteins, enhanced dehydrogenase activity, and an imbalance in ion exchange mechanism with a pronounced loss of $\mathrm{K}^{+}$ions (Mann, 1964).

These processes can be retarded mainly by the addition of proteinaceous or carbohydrate substrate. This is not to imply that nutrition is the only answer, but it is certainly very important. For example, the in vitro 
vitality and the endogenous reserves of fowl sperms can be preserved by the addition of hexose or by the presence of adequate oxygen (Proudfoot and Stewart, 1967). The improvement with oxygen is produced by the high efficiency in metabolising endogenous material, oxidative pathways being some 15 times more efficient in energy production that glycolysis (Gonse, 1962).

At sperm densities of from $105 \times 10^{6} \mathrm{cells} / \mathrm{ml}$. to $3 \times 10^{6} \mathrm{cells} / \mathrm{ml}$. the effect of concentration on Periplaneta spermatozoa was known to be slight and insignificant when compared with individual variability (Davey, 1958a).

It was suggested by Gray, some 37 years ago, that inactivity of sperms in dense masses might be due to a physical, mutual inhibition - a 'packing effect' or ailelostasis (Sleigh, 1962). But as we have seen, in the sea urchin seminal vesicles the inactivity is unlikely to be allelostatic but due to inadequate diffusion of oxygen inwards to the sperms (Rothschild, 1948b). In the case of glycolysing spermatozoa they may presumably be inhibited by an accumulation of metabolites rather than by lack of oxygen.

However, aside from metabolic controls, the viscosity of the surrounding fluids may exert some inhibitory effect (Sleigh, 1962): Also, a mutual inhibition of flagella may be expected when they beat asynchronously (Rothschild, 1962). This inhibition will tend to maintain sperms quiescent when densely packed. But allelostasis alone is of limited significance.

The flagellar beat responsible for sperm motility is produced by the contraction of protein associated with the outer 9 paired microtubules of the axial filament. This protein, dynein, may form the two "arms" of each pair of tubules as seen in cross section and is an active adenosine triphosphatase, similar, but not identical to the myosin of muscle (Gibbon, 1967). Dynein hydrolysis ATP at the rate of from 13 to $35 \mathrm{moles}$ ATP/second/mole of enzyme 
and this possibly represents the dephosphorylation of one mole ATP/mole dynein/ beat cycle (Brokaw, 1967). This would place a theoretical maximum of about 35 beais/sec. $(2,100$ beats/min $)$ on the beating of cilia and flagella. The membranelles of Stentor beat 23 times/sec. at $16.7 \mathrm{C}$ and their maximum rate of $36.3 \mathrm{beats} / \mathrm{sec}$. occurs at 28.1C. Paramecium cilia beat at 28 beats $/ \mathrm{sec}$. (Sleigh 1962). Activity of bull sperms is about 550 beats/min. and sea-urchin sperms from 1,800 to 2,400 beats/min. (Gray, 1953,1955, in Sleigh, 1962). Thus the theoretical maximum may, in fact, be exceeded.

Aside from providing the immediate energy for beating, ATP is thought to have a relaxing or plasticizing action. Pyrophosphate and various other substances or conditions may have a similar effect (Sleigh, 1962; Hayashi, 1962; Mann, 1964). However, the activating effect of ATP has only been demonstrated in glycerinated preparations of sperm tails (Sleigh, 1962; Mann, 1964), although some cilia show an increase at about $10^{-5} \mathrm{M}$ ATP (Sleigh, 1962). Activation of sperms by ATP was first demonstrated in an insect, the locust Tachycines (Hoffman - Berling, 1955). Adenesine triphosphatase activity has been found, associated with the sperm microtubules in an hemipteran (Moses, 1966). Abundant pyrophosphate is passed in the semen of the hawk-moth, Celerio euphorbiae and may be concerned with the activity of the spermatozoa (Heller and Piechowska, 1956).

Ionic and osmotic conditions are important. Sperm metabolism and motility are influenced by the total tonicity of the medium, the relative concentrations of the cations $\mathrm{H}^{+}$and $\mathrm{Na}^{+}, \mathrm{K}^{+}, \mathrm{Ca}^{++}$amd of $\mathrm{Mg}^{++}$, and of some anions e.g. $=\mathrm{HCO}_{3}$ and citrate, and by the partial pressure of $\mathrm{O}_{2}$ and $\mathrm{CO}_{2}$ (Salisbury, 1962). The sodium : potassium ratio is considered important. For example, in bulls the concentration of potassium in testicular fluids may be about double that of sodium and as high as the concentration within sperms themselves. High $\mathrm{K}^{+}$is thought to be inhibitory by some workers (Mann, 1964). 
Steinback and Dunham (1962) postulate "maintenance of normal conducted flagellar movements depends on ion gradients pumped into the tail by the headmidpiece machinery". This implies, among other things, a leaky tail membrane (Bishop, 1962).

Activity is perhaps regulated otherwise, for example, acetylcholinesterase is present in sperms, outside the axial microtubules, especially in the head-middlepiece region (Tibbs, 1962). Eserine at as little as $5 \times 10^{-1} \mathrm{M}$ increases the rate of Mytilus sperms while acetylcholine at $10^{-1}$ to $10^{-3} \mathrm{M}$ has no effect (Applegate and Nelson, 1962). Acetylcholine may be involved in the coordination and propagation of flagellar waves (Nelson, 1964); and it stimulates cilia at from $10^{-5}$ to $10^{-7} \mathrm{~g} \cdot / \mathrm{ml}$. while depressing them at higher concentrations. (Sleigh, 1962).

Adrenaline and noradrenaline have an inhibitory effect on aerobic, but not anaerobid, fructolysis at $10-100 \mu \mathrm{g} / \mathrm{ml}$. They are both thought to be present, at a much lower concentration, in mamnalian semen (Mann, 1964). The other important biogenic amine, seratenin, is probably not found in mammalian semen but is found in the male reproductive tract of other groups (Mann, 1964). There are active amines associated with the reproductive organs of insects (Davey, 1960b, 1965a). These amines are most likely concerned in stimulation of the female tract to assist sperm passage (Mann, 1964). I have found no reports of their effect on sperms. But adrenaline and seratonin have a marked stimulatory effect on the frequency of some cilia at about $10^{-5}$ to $10^{-7} \mathrm{~g} / \mathrm{ml}$. (Sleigh, 1962).

The $\mathrm{pH}$ of the medium is one of the most important factors influencing the respiration, metabolism, motility and viability of spermatozoa. Species variations are rather slight, the optimum level for survival of most 
spermatozoa being a little over $\mathrm{pH}$ 7. Lower values progressively decrease motility and metabolism while values of $\mathrm{pH} 8$ and above may stimulate maximal activity. At values below pH 6 and above pH 9 spermatozoa tend to die off in a few hours or less (Mann, 1964).

Salisbury (1962) has summarised this difficult subject. He tentatively concludes that the $\mathrm{pH}$ of the medium will reflect the activity of spermatozoa in it, both as to motility and rate of energy exchange. In the absence of adequate oxygen, glycolysis is directly related to $\mathrm{pH}$ up to that concentration of $\mathrm{H}$ ions at which glycolysis is optimum. The latter value is unknown but is possibly about pH 8 for mammalian sperms in vitro.

In mammals there is a gradient of from about $\mathrm{pH} 6$ in the epididymis to above pH 7 in follicular fluid (Salisbury, 1962; Mann, 1964). In contrast, the bug Rhodnius has a $\mathrm{pH}$ about 7 above the bulbus ejaculatorius while in the bulbus, penis, bursa copulatrix and spermatheca the $\mathrm{pH}$ is less than 6 . Greater activity of the spermatozoa occurs in acid media but, although violently active at $\mathrm{pH}$ 5.6, the sperms from the male vesicles die (Davey, 1958a).

The spermatozoa of the honey bee keep well in a solution at pH 7.4 (Taber and Blum, 1962) and their activity is greatest in alkaline media (Ruttner, 1956 ). A study by Davey (1958a) had shown that Periplaneta spermatozoa are feebly active below $\mathrm{pH} 6.2$ and that their activity rises steadily until $\mathrm{pH} 7.6$ above which activity stops.

It must be emphasised that conditions producing maximum activity usually result in minimal viability. In view of this and the results obtained by Davey for Periplaneta it was decided to maintain Ringer solutions at pH 7in this study.

The metabolism of spermatozoa is similar to that of other cells; anaerobic 
glycolysis and lactate formation occurring in the absence of oxygen and in its presence, oxidative phosphorylation taking place with the evolution of carbon dioxide (Mann, 1964; Sleigh, 1962; Gonse, 1962; Terner, 1962). But, in contrast to most cells, fructolysis may take place with equal facility. This is considered by Mann (1964) to be of survival value in the female tract where the considerable amounts of seminal fructose will be preferentially metabolised by the spermatozoa rather than by cells of the tract itself. Seminal fructose from the mammalian seminal vesicles (usually) is mixed with the quiescent epididymal spermatozoa only at the moment of ejaculation.

Four features of sperm metabolism require comment. First, some of the energy produced may be utilized for cell maintenance rather than activity (Mann, 1964; Terner, 1962). Secondly, lactate may be removed by amino acids, such as glycine, due to transamination to alanine (Filpse, 1962). Thirdly, bull sperms may produce acetyl-CoA, $\mathrm{CO}_{2}$ and lactate by dismutation of pyruvate under aerobic and anaerobic conditions (Terner, 1962), and fourthly, in mammals, glycolysis occurs preferentially even in the presence of oxygen (Gonse, 1962). The second point concerning improved viability with the addition of glycine may help explain the "chelating effect" discussed by Tyler (1953), amino-acids having both a buffering and nutritive function.

The last point requires further explanation as this preference for glycolysis is probably a general feature of spermatozoa where internal fertilization takes place and oxygen may be scarce. The answer may not be a simple one because it has been clearly shown by Nevo (1965) that oxidative respiration can support full motility of bull, ram and cock sperms down to about $4 \mathrm{~m} \mathrm{Hg}$ partial pressure of $\mathrm{O}_{2}$, whereas in the normal female tract, the value is higher at about $35 \mathrm{~mm} \mathrm{Hg}$. Gonse (1962) postulates that energy carriers are 
more readily available for movement during glycolysis than oxidative phosphorylation and are thus recycled at a more favourable rate. This could explain an adaptive preference for glycolysis. The motility of sea urchin sperms, which are dispersed in the sea, is dependent on oxygen concentration (Rothschild, 1948a, 1948b).

In summary, there appear to be two types of spermatozoa - those that are externally dispersed whose motility is primarily sustained through oxidative phosphorylation, and those deposited internally which utilize anaerobic glycolysis preferentially even in the presence of oxygen.

Internal fertilization is usual in insects and anaerobic glycolysis is known to sustain the activity of the spermatozoa of Rhodnius and Periplaneta (Davey, 1965j) and of Melolontha (Landa, 1961). It is therefore likely that this represents the normal source of energy. Blum and Taber (1965) found that both glycolysis and Krebb's cycle occur in honey bee sperms. They suggest that the concentrated hexoses in the seminal plasma support the sperms during their migration to the spermatheca, just as seminal fructose is used by mammalian spermatozoa.

Let us now turn to the female system and consider the conditions there and their effects on the spermatozoa.

In 1963 Hamner and Williams found that incubation of rabbit spermatozoa in the uterus and of fowl spermatozoa in the oviduct produced a fourfold increase in oxygen consumption of rabbit sperms and a twofold increase with cock sperm. The latter spermatozoa also showed, in vitro, a fivefold increase in oxygen consumption in the presence of oviduct fluids. These observations suggest some relationship between the stimulation of sperm metabolism and their approach to the ovum. 
Continuing their investigations in 1964 they concluded that bicarbonate ion concentration may be the sole stimulatory factor. Maximum respiration of rabbit spermatozoa occurred at $2.36 \times 10^{-3} \mathrm{M}-\mathrm{HCO}$ and at a concentration of $3.54 \times 10^{-3} \mathrm{M}$ for bull and human spermatozoa. The $\mathrm{pH}$ was maintained at 7 throughout. Furthermore, in view of the fact that succinate brought about a similar level of stimulation, they suggested that the action of bicarbonate was to increase the concentrations of intermediates in the citric acid cycle. Soupart and Orgebin-Crist (1966), found that the concentration of bicarbonate in the fowl oviduct was about $21 \times 10^{-3} \mathrm{M}$ and that, with spermatozoa incubated in Hanks solution containing $4 \times 10^{-3} \mathrm{M}$ bicarbonate, respiration increased but there was no corresponding increase in fertilizing capacity.

The problem of the respiratory stimulator present in the female involves more than bicarbonate concentration. Aside from the high value of bicarbonate in vitro reported above, two other workers, Ogaswara and Lorenz (1964) concluded that the active material was a large molecule - very likely a protein in nature - not found, or detectable in egg albumen or blood.

These results may prove compatible on the basis of the hypothesis that bicarbonate stimulates the respiration of the spermatozoa generally, while the protein activator induces greater activity of the spermatozoa, thus increasing respiration. It is known that for bull, ram and cock sperms their motility and oxygen consumption are directly related (Nevo, 1965). It is apparent that motility and respiration must be observed simultaneously to test the above hypothesis.

Evidence for a protein activator comes indirectly from work on echinoderm spermatozoa. Several kinases and in particular, myokinase, 
produce a relaxation of muscle fibres and an activation of the flagella of spermatozoa (Kinoshita, 1959). This problem is related to the roles of $\mathrm{Ca}^{++}$and $\mathrm{Mg}^{++}$, and to the Marsh-factor type of relaxing system in muscle and sperm tails (Sleigh, 1962; Hayashi, 1962).

Alternatively, Lardy et al., (1949) suggest a metabolic regulator in bull sperms which is released in an active form after ejaculation. This may be a sulphydryl compound but according to Mann (1964) the general implications are not clear. However, more work on this problem has been discussed by Blum and Taber (1965). It seems that Broquist and Lodge, in 1960, postulated that the quiescence of bull sperms in the epididymis may be due to the inactivation of lactate dehydrogenase by formation of a complex with NAD and bisulphite. Bisulphite is said to be an effective inhibitor of some sources of this enzyme. Perhaps incidentally, sulphite occurs in bee semen (Blum and Taber, 1965).

This picture of sperm inactivation by the inhibition of one enzyme is rather simple. Davis (1965) is inclined to support Salisbury (1962), that inactivity is produced by a complex set of environmental conditions. It is likely that both suggestions will prove more or less valid when more evidence on sperm inactivity is available.

Why is it that, while possessing a considerable amount of data, we are still rather ignorant of the detailed interactions that take place between the seminal fluids, sperms and female tract from the moment of ejaculation to the point of fertilization of the egg?

The answer is rather simple. The results of most in vitro studies of spermatozoa are as irrelevant to their normal functioning as are laboratory studies to the ecology and ethology of wild animals. There is 
no obvious solution. For the cell-biologist "fieldwork" is, to say the least, restricted and even the act of observing may invalidate the observation, for example, light rays may have a stimulatory effect on fowl sperms (Hamner and Williams, 1963).

The relative inactivity or activity of spermatozoa at any stage may well be of adaptive significance. Considering that there is no further opportunity for cell growth and little chance of repair processes, quiescent sperms are in a state of suspended animation, conserving endogenous enzymes and substrates - or so it might seem. In fact, however, there is evidence that with such sperms there is an appreciable exchange with the surrounding medium (Mann, 1964).

An important theory of the survival value of motility has been proposed by Carlson (1962). He states that, in organisms generally, motility serves either, or all, of the following three functions: escape from predators, finding a mate, increasing the available food supply. Putting aside the first two of these, he concludes that flagella, simply through stirring the medium, increase available nutrients. More important, movements through the medium results in an increase in available food and there must always be a range of velocities at which there is a net gain of food input over energy expended for motility. 'Food' in such a case can apply to oxygen or other essential substance.

This is an attractive theory for two reasons. First, sperm motility has little to do with getting egg and spermatozoon in close proximity, except, perhaps, where the male gametes are freely dispersed as in the case of many marine invertebrates. Secondly, in support of Carson's theory is the fact that in many insects the spermatozoa are active in the spermatheca 
(Davey, 1958b; Lefevre and Jonsson, 1962; Surtees, 1961; Wilkes, 1965), in which case they may presumably be assisting in their own sustenance by stirring the contents of the duct.

In animals generally, semen is either poured directly over the egg, or after insemination the spermatozoa are transported to the appropriate region of the female tract for storage or for fertilizing the eggs. In mammals this transport is entirely due to contractions of the female ducts brought about by stimulation from the sympathetic region of the hypothalmus and the hormone, oxytocin, released from the pituitary (Cross, 1959; Mann, 1964). There are also oxytocic factors, such as prostaglandin, in the semen which probably augment the action of the female hormone (Freund et al., 1964; Rorie et al., 1966). In the bug Rhodnius the male spermatophore, enveloping the sperms, contains a biogenic amine which stimulates the female resulting in contractions of the ducts and the passive transport of the sperms to the spermatheca (Davey, 1958b). It has been suggested that honey bee sperms, by aligning themselves with the duct, probably assist their passive transport into the spermatheca (Ruttner, 1956). In some lepidoptera sperms are apparently passively transported (Norris, 1932); while in others sperm activity may play a part (Hewer, 1934; Omura, 1938a); but in some hymenoptera (Flanders, 1939; Wilkes, 1965) and some diptera (Jones and Wheeler, 1965; Nonidez, 1920) sperm motility may be solely responsible for their migration to the sperm receptacle.

Sperm motility has often been assumed and sperm chemotaxis has been suggested to help explain their passage through the female ducts (Landa, 1961; Weidner, 1934). It has also been suggested as occurring with vertebrate sperms, especially among fishes (Olm Nelson, 1953). It is clear 
from criticisms that there is, as yet, no proven case of chemotaxis occurring with any animal spermatozoa (Davey, 1965a; Hinton, 1964; Monroy, 1965). Sperm rheotaxis (Jones and Wheeler, 1965b) and thigmotaxis (Dewitz, 1886) have been demonstrated and may, in some cases, orientate the sperms in the female. But, except in Rhodnius, it is not known how sperms enter the storage receptacle and why, in some cases, they then become quiescent. Flanders (1939) has suggested a sort of negative kinesis of sperms in relation to a self generated $\mathrm{CO}_{2}$ gradient within the spermatheca. But this remains to be proven.

Cailson's concept is applicable to the enzymatic assault which the spermatozoon must make on the egg. In mammals, vigorous stirring by the sperm tail will assist the digestion of follicular debris and zona pellucida around the egg. In insects there is no zona around the egg and spermatozoa are usually conducted to the vitelline membrane by a narrow micropyle in the chorion. Perhaps in insects fertilization is achieved more by physical than biochemical penetration. The acrosomal reaction, with release of the acrosomal filament and/or a lytic enzyme and the subeequent passage of the sperm nucleus into the egg is quite well understood for several animals (Colwin and Colwin, 1967; Parkes, 1956). This and other phenomena related to fertilization are nicely summarised by Monroy (1965) and Brachet (1960) and considered in detail in 'Fertilization' (Mertz and Monroy, editors, 1967).

There is considerable disagreement concerning the presence and function of a hyaluronidase in the acrosome (Chang, 1959; Kurzrok and Birnberg, 1958; Mann, 1964; Moghissi et al., 1964; and Hartree and Srivastava, 1965). The last named authors postulate a sperm hyaluronidase 
for penetration of the corona cells and a uterine neuraminidase which may remove the sialic acid residues found only in the acrosomal region of the sperm. These residues give the sperm head a negative charge while the hyaluronic acid surrounding the egg is also negatively charged. The removal of sialic acid in or on the acrosome will therefore reduce the negative/ negative repulsion of egg and spermatozoon. Other mechanisms are of course possible. (See Soupart and Clewe, 1965, for a partial contradiction of the neuraminidase effect, and Tyler eta1.1967for the immunological evidence on sperm/egg interactions.)

Suggestions of enzymatic reactions between sperm and female tract are almost certainly part of the phenomenon of 'capacitation'. It now appears likely that in most animals the spermatozoa in the female tract are in a dffferent physiological state from those in the male or a fresh ejaculate. When such a physiological change results in an increased ability of the spermatozoa to fertilise the eggs of the female, they are said to be capacitated.

There is no simple explanation of this process. The positive results obtained by incubation of sperms with $\beta$-amylase in vitro (Kirton and Hafs, 1965) or in ectopic sites (Noyes et al., 1958) are criticised by Soupart and Orgehin-Crist (1966), who set out the correct protocol for testing fertilizing potency.

Capacitation is not obviously related to any morphological change, as suggested by Blanajau and Rumery (1964), but consists of several processes, at least one of which is species specific and possibly restricted to the female tract (Bedford and Shalkovsky, 1967). A further complicating factor in considering this phenomenon is the evidence that capacitated rabbit sperms 
may be decapacitated by some factor in the seminal plasma, (Chang, 1957; Bedford and Chang, 1962; and discussed by Kirton and Hafs, 1965; Tyler et al., 1967).

There is evidence that capacitation may occur in insects. The artificial insemination of females is usually more successful if sperm taken from the spermatheca of another female, rather than from a male, are used (Davis, 1965; Gottschewski, 1937). Jones and Wheeler (1965b), studying insemination in Aedes, say that their studies indicate that sperms must be stored in the thecae before they are capable of fertilizing the eggs. This is clearly suggestive of capacitation. However, Makielski (1966) was first to suggest that capacitation may occur in an insect. But she carefully qualified this, concluding that, while sperm maturation in the spermatheca may be peculiar to the gnat Sciara, other insects should be examined for the existence of capacitation.

Sperm maturation in the female is not peculiar to Sciara. For the males of some insects pass, not free spermatozoa but bundles of sperms held together by a simple hyaline cap (Payne, 1933, 1934), or bound into more or less complex bundles (Gibbons, 1967; Omura, 1938a; Moses, 1962). The disruption or digestion of these sperm bundles in the female can be considered as a step in sperm maturation.

However, although the above phenomena are probably significant steps leading to fertilization, the criterion for capacitation is the improved fertilizing capacity of the sperms in the female. Strictly speaking, one should qualify this by expecting the improvement, however produced, to be as a result of similar changes as occur in the female. Admittedly the mammologists have not clearly demonstrated the latter point, but to be too 
general devalues a useful term.

To sum up, it is clear that there are many problems, concerning spermatozoa and of real importance in reproduction, on which new information would be useful. We may ask how are sperm motility and activity regulated in Peripleneta? How are the spermatozoa transported and maintained in the female? Does capacitation occur?

The present work must be seen as a preliminary investigation concerned with the physiology of the spermatozoa and its role in insemination. The aims were to observe the in vitro behaviour of sperms, that is within the reproductive organs and tracts of both sexes; and the sperms activity, or inactivity, during insemination. Also, to measure sperm motility in terms of tailbeat frequency; the effects on motility of brei from various organs of the male and feinale systems; and the effects on motility of some pharmacological agents and environmental conditions.

The extent to which these aims have beer fulfilled is discussed in the final chapter. 
Chapter Three

MATERIALS AND METHODS

Healthy male cockroaches were removed from the general cultures (see Appendix I), their heads and then their abdomens were cut off. The abdomen was opened from the ventral side and by pulling on the genitalia with forceps, the posterior segments of the abdomen with the ejaculatory duct and mushroombody were separated from the rest. (See Fig. 3 for morphology).

The seminal vesicles were easily distinguished under the $16 \mathrm{x}$ power of a binocular dissecting microscope. They were carefully removed with fine stainless steel forceps, and placed in one drop of a Ringer solution (see Appendix II) on a depression slide where they were opened up and the resulting debris gently homogenised with a Pasteur pipette.

Females were similarly prepared and, after removal of the posterior sternites, oviducts and abdominal ganglion, the spermathecal capsule could be plainly seen. To expose both branches of the spermatheca the spermathecal sclerite was pulled posteriorly until its concave inner surface was turned upwards and the surrounding fatty tissue was carefully removed (see Fig. 3 ). The tightly coiled branch of the spermatheca thus exposed was carefully loosened by the removal of surrounding tracheae and the whole spermatheca was pinched off at the common exit and placed in Ringer on a slide.

When time permitted, observations were made on the activity and morphology of the entire organ and of the sperms inside. The sperm suspension was prepared as described above.

The resulting suspension of spermatozoa was distributed dropwise by pipette onto other slides for experimental observations. Roughly equal 
amounts of solutions were added to all slides and they were sealed with a coverslip which had been lightly smeared with petroleum jelly around the edges. A small bubble of air inevitably became trapped under at least one coverslip and, for consistency, was therefore routinely included. All slides were observed at regular intervals when at least ten readings were taken of the most active spermatozoa on each slide.

Readings of tail frequencies were made with a stroboscope (Strobotac, type 1531 - A, General Radio Co., U.S.A.) as the microscope illuminator. The stroboscope was adjusted until a swimming spermatozoon was "stopped" in a figure of 8 configuration. This represented double the true frequency of tail-beat and, aside from providing greater illumination and less flicker, it removed the possibility of reading some harmonic of the true frequency that might appear normal. Only those that conformed to this method were read and, in fact, the most active spermatozoa do swim with an obvious, monoplanar, stroke. The stroboscope gave a reading on which the observational error was about \pm 20 . This resulted in a final observational error of \pm 10 beats per minute on the true frequency. It was not found necessary to recalibrate the stroboscope over a period of some months.

The method outlined above is that used by Davey (1958a) in a similar study of the spermatozoa of Periplaneta. The use of the stroboscope for investigating ciliary and flagellar activity is discussed by Sleigh (1962) who suggests that it may only be of use with cilia which beat more than 8 to 10 times a second ( 480 to 600 beats/minute). The above technique, using $2 x$ the frequency enabled successful readings to about 300 beats/minute. However, very few readings were taken below $400 \mathrm{~b} / \mathrm{min}$.

The microscope used throughout most of this study was a standard, 
binocular, Zeiss GFL, with phase optics. Observations were routinely made with $8 \times$ oculars, $10 x$ objective $(\mathrm{PH} 1)$ and the condenser set to PH2. This gave a large field, 80x magnification and a satisfactory dark background illumination. There was an advantage that the $\mathrm{PH} 2$ objective could immediately be swung into place for detailed observations at a magnification of 320x. Photomicrographs of living and fixed materials were taken with a Zeiss Photomicroscope. The materials were on a slide in Ringer and no special mounting preparations were used.

Gouldin's solution was used throughout this study, except where stated otherwise. This had been used by Richards (1963) and the spermatozoa were known to live for up to 12 hours or longer in this medium. The full details of the solutions used in the experiments are given in Appendix II.

The $\mathrm{pH}$ of Gouldin's solution was found to be about $\underline{6.5}$, which was considered to be rather low (see Chapter 2). In view of this Gouldin's solution was routinely buffered to $\mathrm{pH} 7 \pm 0.05$ with a few drops of $0.067 \mathrm{M} \mathrm{Na}_{2} \mathrm{HPO}_{4^{\circ}}$ In the cases where phosphate was unsuitable as a buffer, a few drops of $0.05 \mathrm{M}$ tris (2-amino-2-(hydroxymethyl)-1,3-propanediol) were added to about $5 \mathrm{ml}$ of the solution.

The additions of buffer were of insignificant effect on the total tonicity of solutions. Care was taken throughout this study not to alter the osmolarity of solutions to any appreciable extent, except where otherwise stated.

In mammals, the spermatozoa may experience $350-360$ milliosmoles in the epididymis and as little as 285 milliosmoles in the semen (Salisbury, 1962). Spermatozoa are generally rather resistant to such changes (Mann, 1964). Those of Periplaneta exhibit maximal activity in a simple salt solution 
at $1.34 \% \mathrm{NaCl}$ (Davey, 1958a). This represents 458 milliosmoles which is remarkably high, but as the solutions used by Davey did not give such longevity as Gouldin's at about 290 milliosmoles, it was not felt necessary to increase the osmolarity.

The effects of temperature on spermatozoa, in particular extremely low temperatures, is reviewed by Mann (1964).

Two independent observations have been made with the spermatozoa of Periplaneta. Davey (1958a), working with spermatozoa from the seminal vesicles released in a Ringer solution, found that they became very sluggish : below a room temperature of 15C. By means of a heated stage the temperature was raised to some unknown, but constant temperature which gave satisfactory activity. Richards: (1963) found that the velocity of Periplaneta spermatozoa showed an almost straight-line increase from $16.1 \mathrm{microns} / \mathrm{sec}$, at $15 \mathrm{C}$ to $53.6 \mathrm{\mu} / \mathrm{sec}$ at 39C. The range of individual values at the two extremes was from $8.5-35 \mu / \mathrm{sec}(15 \mathrm{C})$ and from $27-107 \mu / \mathrm{sec}(37-39 \mathrm{C})$.

In the present investigation the room temperature was maintained at $24 \mathrm{C}$ and all materials were allowed to equilibrate to this temperature. This was convenient for work, well in the range of good spermatozoan activity and yet not so high that bacterial multiplication was apparent during the first hours of observations.

The dilution effect and allelostasis have been discussed in Chapter 2. Concentrations varied considerably in the present study, but they were the same throughout any single experiment. Concentrations in different experiments varied from about $1 \times$ to $10 \times 10^{6}$ sperms $/ \mathrm{ml}$. In any case, the spermatozoa sank in a mass usually to near the centre of the slide depression and those swimming in the region of the mass were no different from those 
observed on the underside of the coverslip where effective concentration effects were initially negligible.

The spermathecae of females, direct from the colony, frequently contained rather few spermatozoa and this tended to limit the scope of any one experiment.

A Variance Ratio Test on the 10 readings from different preparations, compared one with another, sometimes resulted in $F$ values of about 3 and in a few extreme cases of about 5. These represent significant differences between preparations (Moroney, 1951).

How can this be reconciled with the assumption that results are samples from a normal population distribution? First, if the few extreme results are omitted the general picture remains unchanged. Secondly, reading only 10 of the fastest individuals tended to exaggerate differences and observational errors. It is reasonable to assume, therefore, that data from similar experiments may be grouped to provide a mean result with its standard error.

But we cannot rule out the possibility that differences between cockroaches may be significant, for example, recently moulted males may have more, or less active sperms than old unmated males. Isolation of males for a few weeks did not eliminate the general variability.

Low levels of activity are sometimes denoted by the following comments. Fair; reasonable activity below 400 beats/min.

A Few; spermatozoa swimming but numbers or activity very poor. None; none swimming but tails beating.

Zero; all activity at, or near zero. In some cases the data has been only partially grouped to show the 
variability, in others, one or more "typical" cases are presented, or finally, the mean results are presented. 


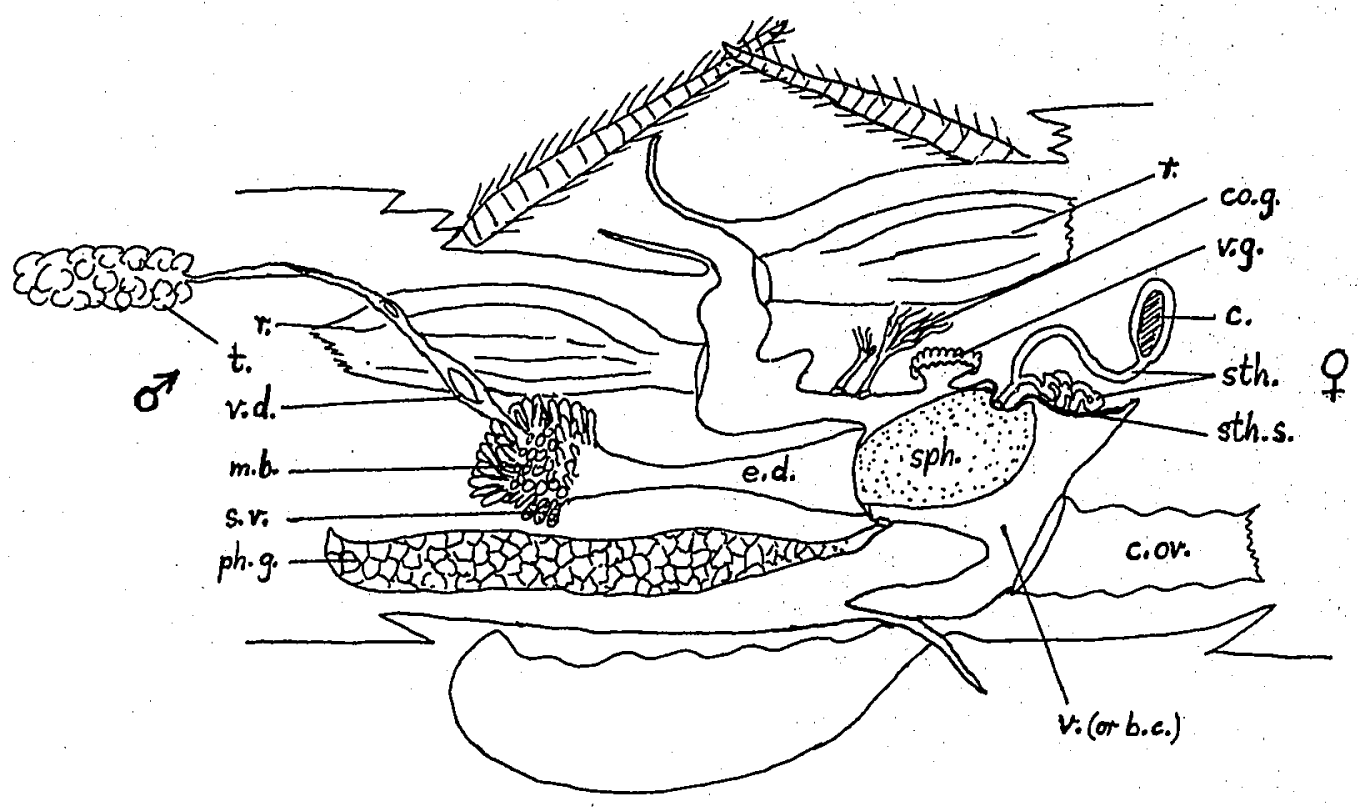

Figure 3. Diagram of the male and female reproductive organs during copulation (Modified after Gupta, 1947). 


\section{Chapter Four}

\section{THE TRANSFER AND MAINTENANCE OF SPERMS}

A brief outline of the morphology of the reproductive systems, with some additional information on the spermatheca, is necessary before considering sperm transfer, their maintenance and some of the experiments to follow this chapter.

The reproductive organs and associated appendages of insects are thoroughly described in a series of papers by Snodgrass (1931, 1933, 1936, 1940). A simplified picture is given in most entomological texts (e.g. Imms, 1957).

The genital organs of Blatta orientalis and Periplaneta americana are considered perfectly homologous (Peytourneau, 1895). The monograph on orientalis by Maill and Denny (1886) is now inadequate, but an excellent description of the organs of $\mathbf{P}$.americana is given by Buck and Keister (in F.A.Brown, ed., 1950). The salient features of the male and female systems are shown in Figure 3. The seminal vesicles and spermatheca are the sperm storage organs of the male and female respectively. The accessory glands of the male provide the substance of the spermatophore (Davey, 1959; Khalifa, 1950). In the female, the colleterial glands secrete the protein for the ootheca (Brunet, 1951). The vestibular organ is secretary and may possibly lubricate the passing egg or assist in producing the glue which binds the egg within the ootheca (Brunet, 1951). This organ and the egg are in apposition at the moment of release of sperms from the spermatheca (Dewitz, 1886). The secretion might conceivably support sperm activity on the egg surface. 
There has been some confusion of terminology and of fact in the literature concerning the spermatheca. A spermatheca develops as an invagination of the cuticle between the 8 th and 9 th abdominal segments (Snodgrass, 1933). There are exceptions, e.g. in Rhodnius the pair of spermatheca are not homologous (Davey, 1958b). They may be single or paired and frequently take the form of a long duct with a terminal or subterminal large chitinous capsule. The duct above the capsule, or a simple branch of the duct near it, is usually called the spermathecal gland, while the capsule is called the receptaculum seminis (see Fig.3). This is confusing as the term 'receptaculum', is a synonym for spermatheca, and 'spermathecal gland', has also been applied to a separate organ (van Wyk, 1952). It is more logical to reserve the term 'spermatheca' for the entire organ and to denote the various parts by descriptive terms only, until their function is correctly known.

In the cockroaches B.orientalis and $\underline{\text { P.americana there is one spermatheca }}$ (Snodgrass, 1940) while in Blattella germanica and Leucophaea maderae there are two (Khalifa, 1950; van Wyk, 1952).

The last two papers caused some trouble in the investigation. Khalifa says: "The spermathecae in germanica are accompanied by two huge spermathecal glands which are almost certainly responsible for stimulating the sperms in the spermatophore." This was an attractive lead. Van Wyk cites Khalifa's statement and, on at least one occasion, omits the original, qualifying, "almost". Van Wyk also cites Snodgrass (1933) with respect. to B.orientalis and P.americana. I can find no reference in Snodgrass's paper to justify his stating: "The spermathecal gland is an apical branch of each spermatheca. In these cases the secretion of the gland activates 
the spermatozoa and has a direct influence on the reproduction of the blattids."

The spermatheca of Periplaneta americana has two branches, as does that of B.orientalis, but both branches store spermatozoa. On this subject, Voy (1949) presents a brief historical summary from which it is clear that as early as 1841, Siebold correctly described the "receptaculum seminis" of orientalis. It appeared, hidden under fat tissues, in the form of two short blind ducts one of which was enlarged at the posterior end; both ducts contained spermatozoa. This was confirmed by in 1925 by Vogel (in Heberday, 1931) and, in part, by Bordas (1909). Bordas found that, although the two branches fused proximally, their ducts and exits remained separate. Voy, on the other hand, found a single short common duct and single orifice. On a very few occasions I found no common duct in Periplaneta, but in several spermathecae it was distinct and from 0.5 to about $1 \mathrm{~mm}$ long. Spermatozoa were always present in both branches of the spermatheca after mating. I found some polymorphism of the capsule and in the branching of the spermatheca.

The capsule slowly darkens after ecdysis to an amber or dark brown colour. It is about $1 \mathrm{~mm}$ in length, more or less, and is usually sausage-shaped (Fig. 4) but may be irregular (Fig. 5), almost globular, or in the form of a dumbell. The capsule wall is thick, firm and brittle, unlike the continuous, thin, flexible, hyaline intima that lines the remainder of the ducts. It is also surrounded by a greater thickness of secretary cells (Fig. 4).

The two main branches of the spermatheca are obviously different in situ; one lies rather freely in the haemocoel and is a loose S-shape 
with a pronounced terminal swelling containing the chitinous capsule. The other branch is tightly folded and tucked unobtrusively in the hollow of the spermathecal sclerite (Fig.3). The form of both branches is partly maintained by a restraining network of tracheae. If these are removed both branches are seen to be from about 3 to $4 \mathrm{~mm}$ in length. A variable feature is the number, size and position of minor branches which may be found on either of the two major branches. Such branches are always similar to the rest of the duct and may contain spermatozoa. The results from a study of 46 spermathecae are in Table 1. A forked branch is shown in Figure 5; Figure 6 illustrates the usual position of the branches of the spermatheca. The percentage frequencies in the table are approximate and no doubt further polymorphism may occur.

The histology of all regions of the spermatheca, aside from the points noted above, is very uniform and consists of a chitinous intima, penetrated by numerous intracellular canaliculi from the large secretory cells surrounding it, which themselves are enclosed in a thin muscular layer (Voy, 1949; Bordas, 1909). The spermatheca is well supplied with tracheae (Figs. 4 and 7).

Now to consider the transfer of semen. Gupta (1947) says that both sexes kecome ready to copulate at least six days after their last ecdysis and that males are capable of copulating at intervals of 6 to 7 days throughout their lifetime. I found that adults lived for many months and that the seminal vesicles of mature males were always full of sperms. Males isolated for a few weeks showed a great enlargement of the vesicles which became anvil-shaped, normally they appeared club-shaped. Thus suggests that the pair of dorsal testes are functional throughout the adult life and produce a 
continuous supply of sperms. The normal form of the vesicles is probably maintained by regular copulation every week or two. It must be said that some authors consider that the testes degenerate after the last moult (Buck and Keister, in Brown ed., 1950).

Copulation in Periplaneta is most fully described by Gupta (1947), but there are many errors. For example, he says "There is no courtship. A male becomes sexually excited when fully formed spermatophore is present in its ejaculatory ducts and moves about in search of a female while the latter behaves indifferently and does not try to mount the back of the male as mentioned by previous workers. There is no glandular secretion to affect sex-attraction."

Virgin and other receptive females secrete a potent sex attractant which stimulates the males (Roth and Willis, 1954; Mann, 1965). In the presence of a virgin or its pheromone males attempt to insert their extended abdomens under other cockroaches in search of the genitalia. These attempts are from the front of the other insect and are accompanied by a vigorous fluttering of the raised wings. After successful attachment the female dismounts and the pair assume a tail-to-tail position (Roth and Willis, 1954, Alexander, 1964; author's observations). I found large seminal vesicles; but no spermatophore, in a male killed 15 minutes after the start of copulation. The spermatophore is formed from the accessory gland material late in copulation as in many other insects (Davey, 1960a; Khalifa, 1950, 1949; Roth and Willis, 1954).

Gupta found that the spermatophore is not discharged from the male within at least 60 minutes from the beginning of copulation which lasts about 75 minutes. The spermatophore remains attached to the papilla for about. twenty-one hours during which the spermatic fluid within the spermatophore 
passes into the spermatheca. The spermatophore then presumably falls out of the bursa and is eaten by the female (Gupta, 1947). In one case only, I have found a brown, shrivelled spermatophore in the bursa of a female mated 48 hours previously.

Females take about 7 days to produce an ootheca and several may be produced in rapid succession (Roth and Willis, 1954). Gupta (1.c.) says that females again copulate only when their store of sperms is exhausted. But he provides no evidence to support this. He found females ready to copulate 3 to 4 hours after depositing an ootheca. The possible mixing in the female of semen from different males raises some interesting problems which have been investigated in Drosophila (Lefevre and Jonsson,-1962), but were not studied in this work.

Table 2 presents a summary of observations on copulation and sperm transfer in Periplaneta. Adult virgin females were isolated for at least 7 days and then mated with healthy males in glass bowls. This usually took place in the dark, in an incubator. Females were killed and the spermatheca removed to Ringer as described in Chapter 3.

The spermatophore is white, pliable but extremely tough and it was impossible to tell if sperms were quiescent within it. When opened or squeezed in Ringer a dense mass of sperms emerged from a pore (perhaps more than one) and they dispersed very rapidly.

Rippling of the muscle layer of the spermatheca in recently mated females was clearly observed in situ and in vitro with the whole organ. This continued for many minutes. The spermatozoa within the spermatheca were quiescent in all cases, except in the spermatheca of female no. 4, or after the organ was some time in Ringer. In the case of no. 4, sperms were 
observed actively ascending the ducts which were sparsely filled, many sperms had reached the capsule and the end of the plain branch (Fig. 7). In the latter region the rhythmic beating of the mass of sperms was clearly seen (Fig. 8). This high activity continued in vitro for 90 minutes, but the sperms did not all ascend to the ends of the two branches. It is possible that a downward flow of secretion or active assistance by the muscles of the ducts is necessary for effective filling to occur.

The picture in Figs. 7 and 8 is very different to that in Fig. 9 where sperms are in a dense quiescent mass. One is forced to ask if sperms are capable of movement in such a mass, and if their active ascent of the ducts could result in their being so tightly packed? Results show that high activity may indeed occur despite the sperm density. In the case of no. 6 (Table 2 and Fig. 9) complete inactivity within the spermatheca was observed for 5 hours. But active spermatozoa were swimming out from the torn end of the ducts and most spermatozoa were vigorously active when the spermatheca was finally opened up.

Inactivity was found in no. 5 (Table 2) also. But after 5 minutes the sperms in the capsule and its duct were incredibly active. This continued for about 30 minutes and then subsided until all movements ceased after 60 minutes. The spermatozoa were now irregularly packed except at the apex of the capsule where free movement was presumably restrained (Figs. 10 and 11). Figure 11 is similar to the sperm pattern found in fixed honey bee spermathecae (Bishop, 1920b) and with the living spermatozoa (Rothschild, 1955).

The other, plain branch of this spermatheca showed no active sperms for at least 15 minutes. After an hour the spermatozoa were found to be 
violently active and the whole branch was contracting spasmodically. ... Thus it is clear that high sperm density per se does not abolish sperm activity.

In female no. 7 (Table 2), the capsule was not full of sperms and a shrivelled spermatophore remained in the bursa. This suggests some abnormal condition of either the male or female.

On the question of sperm maintenance in the female there are two points to note. First, sperms are normally quiescent in the spermatheca, and secondly, that organ is well tracheated (Figs. 4 and 7). The implications of this are discussed in Chapter 9.

A likely mechanism for the release of spermatozoa at fertilization was suggested by Dewitz in 1886. The descending egg is in intimate contact with the spermora (exit of spermatheca) but sperms are not ejected until the egg touches sensory hairs on the cuticle at the posterior of the vestibular gland (Fig. 12). This mechanism would ensure the release of sperms onto the micropylar region of the egg. However, no innervation of the spermatheca or sensory hairs have been reported and Dewitz's suggestion requires to be proved.

In many females I observed vigorous contractions of the capsule branch in situ, and occasionally for over 30 minutes in vitro. After mating the capsule and then its duct were the first to empty of spermatozoa. The neck of the capsule is pliable and twisted (Fig. 9b) and might conceivably collapse during such contractions resulting in the expulsion of sperms and secretion. It is difficult to imagine what special purpose the capsule might serve other than as a store for secretion, that is as a pump reservoir. This might explain why the capsule branch extends far into the blood where fluids are more readily absorbed. 
(2)

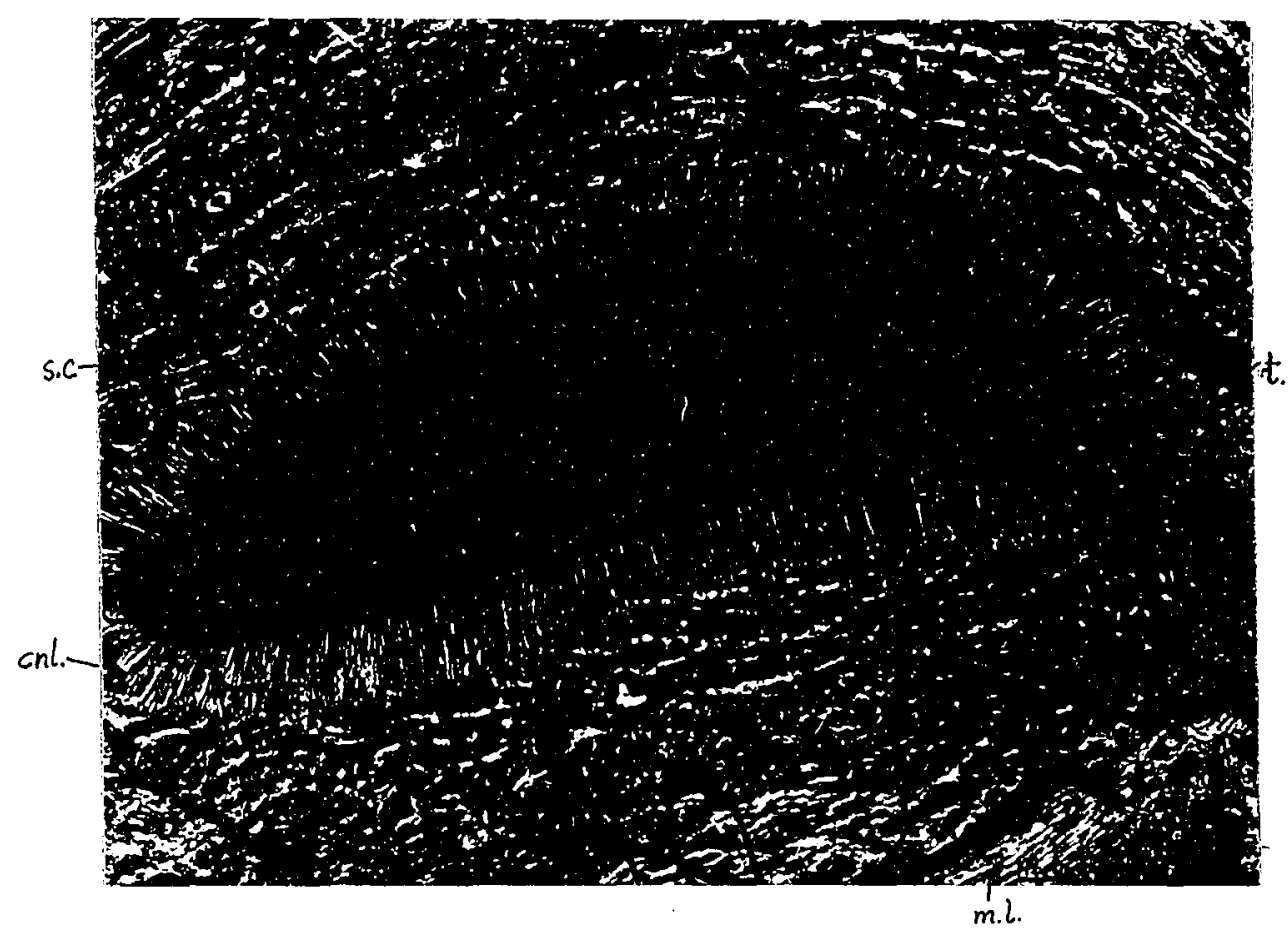

Figure.4. Terminal capsule of the spermatheca showing tracheae and the surrounding layer of secretory cells with canaliculi leading into the capsule. ( $x 120)$.

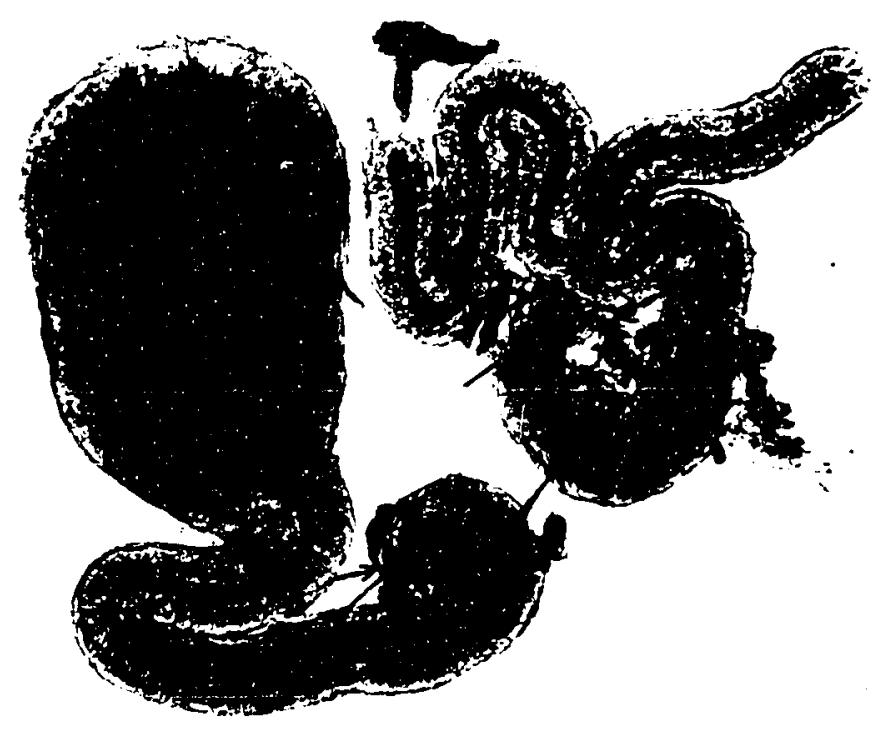

Figure 5. Spermatheca with an irregular capsule and forked branch. Note the torn ends of each major branch (Arrows). $(\mathrm{x} 50)$. 


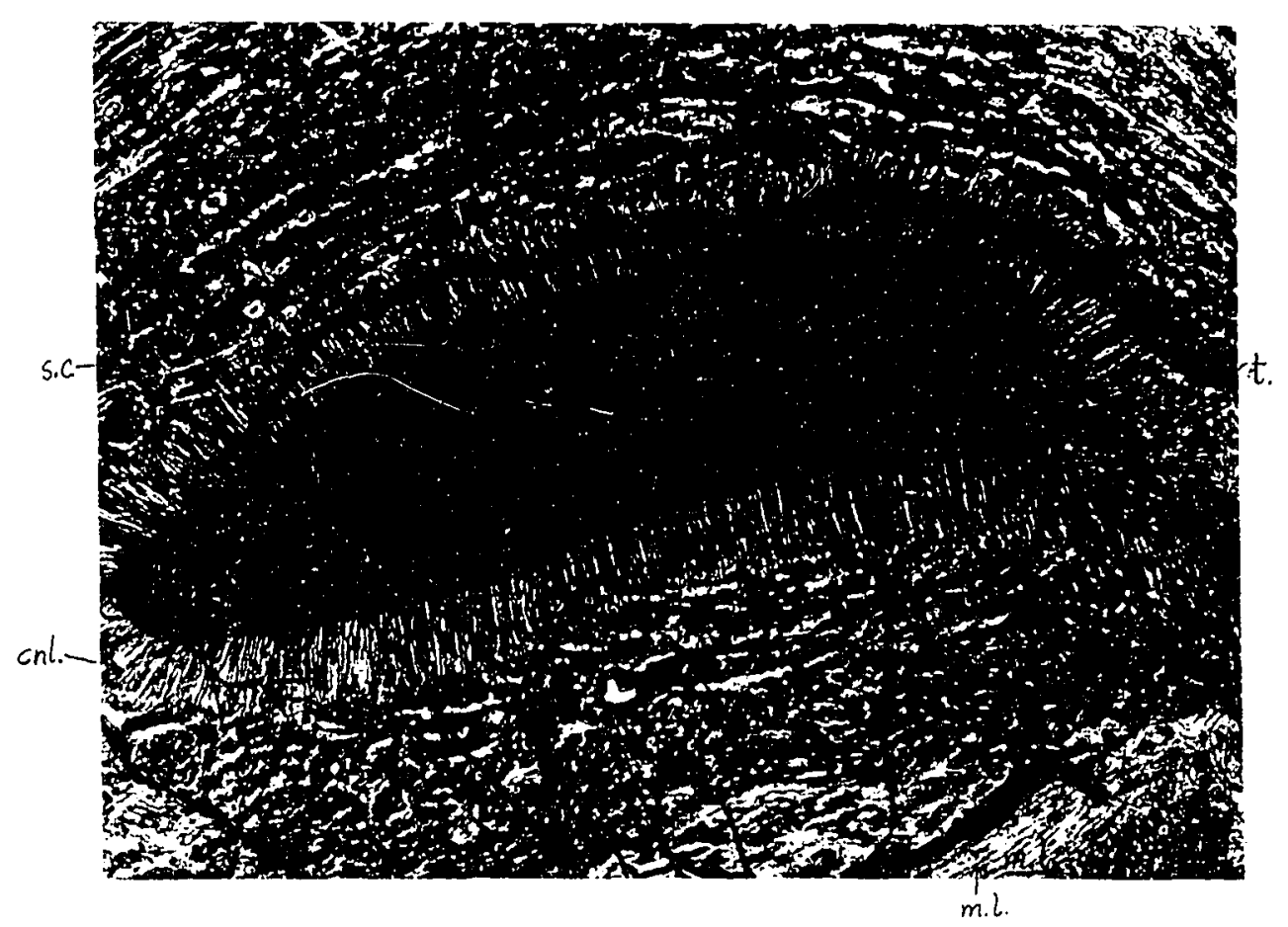

Figure.4. Terminal capsule of the spermatheca showing tracheae and the surrounding layer of secretory cells with canaliculi leading into the capsule. (x120).

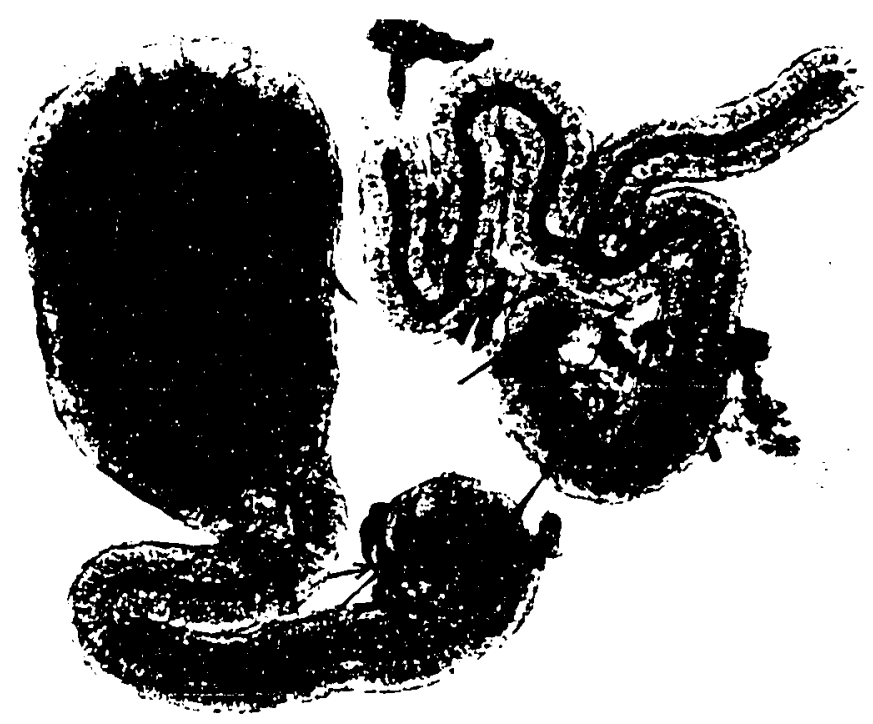

Figure 5. Spermatheca with an jirregular capsule and forked branch. iJote the torn ends of each major branch (Arrows). $(\mathrm{x} 50)$. 


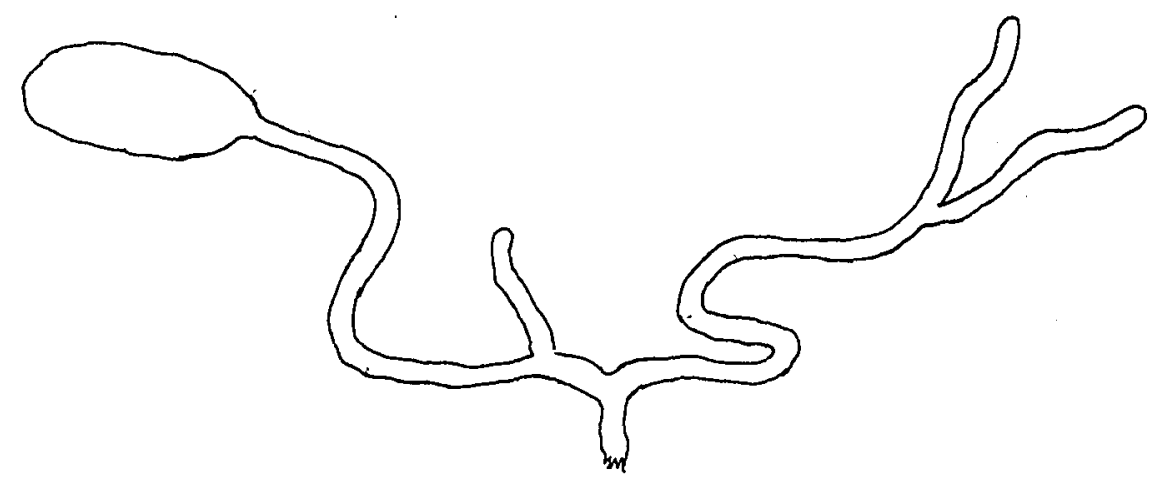

Figure 6. Diagram of a spermatheca showing the usual position of minor branches: when present.

No. of cases

23 (50\%) Normal spermatheca;. capsule and plain branch 18 (38\%) Plain branch forked

3 (7\%) Capsule branch with a small branch

2 (5\%) Both branches branched (as in Fig.6).

46 Total

Table 1. Minor branches of the spermatheca of Periplaneta. 
Virgin Female Time from start Duration of Sperms and Comments Copulation

\begin{tabular}{|c|c|c|c|}
\hline No. 1. & 15 mins. & - & $\begin{array}{l}\text { Large seminal vesicles; } \\
\text { no spermatophore. }\end{array}$ \\
\hline No.2. & 90 mins. & 85 mins. & $\begin{array}{l}\text { Spermatophore attached to } \\
\text { female; no sperms in } \\
\text { spermatheca. }\end{array}$ \\
\hline No.3. & 100 mins. & 90 mins. & As No.2. \\
\hline No. 4. & 7.5 hrs. & $\begin{array}{l}\text { About } \\
90 \text { mins. }\end{array}$ & $\begin{array}{l}\text { Spermatophore attached to } \\
\text { female; active sperms } \\
\text { in the spermatheca. }\end{array}$ \\
\hline No. 5. & $12 \mathrm{hrs}$. & $\begin{array}{l}\text { About } \\
90 \text { mins. }\end{array}$ & $\begin{array}{l}\text { Spermatophore slightly } \\
\text { shrunk; spermatheca } \\
\text { full of quiescent } \\
\text { spermatozoa. }\end{array}$ \\
\hline No.6. & 48 hrs. & - & $\begin{array}{l}\text { No spermatophore; } \\
\text { spermatheca full of } \\
\text { quiescent spermatozoa. }\end{array}$ \\
\hline No.?. & 48 hrs. & - & $\begin{array}{l}\text { Dried, brown spermatophore; } \\
\text { Capsule not full; sperms } \\
\text { quiescent. }\end{array}$ \\
\hline No. 8. & 7 days & - & $\begin{array}{l}\text { No spermatophore; ootheca } \\
\text { partly formed; capsule } \\
\text { part empty; sperms } \\
\text { quiescent. }\end{array}$ \\
\hline
\end{tabular}

Table 2. Copulation and the transfer of semen. 
1.

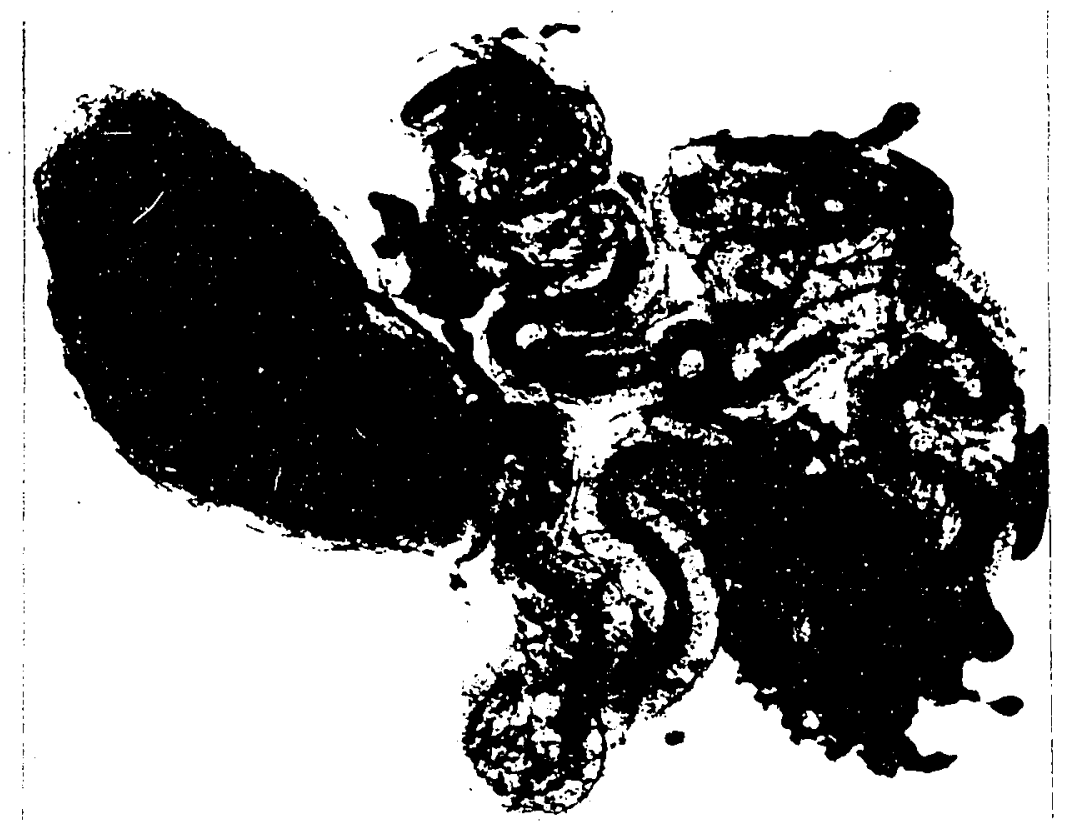

Figure 7. Active spermatozoa within the spermatheca of a recently mated cockroach. Note the denser regions of sperm masses. (x60).

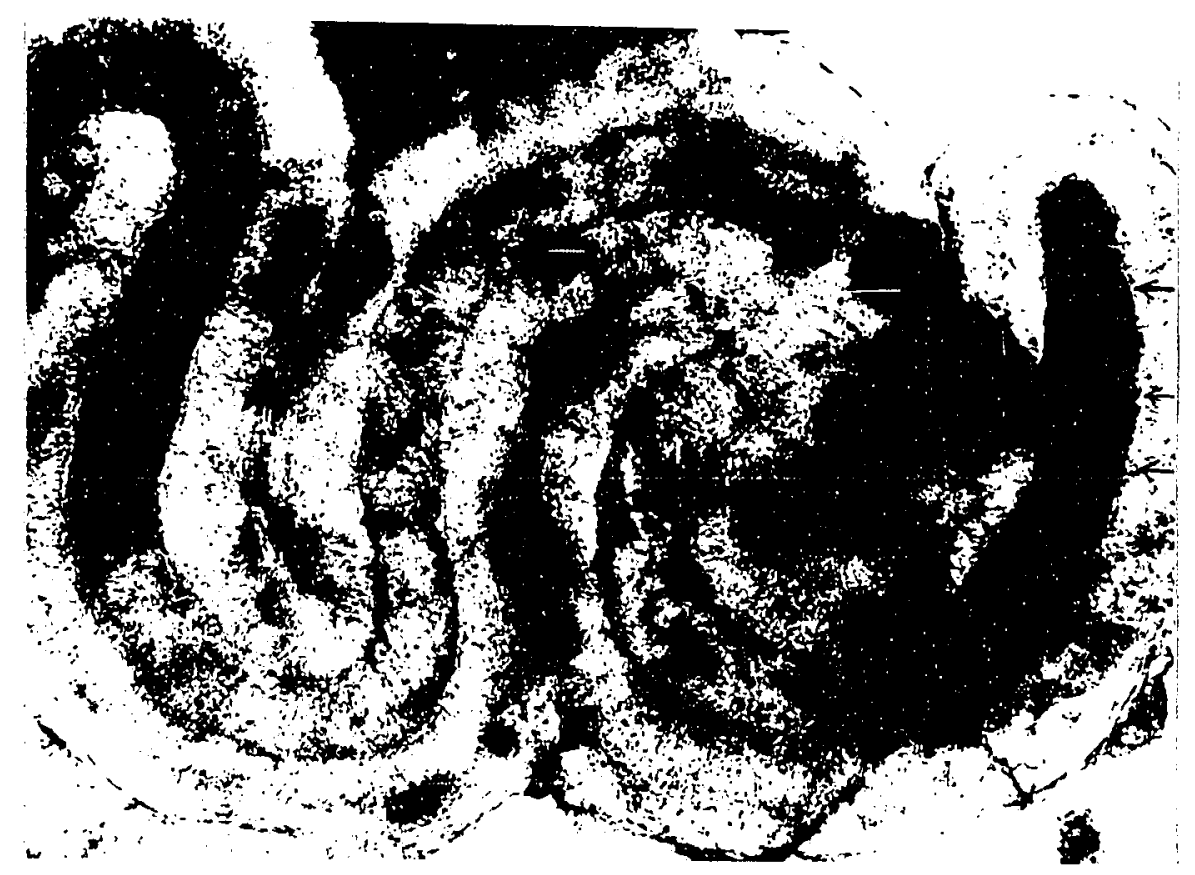

Figure 8. Active sperms within the plain branch of the above spermatheca. Note the synchronous beating of those at the end of the duct (Arrows). ( $x 230)$. 


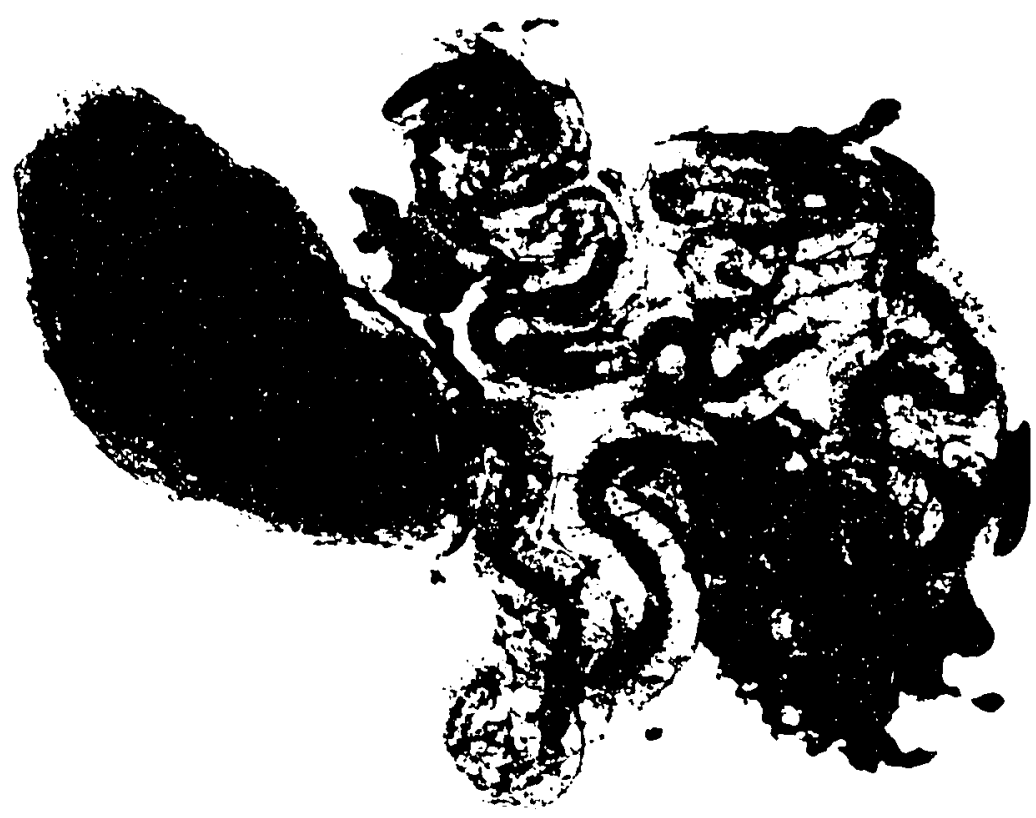

Figure 7. Nctive spermatozoa within the spernatheca of a recently mated cockroach. lote the denser resions of sperm masses. $(x 60)$.

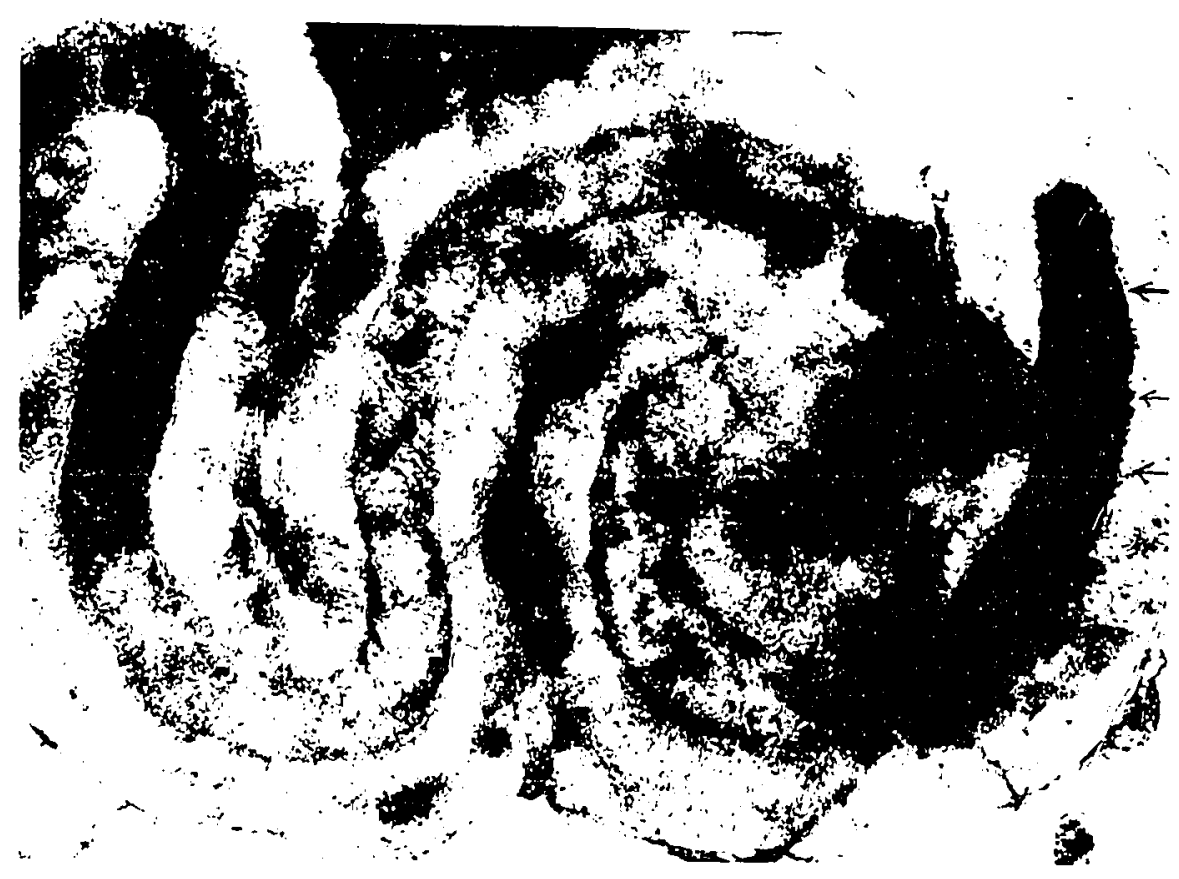

Figure 0 . Active sperus within the plain branch of the above spermatheca. liote the synchronous beating of those at the end of the duct (Arrows). ( $x 230)$. 

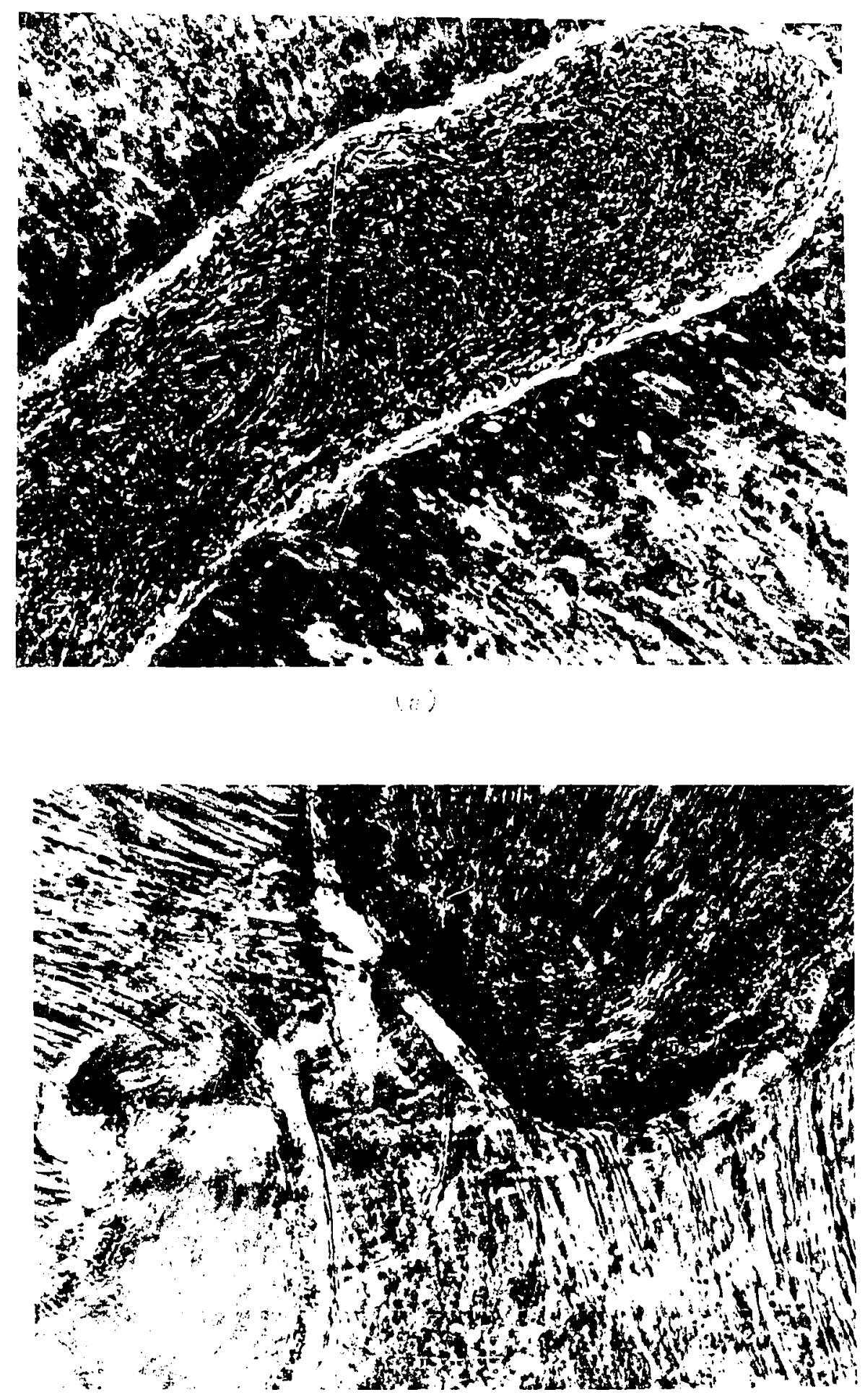


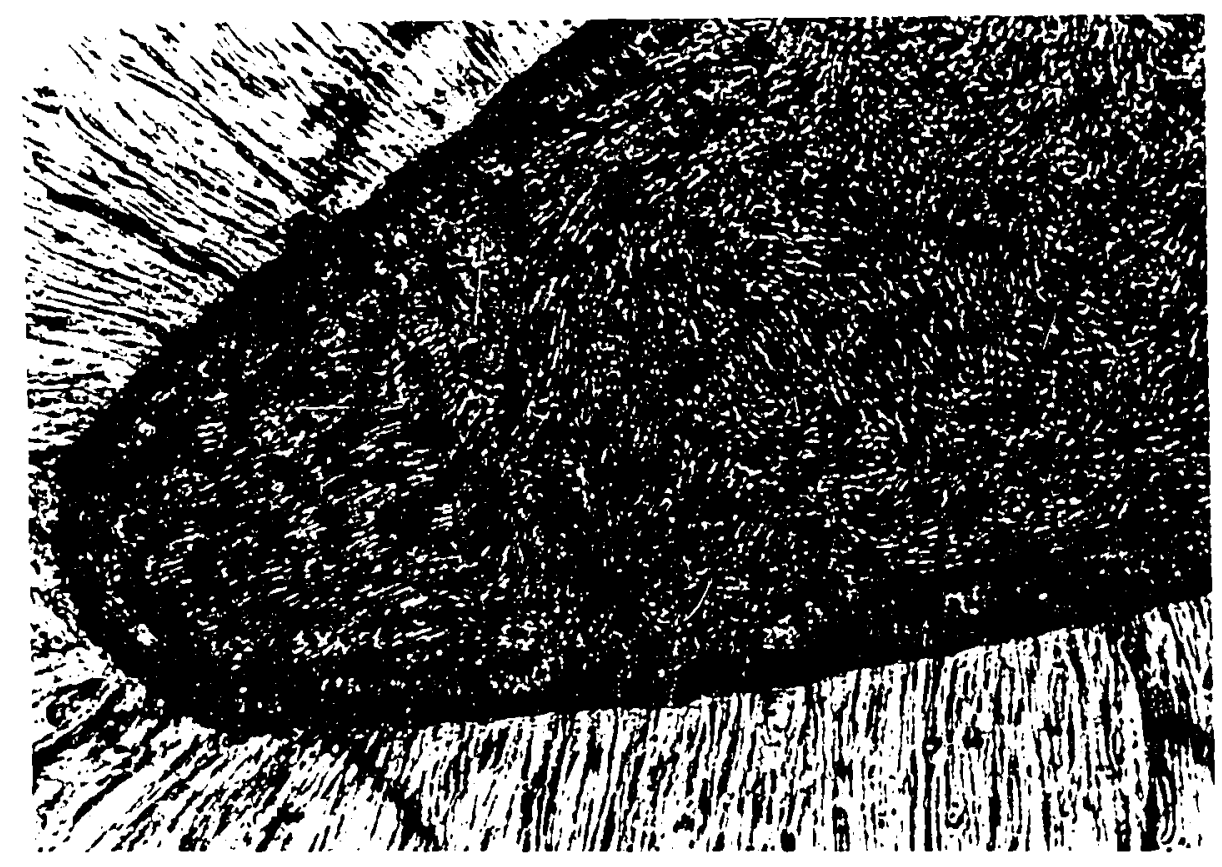

iture 10. jisorioniec suems in tine capsule;

vijescent éter violert activity (xr/ooj).

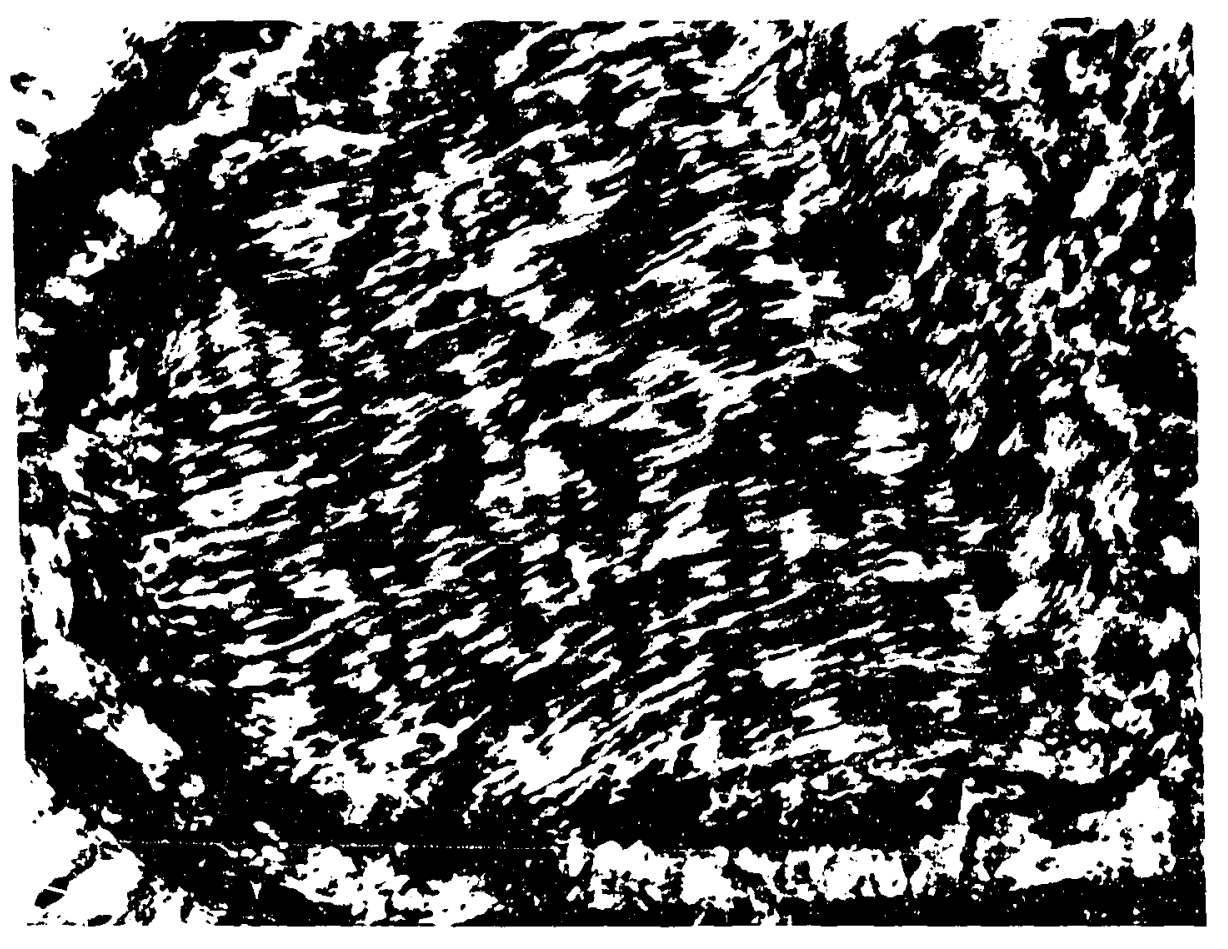

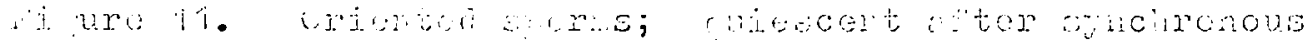

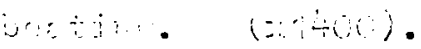




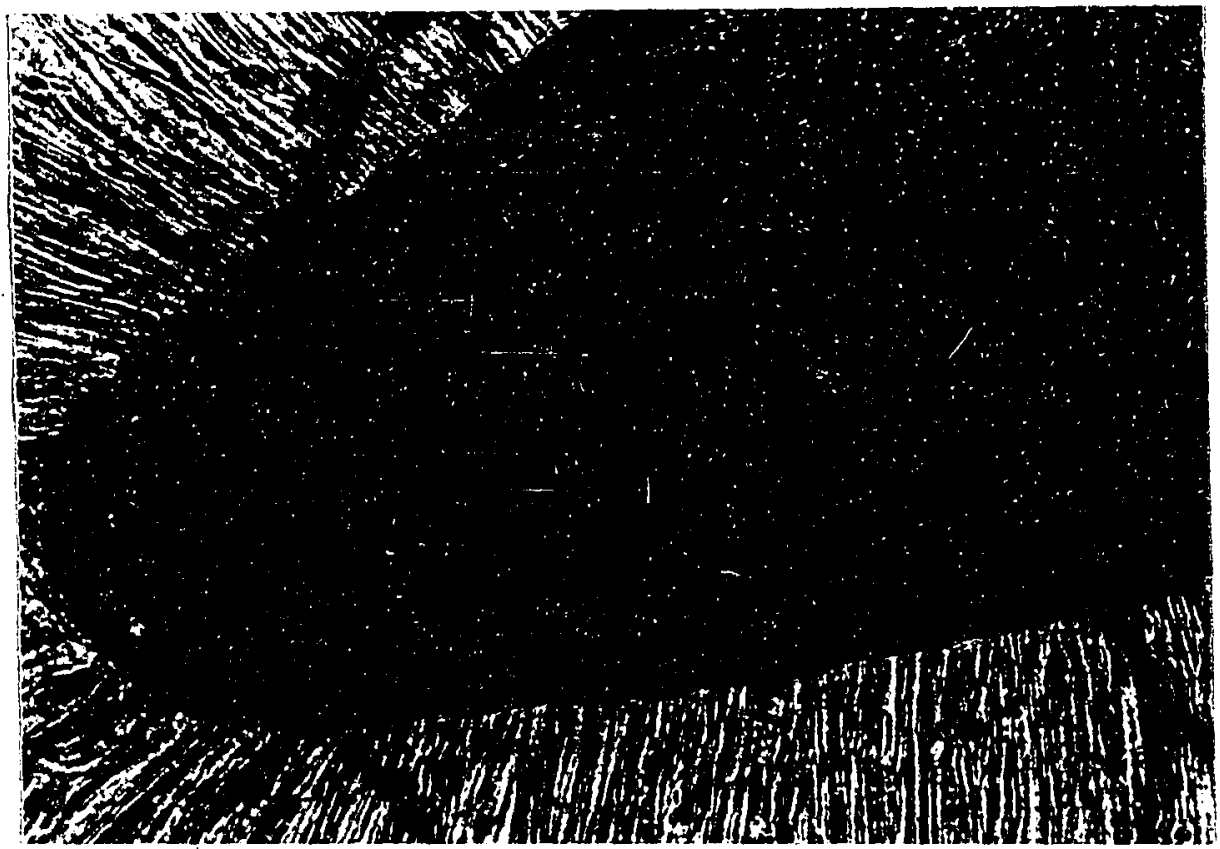

Figure 10. Disoriented sperms in the capsule;

quiescent after violent activity. (x700).

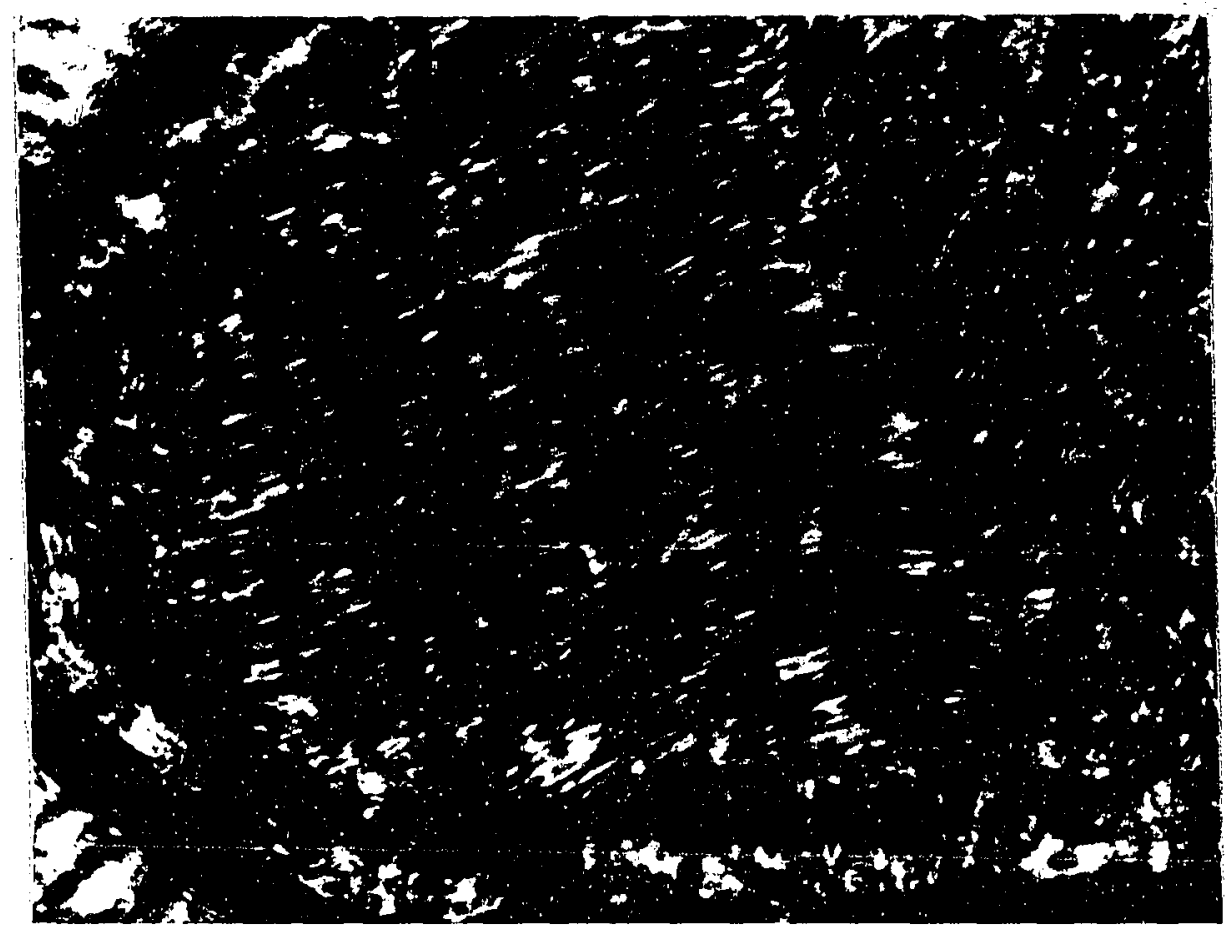

\%

Figure 11. Oriented sperms; quiescent after synchronous beating. $(x 1400)$. 


\section{is}

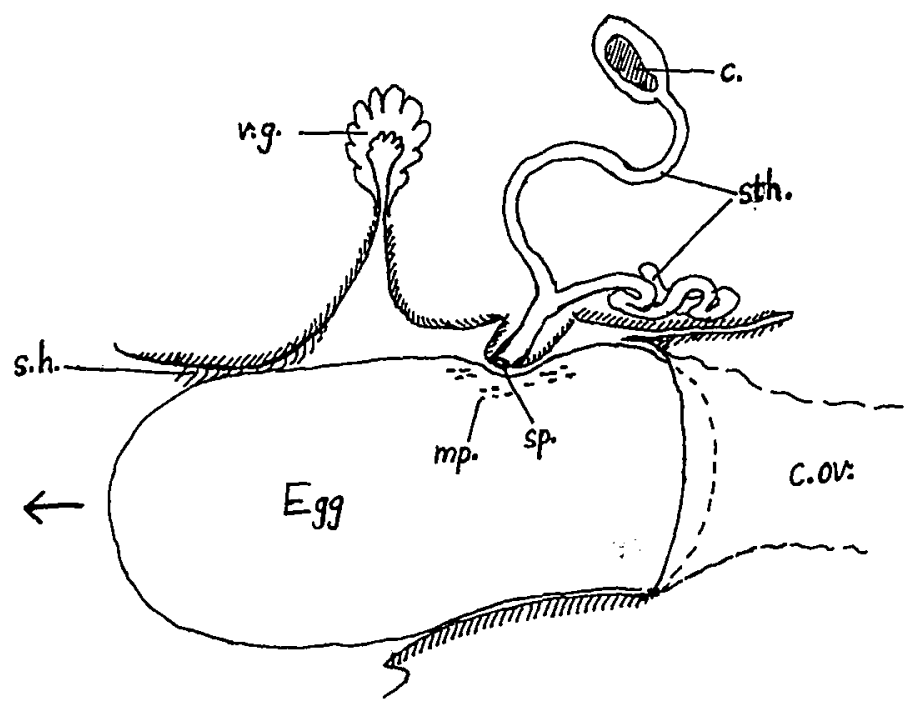

Figure 12. Diagram of the sperm release mechanism at fertilization (After Dewitz, 1886). 


\section{Chapter Five}

\section{SPERMATOZOAN ACTIVITY}

Several preparations of sperms were made by squashing a small piece of adult testis in a drop of Ringer under a coverslip on a plain slide. Almost all stages of developing spermatid and mature spermatozoa were apparent, totally inactive until some minutes passed. Remarkably, not only did the well formed sperms start beating, but most of the spherical spermatids exhibited vigorous undulations of the partly formed flagellar filament. The only sperm cells that appeared unaffected were those, nearly mature, with the kinoplasmic drop passing down their tail region. The kinoplasmic drop consists of excess cytoplasm, sloughed off during late development (Parkes, 1956). No serious attempt was made to take readings, but after 15 minutes some sperms were swimming as actively as those from seminal vesicles. Richards (1963) abandoned such preparations, because of their relative inactivity and poor numbers, for preparations of vesicular sperms.

Spermatozoa in the vasa deferentia were always inactive unless the duct was ruptured, or rarely, after it had been many minutes in Ringer. The sperms behaved in vitro similarly to those from the vesicles.

Spermatozoa were always inactive in the seminal vesicles. But in a ruptured vesicle, activity diffused inwards until all sperms were violently active and they usually issued rapidly from the torn region. In many cases, although apparently active, most of the sperms remained within the vesicles.

Determinations by Richards were made from suspensions of sperms that had been prepared for less than half an hour. He said that, in preparations 
held for longer times, the rates were usually slower and the percentage of inactive sperms increased after about one hour, even though some activity remained for several hours. Also, he found that 20-25\% of the preparations had to be discarded because of initial low activity or rapid drops in activity. Variability between individuals was greater than between preparations from one insect (Richards, 1963).

This applies generally to the present work, but in contrast to Richards, I found that the frequency of tailbeat was maintained for much longer than one hour in good preparations. This may have been due to the more favourable $\mathrm{pH}$ of 7.

About 120 adult male cockroaches provided some 100 successful preparations for the present study. Discarded males either had too few or poorly active spermatozoa from their vesicles, or an accident occurred in preparation. Data from 10 preparations in Ringer alone are shown in a scattergram (Fig. 13) which reflects the spread of results. The lines in the figure trace the activity of three separate preparations over some time.

Initial maximum activity was from about 450 to 700 beats/min. and, after a general slight increase, activity was maintained steady for about an hour. Preparations starting below 450 beats/min, are not included in the figure as they rarely improved and were often discarded. The activity of some preparations was maintained for many hours. Readings between 500 and 600 beats/min. were occasionally made after 10 or 12 hours, although very much fewer sperms were active. After 36 hours, one preparation had some sperms swimming at 300 to 400 beats/min.

The first few dissections of females were rather puzzling as only one branch of the spermatheca, with the capsule, could be found. The activity 


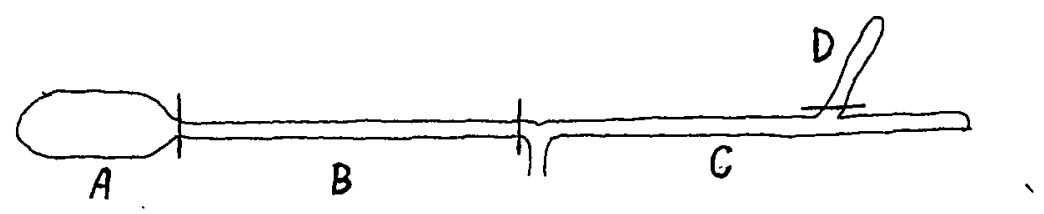

Figure 14. Diagram of the spermatheca.

A

\section{Preparation Capsule}

No.1.

$486 \pm 18$

Few Sperms

No.2. $\quad 450 \pm 23$

Few Sperms

No, 3. $\quad 490 \pm 17$

Very Few

No.4. $\quad 589 \pm 21$

Few
B

Capsular Duct

$635-31$

Good Number

$589 \pm 12$

Fair Number

$629 \pm 17$

Good Number

$663 \div 17$

Good Number
C

Plain Branch

$1121 \pm 22$

Packed

$807 \pm 32$

Good Number

$972 \pm 29$

Packed

$798 \pm 30$

Packed

Note: The two Minor Branches were off shoots of the Plain Branch, but similar, active spermatozoa have been found in all other branches inspected. Comments on sperm density and standard errors are also given.

Table 3. Activity of sperms from different parts of the spermatheca. 
in vitro of the sparse population of spermatozoa from this branch was similar to that of an average to good preparation from the seminal vesicles. However, there was a small number of extremely active spermatozoa which were more active than any previously observed.

Where was the apical spermathecal gland mentioned by van Wyk and Khalifa? This problem has been cleared up in the previous chapter, but the results of the investigation are interesting and are described below.

With improved skill in dissecting, the whole spermatheca could easily be removed into Ringer. No spermatozoa were seen to beat in the ducts except at the torn mouth and where the forceps had damaged the tube slightly, perhaps allowing Ringer to penetrate. It appears then that spermatozoa are maintained in a quiescent state in this organ (Ch. 4).

The capsule, its duct and the plain branch of 4 spermathecae (see Fig. 14) were opened in a drop of Ringer on separate slides to observe spermatozoan activity. The results are shown in Table 3. The difference in activity observed suggested that sperms might pass from the capsular to plain branch in stages of maturation - a suggestion now considered extremely unlikely. (Ch. 4). Let us ignore for the moment the less active sperms and consider the normal suspension of all the spermatozoa from the spermatheca. It was found that of the 70 spermathecal from mated females studied in detail, all, except 8, gave a good number of extremely active sperms and the general level of swimming activity was over $80 \%$. Two of the poorer preparations were from scruffy, unhealthy females and two were accidentally buffered to $\mathrm{pH} 7.8$. The total numbers of spermatozoa in the spermatheca was not estimated but was often only some thousands. Also, the very activity of the spermatozoa tended to result in their being trapped between coverslip and slide at the outer edge of the preparation. It was, therefore, not often possible to maintain 
such preparations for as long as those from the male.

The activity of 8 preparations in Gouldin's solution is shown in Figure 15. Data is presented as in Figure 13 for comparison. There was immediate, high activity at a level of about 1.5 to 2 times that of sperms from the seminal vesicles. After a slight increase, activity was maintained at about the same level for 30 to 45 minutes. Activity tended to decline after an hour and highly active sperms were not found after several hours. This may represent their elimination as described above or a real loss of activity.

A comparison of Figures 15 and 13 shows the markedly higher activity of sperms released from the spermatheca. These sperms were immediately and consistently highly active, while those from the vesicles often took 5 to 15 minutes to become fully active, if at all. The maximum activity exhibited by a spermatozoan from the female was 1440 beats/min. and large numbers at 1300 and 1200 beats/min. were recorded. Maximum activity of sperm from the vesicles was 1100 beats/min. ( 4 sperms) and this, only after 10 to 15 minutes in Ringer. Very few sperms exceeded 900 beats/min. and high activity was always delayed.

These results raise many questions, in particular, how does the activity compare with other sperms and what is the significance of the greater activity of sperms from the female?

For purposes of comparison, two preparations of human sperms were studied, both in whole semen and in semen diluted 1,2 with Gouldin's solution. In semen the sperms were rather restrained, moving erratically and beating at from 700 to 1,000 beats/min. In diluted semen activity was more even, between 900 to 1,100 beats/min. The sperm tails are slender and their beat was often irregular, that is spiral rather than monoplanar, and 
was thus less easily recorded. The activity in Periplaneta compares well with these results.

It is tempting to suggest that the potentially more active sperms in the female cockroach have been capacitated. But first, let us consider some possibilities as to how this change is brought about.

1. Do the seminal vesicles inhibit maximal activity?

2. Do the various male accessory glands activate sperms?

3. Does a substance from the spermatheca activate sperms?

4. Do sperms undergo a physiological or physical change in the spermatheca?

Let us consider these problems in turn, and the experiments performed in attempts to answer them.

The seminal vesicles: Do they inhibit maximal activity?

Half of a preparation from a spermatheca was added to one part of a dense suspension of seminal vesicles in a drop of Ringer. To the other part of seminal vesicle suspension was added an equal amount of female coxal muscle.

Highly active spermatozoa were only observed in the first mixture, moreover, the activity remained equally high over 25 minutes as in the unmixed part of the spermatheca preparation. This was repeated a total of three times to confirm this result.

Simple inhibition by the seminal vesicles cannot explain the poor activity of sperms released from them. But, of course, the spermatozoa from the female may be sufficiently different to be unaffected by an inhibitor from the vesicles. 
The male accessory glands: Do they activate sperms?

Ito (1924), discussing the physiological role of the accessory gland tubules, says: "On peut considérer que la sécrétion contribue à la formation du sperme .... et j'ai pu, de plus, me rendre compte que le produit de la sécrétion, sans doute par sa réaction chimique, stimulait l'activité des spermatozoides."

It is obvious, however, that he was not aware of the details of mating and spermatophore production. His investigation generally is rather superficial and the above observation is therefore not considered a reliable report of activation by the glands specifically.

Richards found that better activity resulted using sperm from the seminal vesicles mashed together with an approximately equal amount of accessory gland material. Roughly the same procedure was followed earlier by Davey (1958a) who observed that this material reduced the adhesion of sperms to the surface of the slide and enhanced their activity. He found a similar improvement by the addition of egg albumen.

It is unlikely that such proteinaceous material acts as substrate; for spermatozoa appear to utilise exclusively rather simple exogenous materials such as hexoses, glycerol, smaller fatty acids, some amino acids, etc. (Mann, 1964). Even the addition of phospholipids is considered by Mann to exert a stabilizing or stimulating effect, not so much by the provision of an oxidisable substrate, but from the formation of some sort of protective colloid. The following experiment was performed to test the effect of accessory material. A sperm suspension from all the seminal vesicles was equally divided onto three slides to which were added two drops of the same Ringer stock. Slide A was sealed with Ringer alone. To slide B was added a 
small amount of accessory gland (one or two utriculi) and to $C$ an equal amount of leg muscle from the coxal region. These materials were minced up with clear forceps and both slides covered. Observations were made immediately and over a period of at least 30 mins. The results from 8 separate preparations axe summarised in Table 4.

The conclusion is fairly clear, the addition of accessory material or muscle does not increase the rate of beating of the spermatozoa, but it may prolong their activity. A feature, not shown in the table, is that the proportion of swimming spermatozoa was higher in B and C. This was too difficult to measure with any accuracy. Accessory gland material was not included in routine preparations as its presence caused considerable optical interference and might have interfered with other experiments.

In the above experiment utriculi from several regions of the mushroom-body were used to check on the effect of the various utriculi, the contents of which are known to differ (Jurecka, 1950).

The phallic gland: Does it activate sperms?

The secretions of this gland are said to be poured over the spermatophore after it has been deposited in the female bursa (Gupta, 1947). However, there is a 'prostate' gland in the male of Bombyx which produces a sperm activating fluid, essential for sperm motility and successful artificial insemination. A similar secretion is found in other lepidoptera (Omura, 1936a). Spermatozoa from each of three suspensions of seminal vesicles were added to various amounts of phallic gland in a drop of Ringer. No general activation was observed in any case and the fastest sperms were of normal male-type activity. The phallic gland did not activate sperms from the vesicles. 
The spermatheca: Does it activate sperms?

To investigate the effect of the spermatheca on sperm from the vesicles 3 approaches were tried using;

1. Virgin Spermathecae

2. Spermathecae from Mated Females

3. Spermathecae from Mated Iriatoma (a large Hemipteran blood-sucking insect used for other studies in this laboratory).

Virgin Spermathecae

Spermatozoa from seminal vesicles were prepared and added to a drop of Ringer; a drop plus brei of a spermatheca; and, as a control, to a drop plus an equal amount of muscle brei. The coxal muscle of the female was used. The three slides were sealed and activity observed at least 30 minutes. The data from 4 preparations have been averaged, while the most active preparation is presented in detail (see Table 5).

Brei from virgin spermathecae did not activate the spermatozoa. Spermathecae of Mated Cockroaches

The problem of eliminating the sperms already present was tackled in various ways. First, the spermatheca was thoroughly ground in a miniature glass mortar. One or two sperms usually survived and evaporation was appreciable during grinding. Secondly, the brei was sealed with a drop of Ringer and chilled to $-20 \mathrm{C}$ for 20 minutes. Surprisingly, after removal and on inspecting the cold slide, some spermatozoa were seen to recover full motility with the rise to room temperature, soon exceeding 800 beats/min. This approach was abandoned, but incidentally, I suspect that had Richards (1963) persisted with sperms from the spermatheca the temperature of sperm inactivation would have been much lower than the $10-11 \mathrm{C}$ observed. Thirdly, 
a drop of Ringer was subjected to an ultrasonic shock from a portable ultrasonic probe (Electronic Systems Inc.). The drop rapidly evaporated, and this idea too was abandoned. Finally, the brei from 5 spermathecae was suspended in a little over $0.2 \mathrm{ml}$ Ringer and centrifuged. When the brei had settled the supernatant was drawn off and inspected for sperms before putting it in a small test-tube on ice.

Two preparations with ground brei and 3 with the supernatant were successful and the mean activities over at least 30 minutes are shown in Table 6. Mated spermathecae did not stimulate activity.

It was hoped to obtain a more general result by mixing sperms from the vesicles of 5 males and adding this to the above supernatant. But this mixture appeared to coagulate and the activity was poorer than in separate preparations. Spermathecae from Mated Triatoma

Hormones and pharmacological substances are often common to whole groups of animals, therefore the effect on cockroach sperms of the spermathecae of Triatoma was of interest. Fortunately the filamentous sperms of this bug are easily distinguished from those of Periplaneta. Both spermathecae of each female were added to a small drop of cockroach sperm suspension and finely chopped. The filamentous sperms of Triatoma were easily apparent but not very active. Another slide with cockroach sperms plus some coxal muscle of Iriatoma was used as a control.

The spermathecae of mated Triatoma did not activate the sperms from the vesicles of Periplaneta (Table 5).

It is likely that the spermathecae and sperms are more active and responsive respectively during copulation. Three experiments to test this 
point are described here. The materials were taken from copulating pairs of cockroaches on which a full report comes later (Table 7).

In preparations nos. 1,2 and 3 (Table 7) each virgin spermatheca was chopped up in a drop of Ringer and some spermatozoa added from the suspension of sperms from the seminal vesicles (no. 1) or spermatophore (nos. 2 and 3 ). This was compared with a similar drop from the stock suspension (see Table 6). In nos. 1 and 3 there was better activity with the spermatheca brei. But this was slight and in no. 2 the activity in both slides proceeded apace. In no case did the activity reach the 'female' level. It must be emphasised that the whole organ in situ may be necessary for proper functioning. Thus we may conclude that, certainly in vitro, the spermatheca does not stimulate sperms. During copulation some stimulant may, perhaps, be produced (nos. 1 and 3 above) but in no case is there activity produced to equal that of the very active sperms from the normal spermatheca.

To find when the increase in potential activity takes place, several virgin cockroaches were mated and the spermatozoa removed and inspected at various stages during and after copulation (Table 7 ).

Two important facts must be presented before considering the results. First, spermatozoa suffer a reduction in size of the large acrosome after more than about 5 hours in the spermatheca (see Ch. 7). Secondly, spermatozoa may be actively migrating into the spermatheca during the first 10 hours or so (see Ch. 4).

The significant preparation is no. 4, 5 hours after copulation (Table 7). The male-type spermatozoa from both spermatheca and spermatophore were violently active. Thus the large male-type acrosome is not, per se, a restraint on activity. Further, this result suggests that a process of activation takes 
place in the spermatophore. However, in view of the poorer, male-type activity of other spermatophore preparations we may cautiously consider the possibility of a secretion from the spermatheca having activated the sperms. High activity at that time would assist sperm transfer to the spermatheca. But it appears that, although high activity may be possible, it is not a consistent feature of sperms until after a few days in the spermatheca. 
-

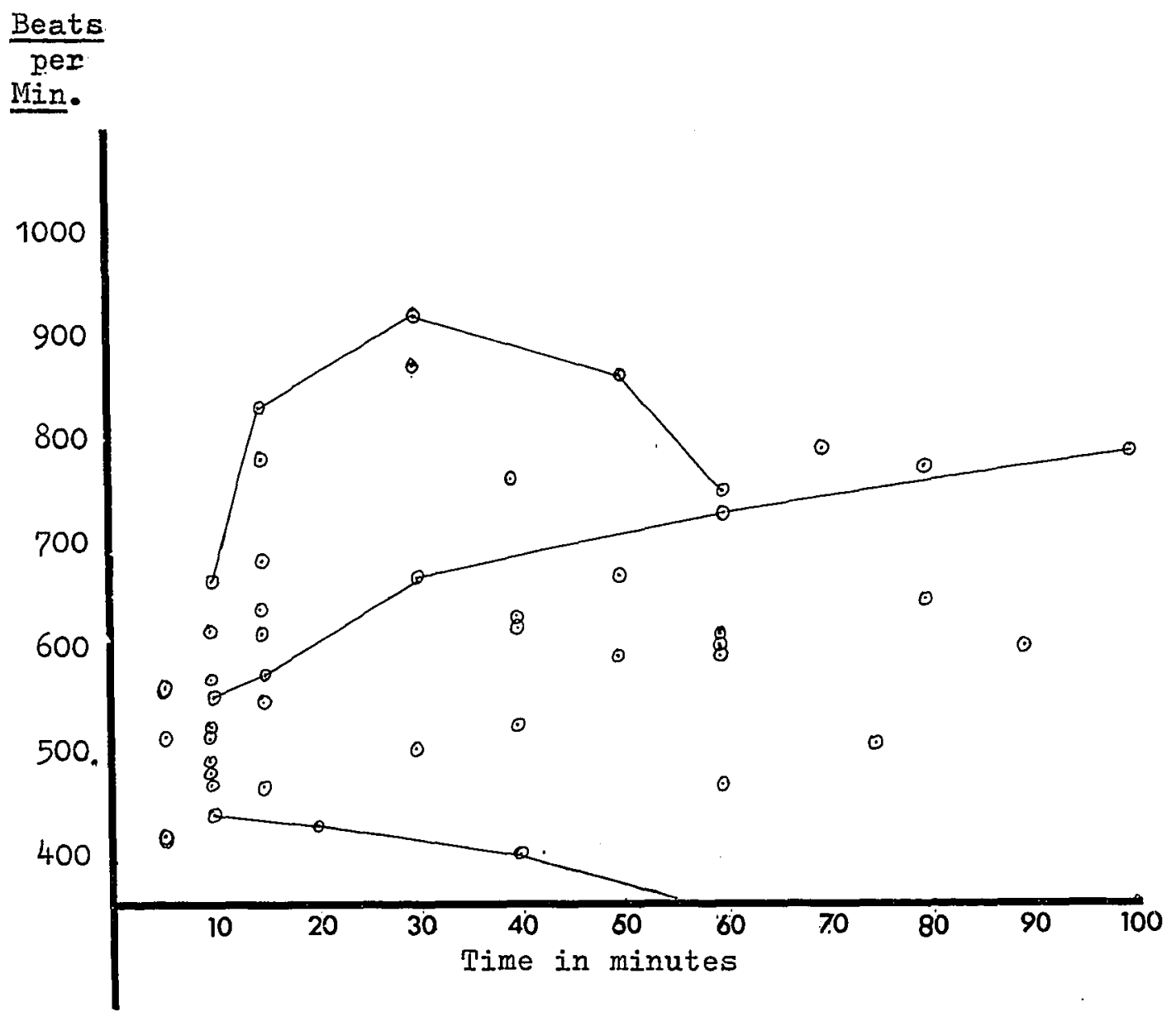

Note: Each point represents the mean of 10 readings. Standard errors were not significant at the scale drawn. Results are from 15 preparations, but the most active, an average and a poorly active preparation are followed for some time (solid lines).

Figure 13. Activity of sperms from the seminal vesicles in Gouldin's solution. 
-

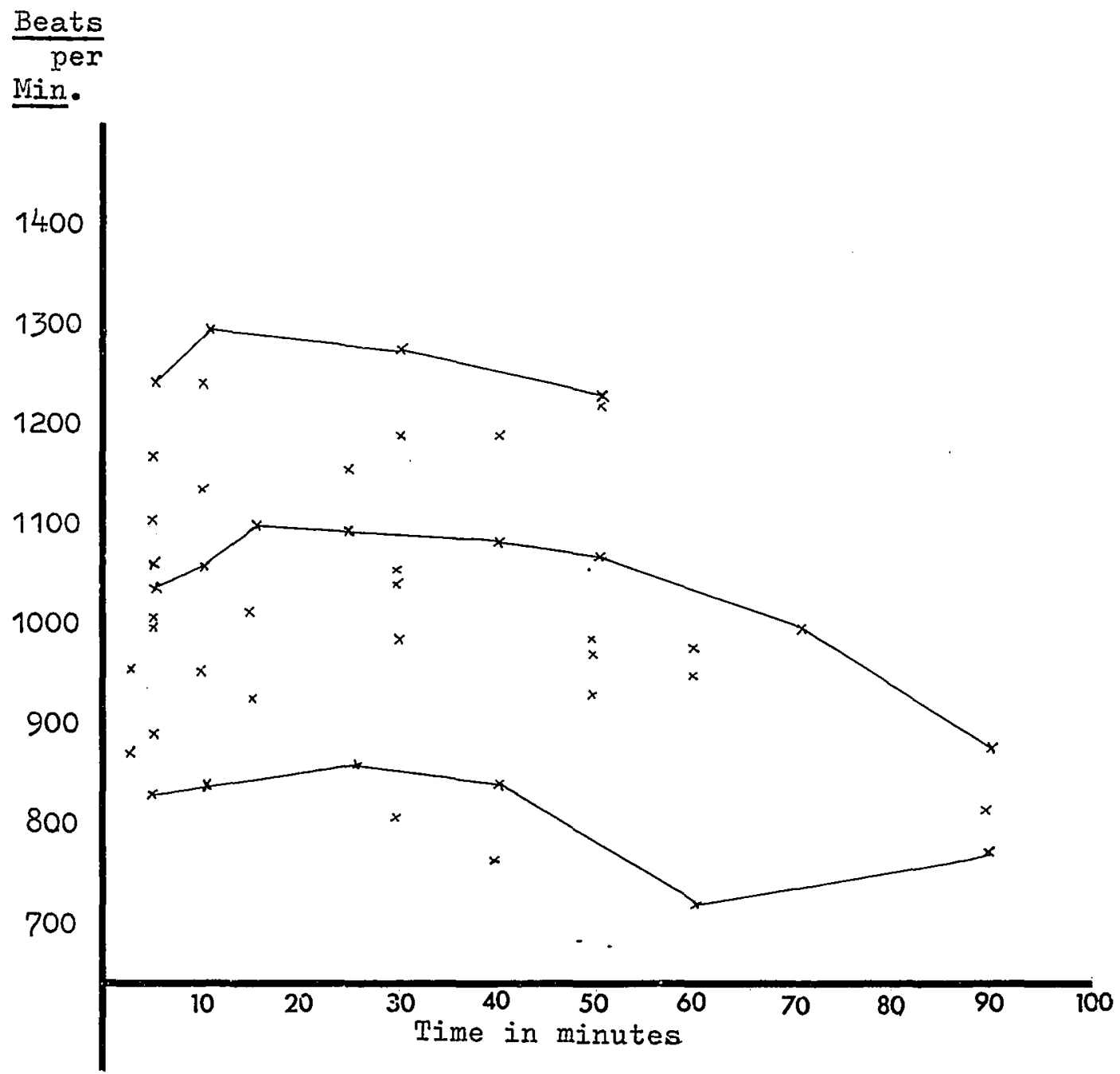

Note: As for Fig. 13; but in this case, results are from 8 preparations.

Figure 15. Activity of sperms from the spermatheca in Gouldin's solution. 


\begin{tabular}{|c|c|c|c|c|}
\hline Prep. & Ringer & $+\frac{\text { Accessory }}{\text { Gland }}$ & + Coxal Muscle & Time Lapse \\
\hline No. 1. & $\begin{array}{l}548 \pm 14 \\
\text { Fair }\end{array}$ & $\begin{array}{l}562 \pm 18 \\
\text { Fair }\end{array}$ & $\begin{array}{l}521 \pm 15 \\
\text { Fair }\end{array}$ & $4 \mathrm{hrs}$. \\
\hline No.2. & $\begin{array}{l}521 \pm 24 \\
\text { None }\end{array}$ & $\begin{array}{l}510 \pm 20 \\
\text { None }\end{array}$ & $\begin{array}{l}499 \pm 12 \\
\text { A Few }\end{array}$ & 10 hrs. \\
\hline No. 3. & $\begin{array}{l}460 \pm 18 \\
\text { None }\end{array}$ & $\begin{array}{l}480 \pm 16 \\
\text { Fair }\end{array}$ & $\begin{array}{l}481 \pm 20 \\
\text { None }\end{array}$ & $5 \mathrm{hrs.}$ \\
\hline No. 4 . & $\begin{array}{l}459 \pm 23 \\
\text { None }\end{array}$ & $\begin{array}{l}464 \pm 21 \\
\text { A Few }\end{array}$ & $\begin{array}{l}472 \pm 13 \\
\text { Fair }\end{array}$ & 2 hrs. \\
\hline No. 5. & $\begin{array}{l}675 \div 20 \\
685 \pm 20\end{array}$ & $\begin{array}{l}620 \pm 19 \\
610 \pm 27\end{array}$ & $\begin{array}{l}644 \pm 25 \\
625 \pm 17\end{array}$ & 45 mins. \\
\hline No.6. & $\begin{array}{l}429 \pm 15 \\
\text { None }\end{array}$ & $\begin{array}{l}413^{+}-21 \\
\text { Fair }\end{array}$ & $\begin{array}{l}443^{+}-21 \\
\text { Fair }\end{array}$ & 2 hrs. \\
\hline No.7. & $\begin{array}{l}530 \pm 19 \\
\text { None }\end{array}$ & $\begin{array}{l}511 \pm 15 \\
\text { None }\end{array}$ & $\begin{array}{l}541 \pm 18 \\
\text { A Few }\end{array}$ & $4 \mathrm{hrs}$ \\
\hline No. 8. & $412 \pm 11$ & $461 \pm 12$ & $432 \pm 8$ & \\
\hline
\end{tabular}

Note: Initial frequencies are the means of at least 30 readings taken in the first 30 minutes.

Table 4. Activity of sperms from the seminal vesicles with male accessory glands and muscle. 
-

1. Virgin Spermathecae ( 1 organ/drop Ringer)

$\begin{array}{llll}\text { Prep. } & \text { In Ringer } & + \text { Spermatheca } & + \text { Muscle } \\ \text { No.1-4. } & 554 \pm 11 & 534 \pm 10 & 544 \pm 9 \\ \text { No.5. } & & \\ 10 \text { mins. } & 578 \pm 18 & 567 \pm 21 & 586 \pm 15 \\ 15 \text { mins. } & 609 \pm 13 & 564 \pm 15 & 578 \pm 21 \\ 30 \text { mins. } & 623 \pm 24 & 723 \pm 26 & 538 \pm 19 \\ 45 \text { mins. } & 717 \pm 17 & 658 \pm 24 & 548 \pm 14\end{array}$

2. From Mated Cockroaches ( 1 organ/drop Ringer)

Nos.1-5 $\quad 537 \pm 12 \quad 561 \pm 10 \quad 564 \pm 12$

3. From Mated Triatoma (1 pair organs/drop Ringer)

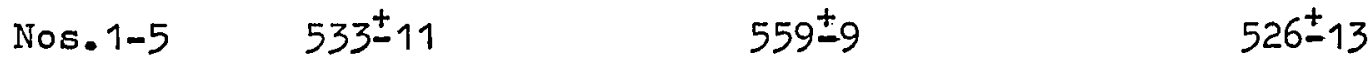

Note: A 'drop' is approximately $0.05 \mathrm{ml}$. Activity over some time is given for No.5. (1.) and standard errors are shown.

Table 5. Activity of sperms with spermathecae and insect leg muscle. 
No.1. Sperms from the Seminal Vesicles

Time

10 mins.

30 mins.

45. mins.
Ringer

Fair

496:24

$508 \pm 21$
Ringer + Virgin Spermatheca (1 organ/drop Ringer)

Fair

$468 \pm 19$

$720 \pm 25$

No:2. From the Spermatophore

5 mins. $\quad 584 \$ 20$

15 mins. $\quad 745-19$

$735 \pm 1.8$

45 mins. $\quad 760 \pm 22$

$755 \pm 18$

75 mins.

$691 \pm 15$

$665 \pm 17$

No.3. From the Spermatophore

5 mins. $605 \pm 14$

15 mins. $\quad 612 \pm 17$

30 mins. $\quad 580 \div 22$

55 mins. $\quad 537 \pm-16$

-
$628 \pm 21$
$700 \pm 14$
$577 \pm 23$

Table 6. Activity of sperms with spermathecae removed during copulation. 
Female

1.

2.

5 mins.

3.

4.

5.

6.

7.

3 days

5 hrs.

48 hrs.
10 mins.

$10.5 \mathrm{hrs}$.
Location of Sperms

seminal vesicles

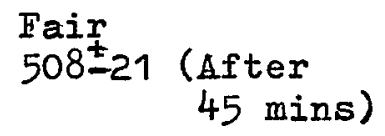

spermatophore

spermatheca

Activity in Ringer

$584 \div 20$

$760 \pm 22$ (After 45 mins)

spermatophore $\quad 605 \pm 14$

spermatophore

spermatheca

spermatophore

spermatheca

spermatheca

$1025 \pm 18$

$1048 \div 20$

$600 \pm 21$

$1015 \pm 25$

$607 \pm 22$ $1005 \frac{t}{14}$ (15 mins) $1030 \pm 15$ (20 mins)

$948 \pm 26$ $1057 \pm 30$ (10 mins)

Table 7. The activity of sperms removed during and after copulation. 
Chapter Six

SUBSTRATES IONS AND PHARMACOLOGY

In the preceding chapter it was found that the spermatozoa of Periplaneta are in a different physiological state in the female. In Chapter seven we shall see that this difference is accompanied by a morphological change in the acrosome of the sperm. It was therefore reasonable to have expected further differences in the behaviour of sperms from the male and female when subjected to a variety of pharmacological and physiological conditions. Any such differences might provide a clue as to the nature of the changes which occur in the female.

Aside from this important problem, the simple experiments below provide information of general interest to the sperm biologist. The effect of substrates: Dextrose, fructose, glucosamine, citrate. Sperms are known to absorb and metabolise small molecules, particularly hexoses (Mann, 1964). This is the case with honey bee sperms in which the glycolytic and Kreb's cycle mechanisms occur (Blum and Taber, 1965). Citrate is an important constituent of vertebrate semen (Mann, 1964; Wales, Wallace and White, 1966) and the tri-sodium salt solution $(0.07 \mathrm{M})$ was found to be a successful medium for the artificial insemination of the bed-bug (Davis, 1965a). The presence of giucosamine in cervical mucous of women may be used as a sign of ovulation (Kurzrok and Birnberg, 1958). These authors considered glucosamine to be formed, partly by the action of the sperms, by the degradation of mucous hyaluronic acid. Thus, we may speculate, glucosamine may be available for sperm metabolism and it may even further activate the sperms。 
Solution

Abbreviation

1. Gouldin's solution

2. Fructose Ringer

3. Glucosamine Binger

4. Citrate Ringer

5. Salt Ringer

6. Gitrate only
R. Dextrose

R. Fructose

R. GIucosamine

R. Citrate

R. $\mathrm{NaCl}$

Citrate
Concentration of Substrate or Substitute
$0.04 \mathrm{M}$ Dextrose

$0.04 \mathrm{M}$ Fructose

$0.02 M$ Glucosamine HCI

$0.014 \mathrm{M}$ Trisodium

eitrate.

$0.02 \mathrm{~m} \mathrm{NaCl}$

$0.07 \mathrm{M}$ Trisodium

Citrate.

Note: The solutions are, or are very nearly, of equal osmolarity.

Table 8. Modified Ringer solutions. 
The above evidence formed a basis for experiments. Later, conflicting evidence was found that hyaluronic acid does not appear in cervical mucous which is thought to be a mucoid containing sialic acid (Moghissi et al., 1964). However, glucosamine surely occurs in the mucous as reported above.

To investigate the effect of a substrate there must first be an absence of it; the solutions in Table 8 were therefore prepared. Further details are given in Appendix II. R.Dextrose (no. 1, Table 8) is Gouldin's solution, while nos. 2 to 5 are Gouldin's with a dextrose substitute of equivalent osmolarity. The $\mathrm{pH}$ was adjusted to 7 in all cases (see Ch. 3 ).

Sperms were suspended in a small drop of R.NaCl which was split between two or three slides. To each of these slides was added approximately equal amounts of R.NaCl, R.Dextrose, etc., and the slides were sealed. This procedure is by no means exact, but it does result in grossly different environments for the sperms, for example, no substrate versus appreciable hexose.

Table 9 shows that the spermatozoa were only slightly less active in R. $\mathrm{NaCl}$ compared with hexose Ringer, but they did not survive as well. Fructose appeared to support slightly greater activity than dextrose but survival was similar. These results were not compared statistically and the point on survival is alone considered fully significant.

Less information was obtained using sperms from the spermatheca (Table 9c). The results indicate slightly better activity in fructose over the salt and dextrose solutions.

Glucosamine was tested in two ways, first, as a substitute for dextrose (Table 10), and secondly, by adding small amounts of R.Glucosamine to preparations after some time had passed.

In the first case, no higher activity was produced in sperms from the 
male or from the female. Similarly, in the second case, no increase in activity occurred that could be credited to the addition of glucosamine. However, in some of the 8 preparations to which R.Glucosamine was added an increase in activity occurred. But in each case a similar increase was produced by $\mathrm{R} . \mathrm{NaCl}$ in another portion of the same preparation.

It was often found that disturbing a coverslip sealed for some time tended to briefly activate many immobile sperms; the addition of $\mathrm{R} . \mathrm{NaCl}$ produced a slight increase for some minutes; Gouldin's solution produced a more prolonged slight increase in activity. This suggests that it is an increase in oxygen which revives ailing sperms and that this effect is supplemented by buffered Ringer and additional hexose. This may be explained simply as a result of improved metabolism with oxygen, or of a rise in $\mathrm{pH}$ through the oxidation of metabolites or addition of fresh buffer. But this requires careful investigation.

Citrate did not activate sperms from the male, and supported good activity even as a replacement for Ringer (Table 11.). Sperms from the female proved equally hardy in Citrate, showing normal high activity (Table 11). It will be noted that both citrate Ringer and Citrate of Table 11. have some of the stock salt Ringer added with the sperms; this amounted to less than a quarter of the total fluid on the slide.

From the results above, we can conclude that the provision of suitable substrate does not initiate sperm activity and is not essential for activity over at least an hour; nor can a difference in substrate, in kind or in concentration, account for the differences in activity observed between sperms from the male and female. 
The effects of various ions: $\mathrm{K}^{+}, \mathrm{Ca}^{++}, \mathrm{HCO}_{3}^{--}, \mathrm{PO}_{4}^{--}$.

To summarise evidence on sperm activity presented in Chapter 2: it has been suggested that a high concentration of $\mathrm{K}^{+}$, relative to $\mathrm{Na}^{+}$, is inhibitory; $\mathrm{Ca}^{++}$is involved in the flagellar beat; certain concentrations of $\mathrm{HCO}_{3}{ }^{-}$ appear to stimulate sperms; and inorganic $\mathrm{PO}_{4}^{--}$may have some effect on sperms. We must note also that experiments involving variations in the ionic composition of media are awkward for several reasons the metabolism of the cells alters the composition of the medium; the tonicity, or osmolarity, must be maintained constant; but changes in one ion produce concomitant changes in other ions; atmospheric $\mathrm{CO}_{2}$ is reflected in the $\mathrm{HCO}_{3}{ }^{-}$concentration of the . medium; but the $\mathrm{pH}$ must be kept constant.

In view of these hazards, only very simple experiments were attempted, the main point being to either markedly inhibit or activate motile spermatozoa. Bicarbonate contributes to the buffering system of Gouldin's solution $\left(1.5 \times 10^{-3} \mathrm{M} \mathrm{HCO}_{3}^{-}\right)$. It may be omitted or its concentration increased by a compensating increase or decrease respectively in $\mathrm{NaCl}$ concentration. Spermatozoa from 5 males were suspended in bicarbonate-free solution, Gouldin's solution, and Gouldin's with $4.5 \times 10^{-3} \mathrm{M} \mathrm{HCO}_{3}^{-}$. The $\mathrm{pH}$ of each solution was adjusted beforehand to 7 with $0.06 \mathrm{M}$ phosphate buffer (see Ch. 3 ). No pronounced differences in activity occurred and it was decided to continue with the original Gouldin's solution.

On one occasion vesicular sperms were accidentally mounted in a phosphate buffer solution $\left(0.067 \mathrm{M} \mathrm{NaH}_{2} \mathrm{PO}_{4} / \mathrm{Na}_{2} \mathrm{HPO}_{4}\right.$ at $\left.\mathrm{pH} 7\right)$. Some 30 mins. after this error the slide was inspected and a remarkably high level of activity recorded ( 850 beats/min.). A few readings over 900 beats $/ \mathrm{min}$. were noted and this is in the range for sperms from the female. To investigate this, 
three solutions were prepared; normal Gouldin's, the phosphate buffer above and Gouldin's free of phosphate. The latter ion was replaced by $\mathrm{NaCl}$, and the solution buffered to $\mathrm{pH} 7$ with tris. Sperms were first prepared in a drop of phosphate-free Gouldin's solution which was divided between three slides. Once again, excess of the above solutions was added to each of the slides and activity compared (Table 12\%).

The results do not suggest that phosphate has a marked stimulatory or inhibitory effect on sperm activity. But these results and those immediately following are to be interpreted with caution.

Rather than manipulate the ions of Gouldin's solution, solutions of $0.15 \mathrm{M} \mathrm{NaCl}, \mathrm{KCl}$, and $\mathrm{CaCl}_{2}$ were prepared (see Appendix II). A drop of sperms in Gouldin's solution was divided onto 3 other slides and each slide flooded with two drops of (a) Gouldin's, as control, (b) $\mathrm{NaCl}$, (c) $\mathrm{KCl}$, and (d) $\mathrm{CaCl}_{2}$ solutions, and activity compared (Table 13).

There was no abnormal activity with sperms from either the male or female. The intrinsic difference between 'male' and 'female' sperm activity was maintained. An important fact is that the $\mathrm{CaCl}_{2}$ solution was not isomolar with the others; in some preparations the sperms were immobilized in the form of a tight whorl or perfectly straight. The latter effect was almost certainly produced by the $0.15 \mathrm{M} \mathrm{Ca}^{++}$present, for other, unreported observations with $0.2 \mathrm{M} \mathrm{NaCl}$ solution did not show this, nor were 'pokerstraight' sperms seen in any preparation in which immobilization occurred. Pharmacological effects: ATP, Adrenaline, Seratonin, Dopamine (see Appendix

$$
\text { II for details). }
$$

The beating of cilia increases at concentrations of ATP from about $10^{-7} \mathrm{M}$ to $10^{-4} \mathrm{M}$, of adrenaline from $10^{-8}$ to $10^{-4} \mathrm{~g} / \mathrm{ml}$ (about $6.7 \times 10^{-8} \mathrm{M}$ to 
$6.7 \times 10^{-4} \mathrm{M}$ ), and of seratonin from $10^{-9}$ to $10^{-4} \mathrm{~g} / \mathrm{ml}$ (about $2.5 \times 10^{-9} \mathrm{M}$ to $\left.2.5 \times 10^{-4} \mathrm{M}\right)$. The maximum increase usually occurs at about $10^{-5} \mathrm{~g} / \mathrm{ml}$ of substance (Sleigh, 1962). The effect of dopamine has not been reported. ATP at $2 \times 10^{-5} \mathrm{M}$ and $2 \times 10^{-4} \mathrm{M}$ in Gouldin's solution was tested on fresh suspensions of sperms on open slides. First, 10 readings from the drop of sperms were made, then a drop of $2 \times 10^{-5} \mathrm{M}$ ATP solution was added and further readings noted, and finally readings were taken after adding a drop of $2 \times 10^{-4} \mathrm{M}$ ATP. This procedure took less than 30 minutes, and a control slide was treated in similar fashion with Gouldin's solution. It can be seen that the sperms were subjected to ATP at about $10^{-5} \mathrm{M}$ and $10^{-4} \mathrm{M}$, when due allowance for dilution on the slide is made. Also, in several cases, a drop of sperms was added to each of 3 slides along with a drop of Gouldin's, $2 \times 10^{-5} \mathrm{M}$, and $2 \times 10^{-4} \mathrm{M}$ ATP respectively. The slides were sealed and inspected over at least 30 minutes. Fresh ATP solutions were used for each experiment.

Neither sperms from the male nor from the spermatheca responded to ATP (Table 14) except in the case of poorly active sperms from one female. A definite burst of activity followed the addition of ATP, but not Ringer alone. However, the lower activity of those from the male is not due to a deficiency in ATP.

The procedure for testing the other substances was similar to that outlined, except that separate slides were used for testing different concentrations.

Adrenaline had no effect over a range of from $10^{-7} \mathrm{M}$ to $10^{-2} \mathrm{M}$ (Table 15). Seratonin had no effect from $10^{-10} \mathrm{M}$ to $10^{-2} \mathrm{M}$ (Table 15). The results at the lower concentrations are rather few, however, it is unusual for an effect to 
be produced by a sharply defined concentration of active substance; but no effect at slightly higher concentrations was found. That a gradient effect is usual was borne out by the results with dopainine (Table 16, Fig. 16). Sperm activity was extremely depressed by dopamine at $10^{-2} \mathrm{M}$ and this effect persisted, but nicely diluted, down to $10^{-6} \mathrm{M}$ and possibly to $10^{-7} \mathrm{M}$, for sperms from the male, and down to $10^{-4} \mathrm{M}$ and probably $10^{-5} \mathrm{M}$, for sperms from the female. No effect over some hours was found at $10^{-8} \mathrm{M}$ to $10^{-10} \mathrm{M}$ with sperms from the male, and over an hour at $10^{-6} \mathrm{M}$ to $10^{-7} \mathrm{M}$ with sperms from the female. In Figure 16 single, typical experiments are shown to demonstrate the inhibition by dopamine and data from the remaining preparations are assessed in Table 16 to complete a general picture of the extent of inhibition. The inhibition produced by dopamine was reversible to some extent. In a number of strongly inhibited preparations the dopamine solution was partly sucked off with a fine pipette and the slide was then flooded with Gouldin's solution. This resulted in a marked improvement in activity (see Fig.16) while a similar procedure with the addition of the same strength of dopamine solution did not, but maintained the depressant effect. 
(a) 10 preparations from the male (Results are means of 100 readings)

$\begin{array}{clll}\underline{\text { Time }} & \mathrm{R} \mathrm{NaCI} & \text { R Dextrose } & \text { R Fruct } \\ 5-15 \text { mins } & 510 \pm 8 & 540 \pm 8 & 543 \pm 9 \\ 30-60 \text { mins } & 575 \pm 9 & 640 \pm 11 & 660 \pm 12 \\ 100-130 \text { mins } & 619 \pm-13 & 639 \pm 11 & 689 \pm 10\end{array}$

(b) 6 of the above preparations, after 10-14 hrs.

$\begin{array}{llll}\text { 1. } & \text { Zero } & \text { Few } & \text { Few } \\ \text { 2. } & \text { " } & \text { " } & \text { " } \\ \text { 3. } & \text { " } & \text { None } & \text { None } \\ \text { 4. } & \text { " } & \text { None } & \text { (Accident) } \\ \text { 5. } & \text { INone } & 575-24 & 584 \pm 20 \\ 6 . & \text { Zero } & \text { Few } & \text { Few }\end{array}$

(c) 5 preparations from the female (Results are means of 50 readings) Time

$\begin{array}{llll}5-15 \text { mins } & 1009 \pm 16 & 956 \pm 15 & 1016 \pm 16 \\ 15-30 \text { mins } & 985 \pm 12 & 1012 \pm 15 & 1070 \pm 17 \\ 45-60 \text { mins } & 983 \pm 12 & 981 \pm 11 & 1022 \pm-16\end{array}$

Table 9. The activity of spermatozoa from the male and from the female with hexose. 
(a) Sperms from the male R. Dextrose R. GIucosamine

$$
\begin{aligned}
& \text { No. } 1 . \\
& \text { No. } 2 . \\
& \text { No. } 3 . \\
& \text { No. } 4 .
\end{aligned}
$$$$
520 \pm 22
$$$$
510 \pm 15
$$$$
506 \pm 12
$$$$
4.85 \pm 23
$$$$
621 \pm 15
$$$$
452 \pm 12
$$$$
600 \pm 18
$$

(b) Sperms from the female R. Dextrose R. Glucosamine

Note: Each result is the mean of at least 20 readings in the first 30 minutes. See Table 8 for details of solutions.

Table 10. Activity of spermatozoa with glucosamine.

(a) Sperms from the male

Time R. NaCl

No. 1.

Nos. 2-5

(b) Sperms from the female

Nos. $1-4$

$$
\begin{aligned}
& 559 \pm 18 \\
& 590 \pm 39 \\
& 717 \pm 21 \\
& 729 \pm 23 \\
& 868 \pm 33 \\
& 842 \pm 16 \\
& 828 \pm 25
\end{aligned}
$$

$$
548 \pm 13
$$

$$
1025 \pm 15
$$

R. Citrate

$$
\begin{aligned}
& 580 \pm 22 \\
& 589 \pm 25 \\
& 633 \pm 27 \\
& 7.13 \pm 31 \\
& 786 \pm 29 \\
& 856 \pm 28 \\
& 795-32
\end{aligned}
$$

$571 \pm 12$

\section{Citrate}

$541 \pm 18$ $604 \div 22$ $674+28$ $729 \pm 28$ $799 \div 30$ $775 \div 31$ $800 \pm 34$ $564 \pm 13$$$
988 \pm 15
$$

$1042 \pm 17$

Note: No.1(a) shows the most active preparation of vesicular sperms. The other results are the means of at least 100 readings: taken within one hour. See Table 8 for Ringer details.

Table 11. Activity of spermatozoa with citrate. 
(a) Sperms from the male

\begin{tabular}{|c|c|c|c|}
\hline 5 preps. & R. Dextrose & $={ }_{\mathrm{PO}}{ }_{4}$ Free & $\underline{0.067 \mathrm{M}=\mathrm{PO}}_{4}$ \\
\hline $\begin{array}{r}0 \\
15 \text { - } 15 \text { mins } \\
10 \text { mins }\end{array}$ & $\begin{array}{l}615 \div 17 \\
641-16\end{array}$ & $\begin{array}{l}596 \pm 21 \\
611 \pm-17\end{array}$ & $\begin{array}{l}582 \pm 18 \\
635 \pm-18\end{array}$ \\
\hline
\end{tabular}

(b) Sperms from the female

4 preps

$\begin{array}{rrrr}0-15 \text { mins } & 984 \div 15 & 959 \pm 17 & 1004 \div 22 \\ 15-30 \text { mins } & 822 \pm 20 & 895-19 & 846 \pm 24\end{array}$

Note: Details of solutions are in the text.

Table 12. Activity of spermatozoa with variations in phosphate.

(a) Sperms from the male

\begin{tabular}{|c|c|c|c|c|c|}
\hline & Time & R. Dextrose & $\mathrm{NaCl}$ & $\underline{\mathrm{KCl}}$ & $\mathrm{CaCl}_{2}$ \\
\hline No.1. & $\begin{array}{r}15 \text { mins } \\
20 \text { mins } \\
60 \text { mins } \\
2 \text { hrs. } \\
5 \text { hrs. }\end{array}$ & $\begin{array}{l}578 \pm 31 \\
704 \pm 26 \\
735 \pm 33 \\
611 \pm 27 \\
520 \pm 21\end{array}$ & $\begin{array}{l}569 \pm 28 \\
687 \pm 27 \\
700 \div 17 \\
632 \pm 19 \\
441 \pm 15\end{array}$ & $\begin{array}{l}630 \pm 24 \\
679 \pm 18 \\
737 \pm 29 \\
633 \div 19 \\
513-22\end{array}$ & $\begin{array}{l}596 \pm 19 \\
734 \pm 25 \\
786 \pm 32 \\
668 \pm 25 \\
447 \pm 16\end{array}$ \\
\hline Jos.2- & -6. 0-60 mins. & $590 \pm 12$ & $584 \pm 16$ & $577 \pm 11$ & $637 \pm-11$ \\
\hline
\end{tabular}

(b) Sperms from the female

Nos.1-5. $0-40$ mins. $\quad 945 \pm 11 \quad 989 \pm 14 \quad 952 \pm 15 \quad 940 \pm 12$

Note: Details of solutions are in the text.

Table 13. Activity of spermatozoa in solutions of simple salts. 
(a) Sperms from the Male

Open Slides

Ringer

No. 1.

No.2.

No.3.

No. 4.

Sealed SIides

$\begin{array}{cl}\text { No. 1. } & 440 \pm 27 \\ & 485 \pm 26 \\ \text { No.2. } & 550 \pm 15 \\ & 567 \pm 15 \\ \text { No.3. } & 426 \pm 17 \\ . & 405 \pm 17\end{array}$

(b) Sperms from the Female

Open Slides

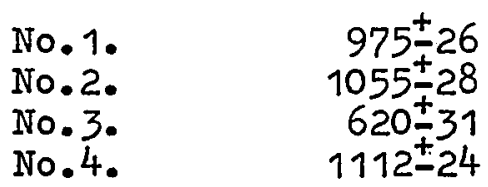

Sealed Slides

No. 1.

$1025 \div 19$

$1065 \div 26$

No.2.

No. 3.
$495 \div 22$

$569 \div 18$

$604 \div 25$

$528 \pm 16$
Change in Activity $(+, 0,-)$

$10^{-5}$ ATP $10^{-4}$ ATP Control

0

$+$

0

0

0

0

0

$+$

0

0

Time

$462 \pm 19 \quad 458 \pm 21 \quad 5$ mins 478 $\pm 20 \quad 490 \pm 18 \quad 10$ mins

$544 \div 22 \quad 532 \div 24 \quad 5$ mins $550 \pm 19 \quad 570 \pm 16 \quad 15$ mins

$440 \pm 26 \quad 422 \pm 17 \quad 5$ mins $420 \pm 20 \quad 400 \pm 23 \quad 15$ mins

Control

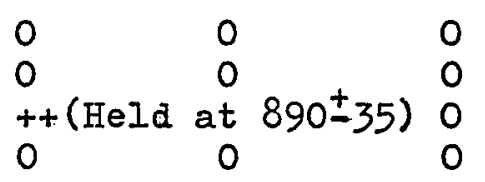

\begin{tabular}{rrr} 
& & \multicolumn{1}{c}{ Time } \\
$1000 \pm 22$ & $1008 \pm 27$ & 5 mins \\
$1048 \pm 20$ & $1055 \pm 20$ & 10 mins \\
$954 \pm 18$ & $962 \pm 20$ & 5 mins \\
$925 \pm 18$ & $934 \pm 22$ & 15 mins \\
$856 \pm 24$ & $904 \pm 34$ & 5 mins \\
$865 \pm 23$ & $900 \pm 25$ & 15 mins
\end{tabular}

Table 14. The effect of ATP on spermatozoa from the seminal vesicles and from the spermatheca. 


\begin{tabular}{|c|c|c|c|c|c|}
\hline $\begin{array}{l}\mathrm{Mx} 10 \\
\text { to the }\end{array}$ & $\begin{array}{l}-2 \\
-3 \\
-4 \\
-5 \\
-6 \\
-7 \\
-8 \\
-9 \\
-10\end{array}$ & $\begin{array}{l}\text { Males } \\
485 \div 21(4) \\
549 \pm 15(8) \\
600 \div 14(8) \\
585 \div 10(9) \\
575 \div 16(8) \\
502 \pm 22(4) \\
- \\
- \\
- \\
559 \pm 8\end{array}$ & $\begin{array}{c}\text { Females } \\
980 \pm 29(3) \\
885 \pm 18(7) \\
945 \pm 21(6) \\
1014 \pm 24(6) \\
895 \pm 19(5) \\
932 \pm 31(4) \\
- \\
- \\
965 \pm 9\end{array}$ & $\begin{array}{l}\text { Males } \\
- \\
577 \pm 14(6) \\
495 \pm 12(7) \\
552 \pm 13(7) \\
571 \pm 9(7) \\
533 \pm 11(6) \\
552 \pm 16(6) \\
507 \pm 19(4) \\
529 \pm 27(3) \\
515 \pm 7\end{array}$ & $\begin{array}{l}\text { Females } \\
- \\
875 \pm 17(5) \\
960 \pm 21(6) \\
920 \pm 14(8) \\
880 \pm 30(2) \\
954 \pm 11(6) \\
972 \pm 15(6) \\
870 \pm 19(4) \\
939 \pm 22(4) \\
925 \pm 9\end{array}$ \\
\hline
\end{tabular}

Note: Brackets enclose the number of preparations per concentration.

Table 15. The concentrations of adrenaline and seratonin tested on various preparations of spermatozoa.

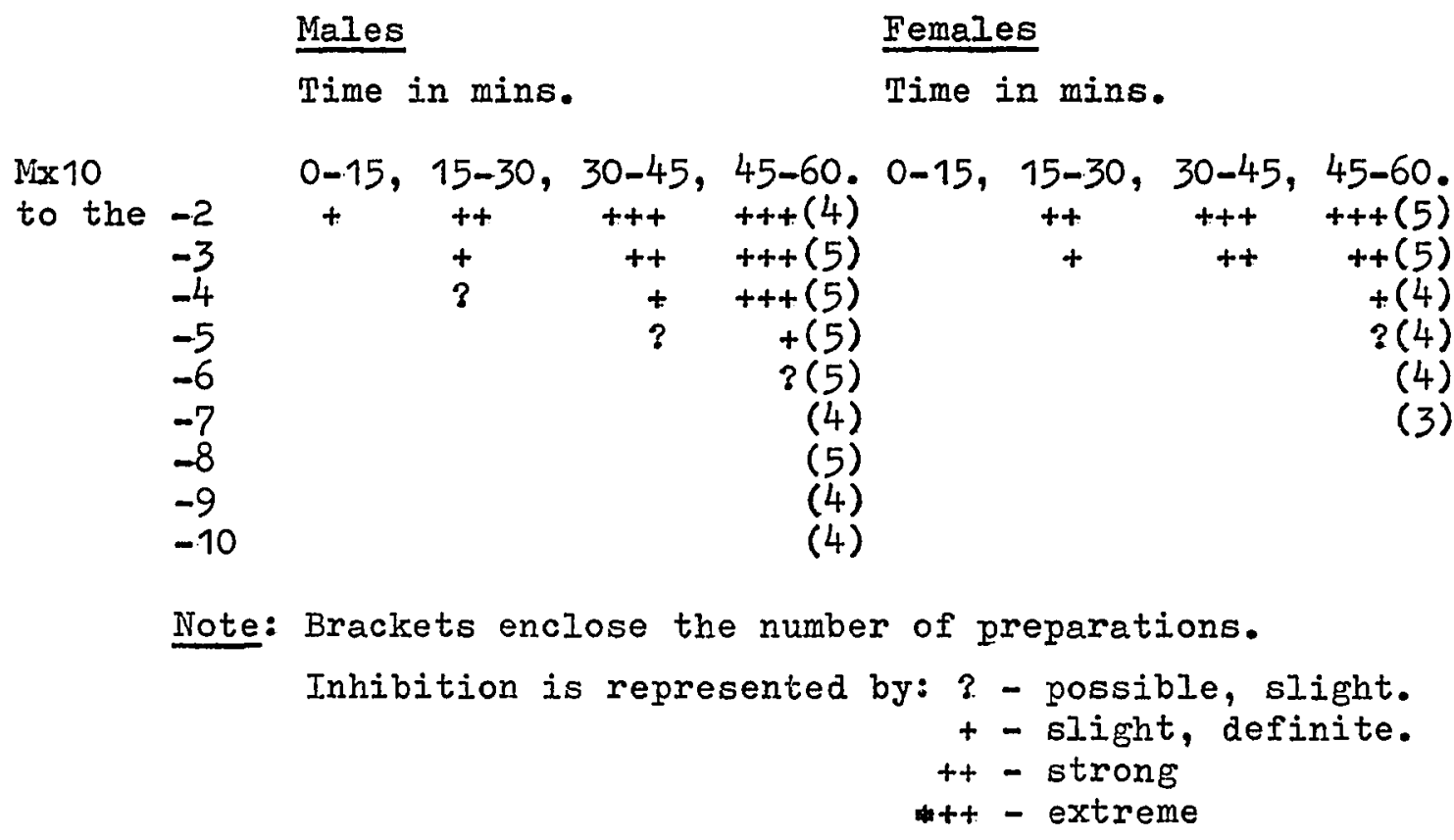

Table 16. The inhibition of sperm motility by dopamine. 


\section{$\frac{\text { Beats }}{\text { per }}$ \\ Min.}

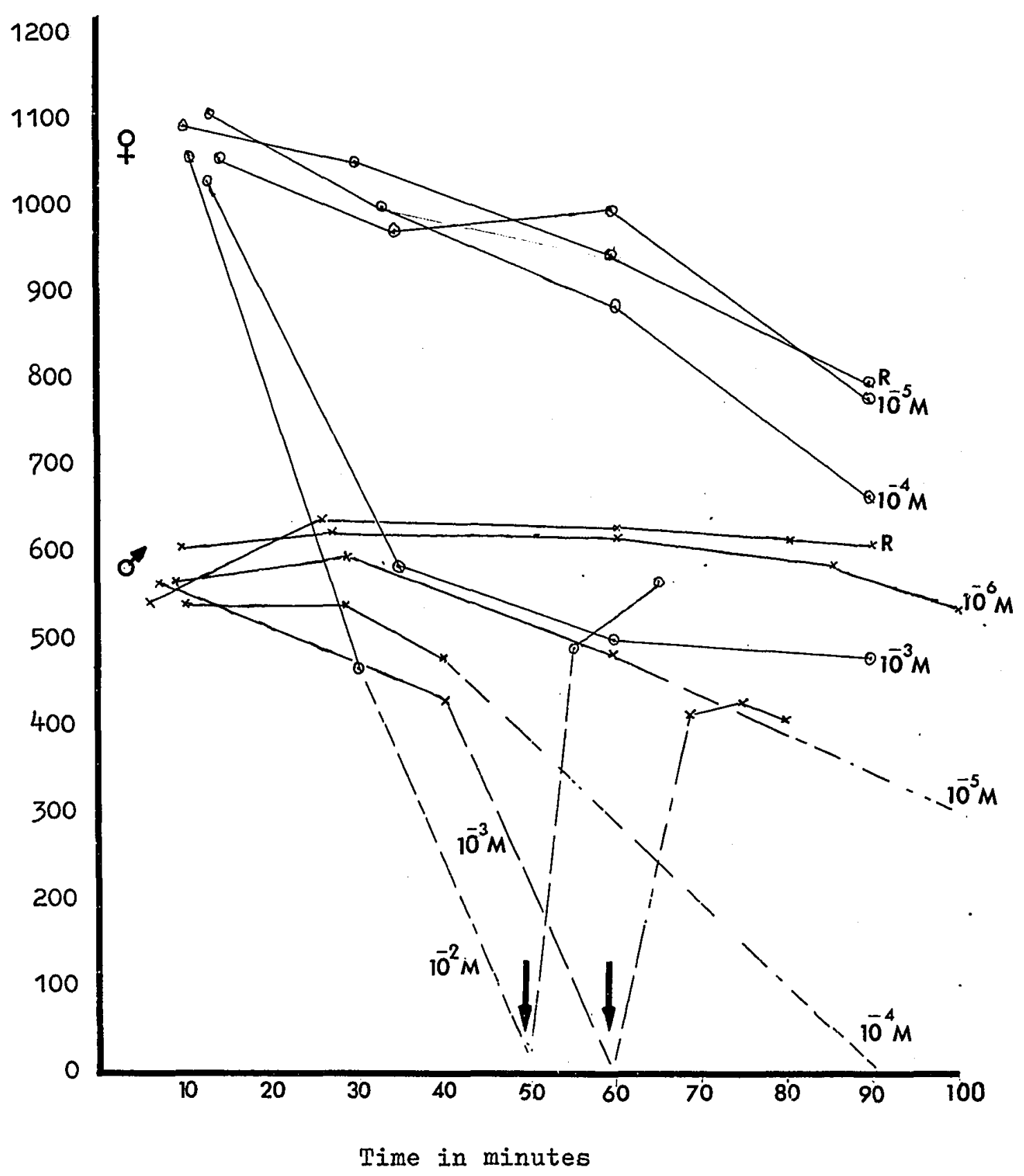

Note: Arrows denote washing of sperms (details in text). The lines trace the activity of one preparation, from both the male and female, under different concentrations of inhibitor.

Figure 16. The efiect of dopamine on sperms from the male and the female. 
THE ACROSOME AND CAPACITATION -

The spermatozoon of Periplaneta has a large disc-shaped acrosome (Fig. 17). The formation and structure have been previously described (Nath et al., 1957). This acrosome is similar in side view to that of Acheta domestica, the fine details of which have been described by Kay (1962). Spermatozoa from the spermatheca, however, have a modified acrosome. The acrosome is smaller, less flattened, homogeneous, and in optical density similar to the leaf region found in the male (Fig. 18). Fresh smears of sperms from spermathecae in Ringer (Fig. 19a), or without added fluid (Fig. 19b), and fixed smears (see Appendix II) (Fig. 19c) confirmed the original observations.

Various pathological changes in the acrosome were noted and frequently there appeared to be a reduction in the leaf region through the extrusion of its contents which appeared to be sticky. Some stages of this process are illustrated in Figure 20. Very rarely, disintegration of sperms occurred and the acrosome, either whole or fragmented, fell from the nucleus as did the tail. The tails alone were capable of vigorous beating for some time. This disintegration, for which no explanation is offered, is shown in Figure 21.

It was found impossible to produce a normal reduction in the acrosome from the vesicles with either chemicals or tissue extracts. Incubation of sperms with either mated or virgin cockroach spermathecae for up to 12 hours did not reduce the acrosome. This suggested that the changes in vivo might take many hours and to check this, a series of virgin cockroaches were mated and 
dissected at various intervals.

The evidence in Table 17 suggests that:

1. Reduction of the leaf occurs after at least 5 hours in the spermatheca.

2. Complete reduction of the leaf may take up to 12 hours and in some cases up to 48 hours.

3. Disappearance of the cap may occur from 12 hours to several days, but appears to be complete after about 7 days.

4. The rod swells slightly and becomes optically less dense after removal of leaf and cap.

It is tempting to relate these changes to those which occur in mammalian sperms in the female. Perhaps the reduction in the acrosome in Periplaneta represents the capacitation of the sperms?

Capacitation is a difficult phenomenon to study but of such importance that preliminary observations on two questions are reported. First, are spermatozoa with complete acrosomes capable of entering the micropyles of the egg, and secondly, can these spermatozoa initiate egg development as effectively as those from the spermatheca?

A piece of chorion, removed from the egg and with numerous micropyles, and clearly, they appear to be many times larger than the sperm acrosome (Fig. 22). I did not see micropyles on eggs when placed in Ringer and could not observe spermatozoa entering the egg. Dewitz (1886) first described the micropyles in $\underline{B}$. orientalis and stated that spermatozoa enter them. But, it is not clear that he observed this happening. In his studies he used spermatozoa from the seminal vesicles.

There is unlikely to be a simple physical block to the entry of an egg 
by sperms taken from the male. Histological studies of other insect eggs have shown sperms entering the micropyle (Omura, 1938a; Wigglesworth, 1965) and a similar study in Periplaneta would be illuminating.

To study development in eggs materials were prepared as follows. Pyrex petri-dishes with a small piece of corrugated filter paper were autoclaved along with a stock of Ringer, distilled water and pipettes. Several female cockroaches were disected and the largest eggs removed from the proximal oviduct region into sterile Ringer in a pyrex cavity. A single egg was removed and placed in $0.5 \mathrm{ml}$ of the Ringer in another cavity to which was added some sperm from a freshly disected male or from the spermatheca of the female. The egg was left in the sperm suspension for about 15 minutes. It was removed, placed on the moist filter paper in the petri-dishes which were then placed in an incubator at $28 \mathrm{C}$ until signs of development could be detected in the 'male' or in the 'female' treated eggs. Eight preparations, that is 16 eggs, were made up in this way.

All of these preparations were, not surprisingly, unsuccessful. None dried-out at all, nor was there a trace of fungus over at least 10 days. The eggs simply "melted" away, forming faint yellowish patches on the filter paper.

The reason for this failure was probably due to the environment being unsuitable for development. In any case, attempts to show development in eggs of Periplaneta must take into account both the high level of parthenogenetic development and the long developmental period of up to many weeks (Roth and Willis, 1954).

I would suggest that capacitation should be studied in a nonparthenogenetic insect having fast developing eggs. Otherwise a more sophisticated set up is necessary. 


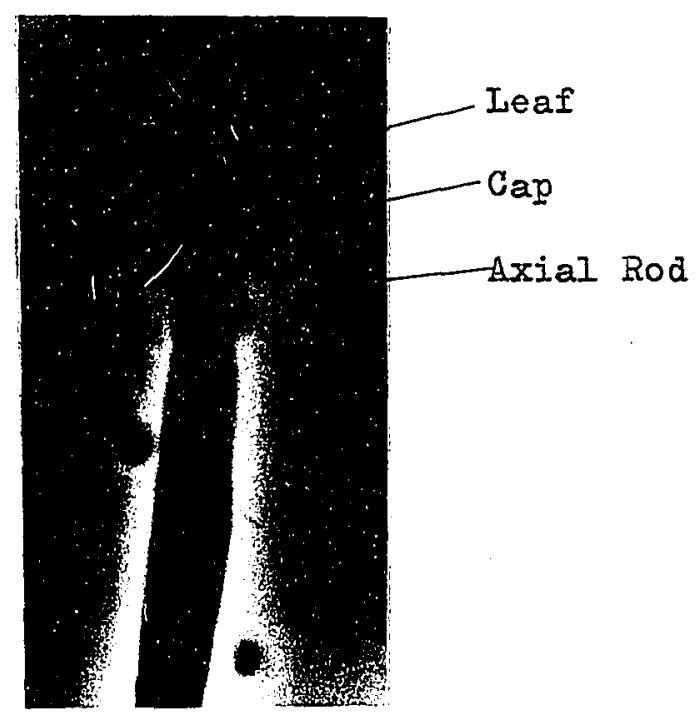

(a)

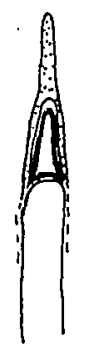

(b) Side view

Figure 17. The acrosome in the sperm from the male $(x 7,500)$ (Acrosome nomenclature suggested by Nath etal., 1957).

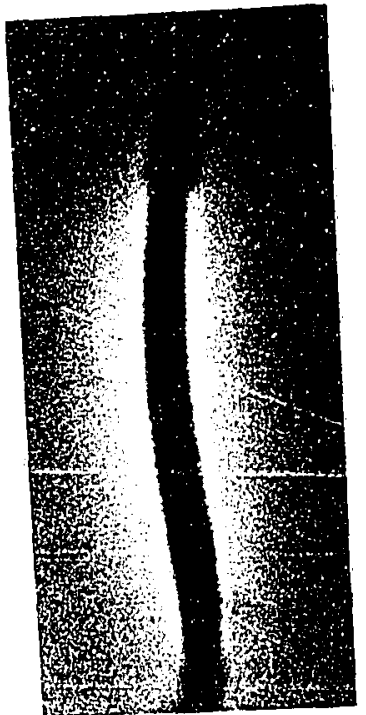

(a)

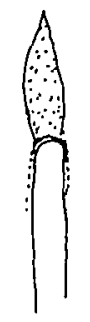

(b) Side view

Figure 18. The acrosome in the sperm from the female $(x 4,000)$. 
9
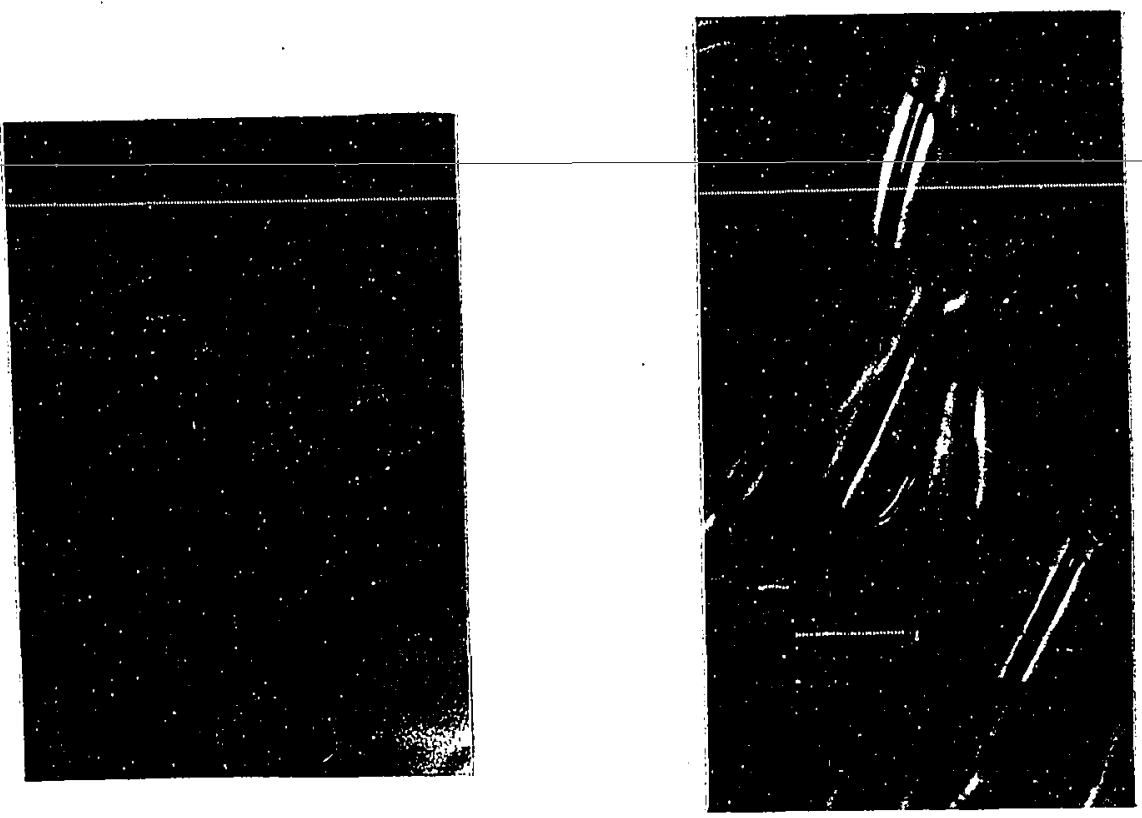

(a)

(c)

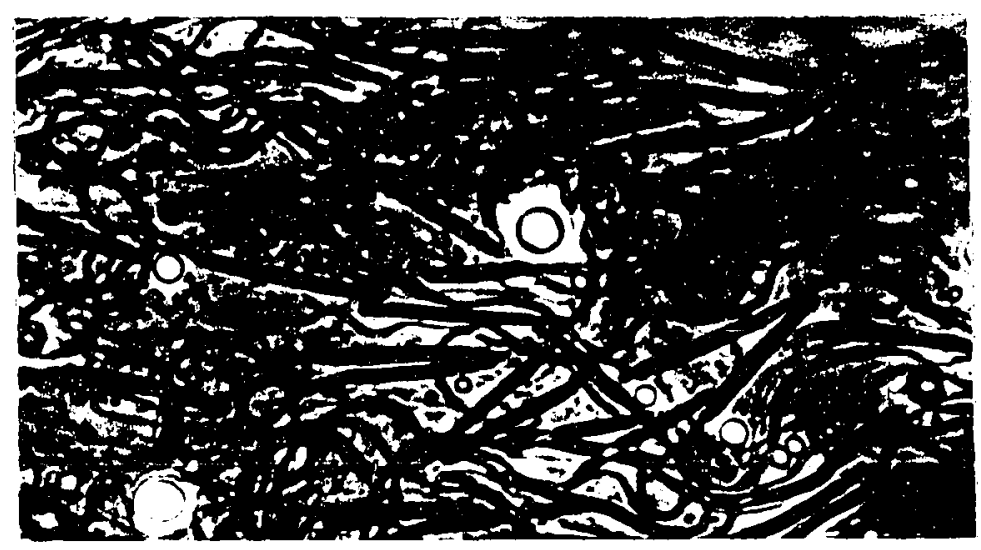

(b)

Figure 19. Smears of spermatozoa from spermathecae;

(a) in Ringer $(x 1,800)$

(b) without added fluid $(x 1,000)$

(c) fixed ( $5 \%$ neutral formalin $\times 1,000$ ) 


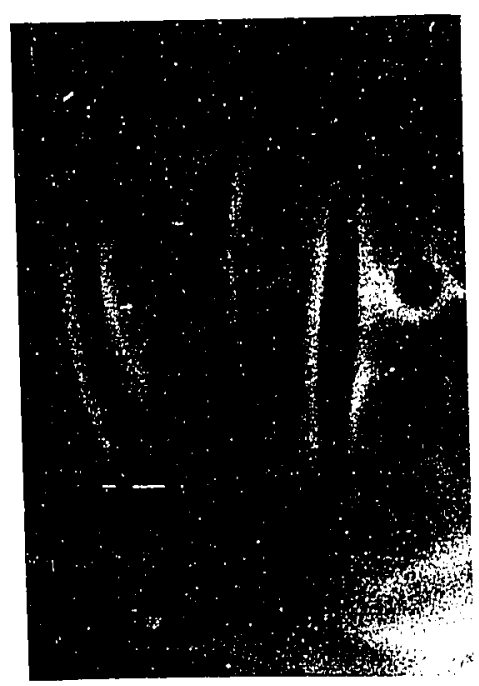

(a)

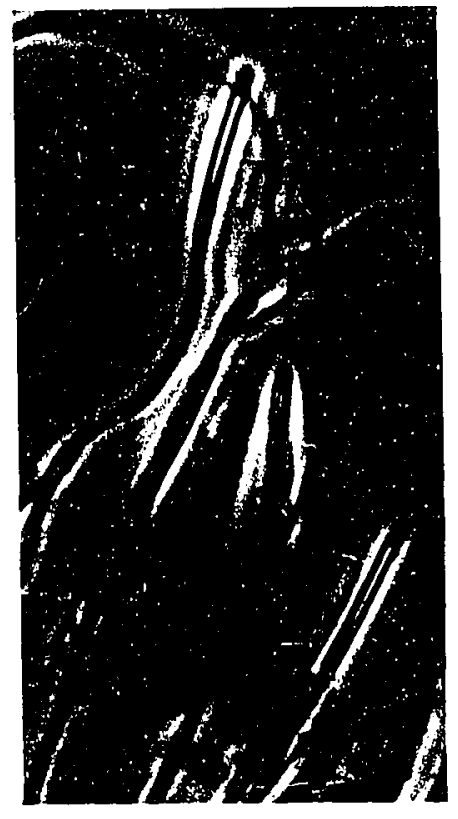

(c)

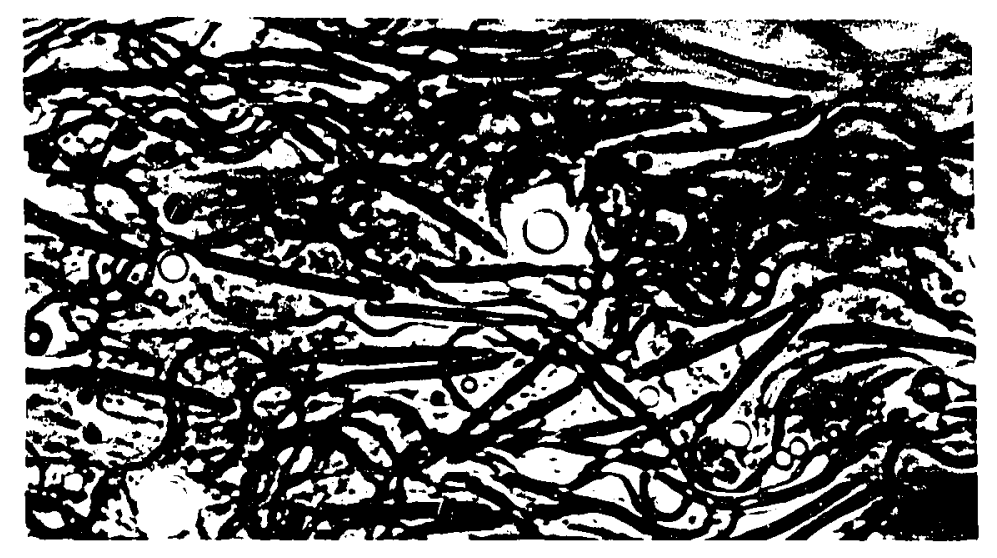

(b)

Ficure 19. ismears of spermatozoa from spernathecae;

(a) in kinger $(\times 1,800)$

(b) without added fluid $(x 1,000)$

(c) fixed ( $5 \%$ neutral formalin $\mathrm{x} 1,000$ ) 
19

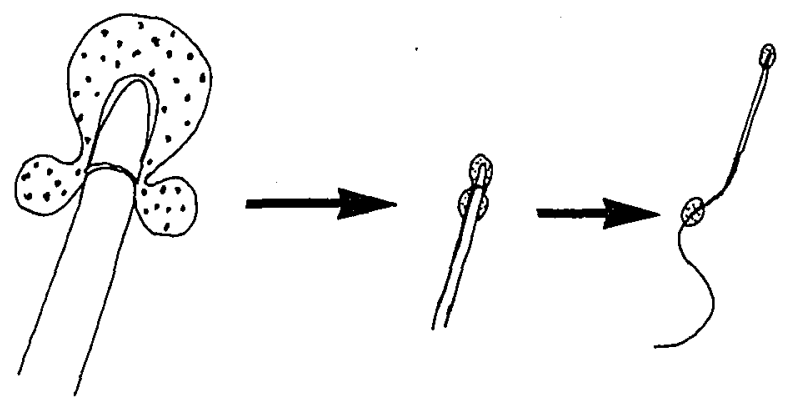

Figure 20. Diagram of pathological changes in the sperm acrosome.

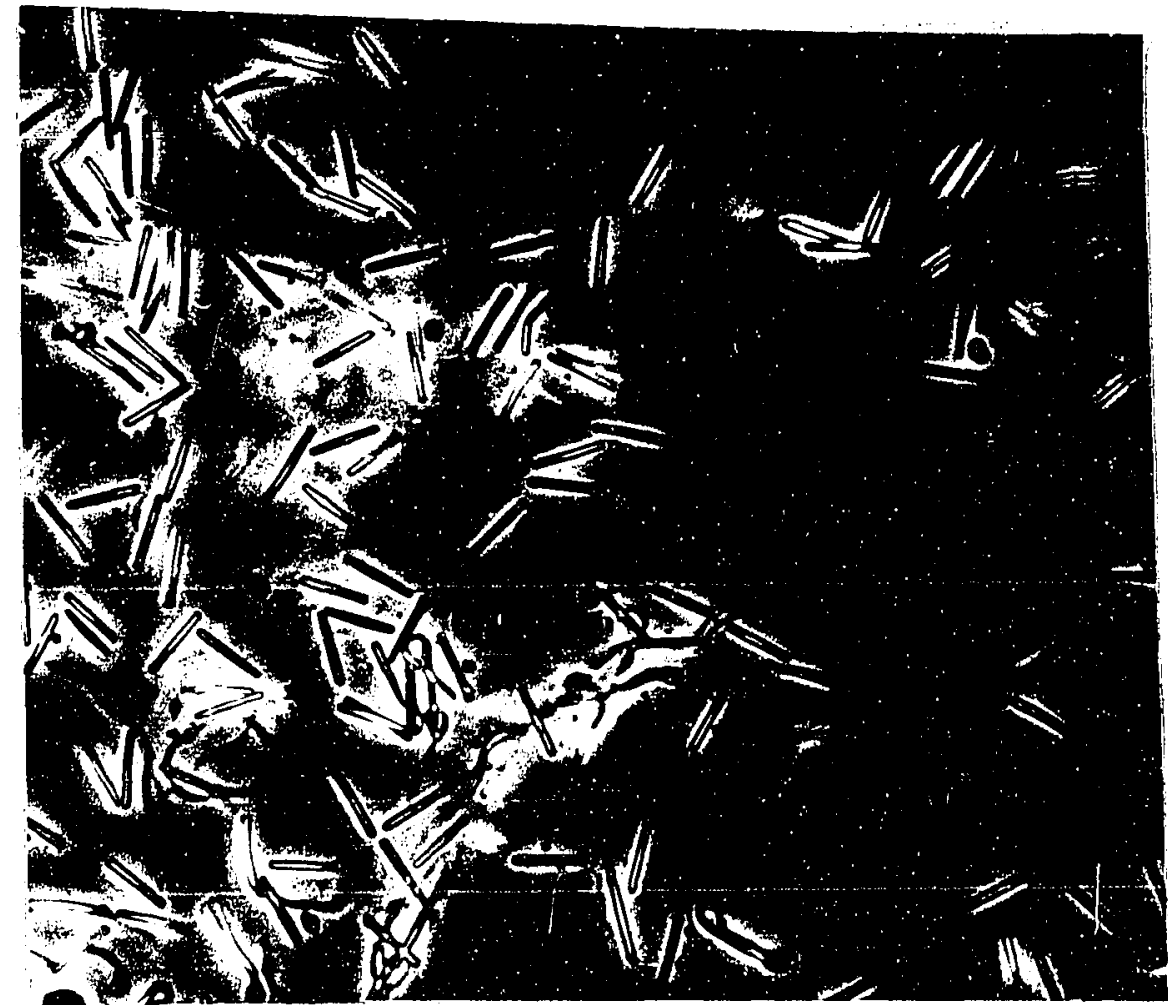

i.

Figure 21. Sperm from the male disintigrating in Ringer ( $x 650$ ) 


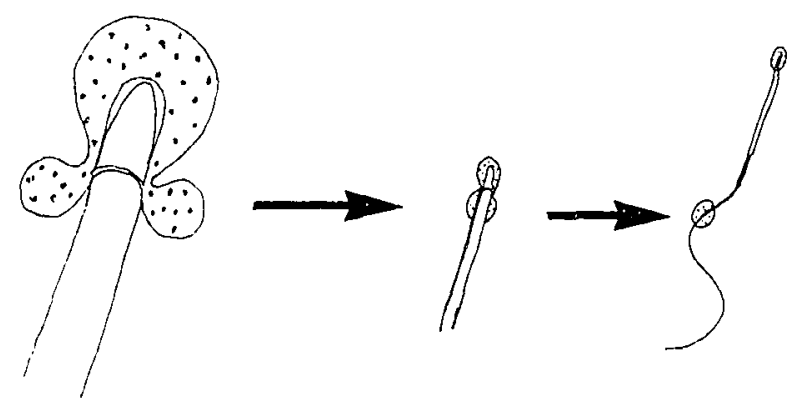

Hifure 20. Diaman of patholouical chanes in the sperm acrosone.

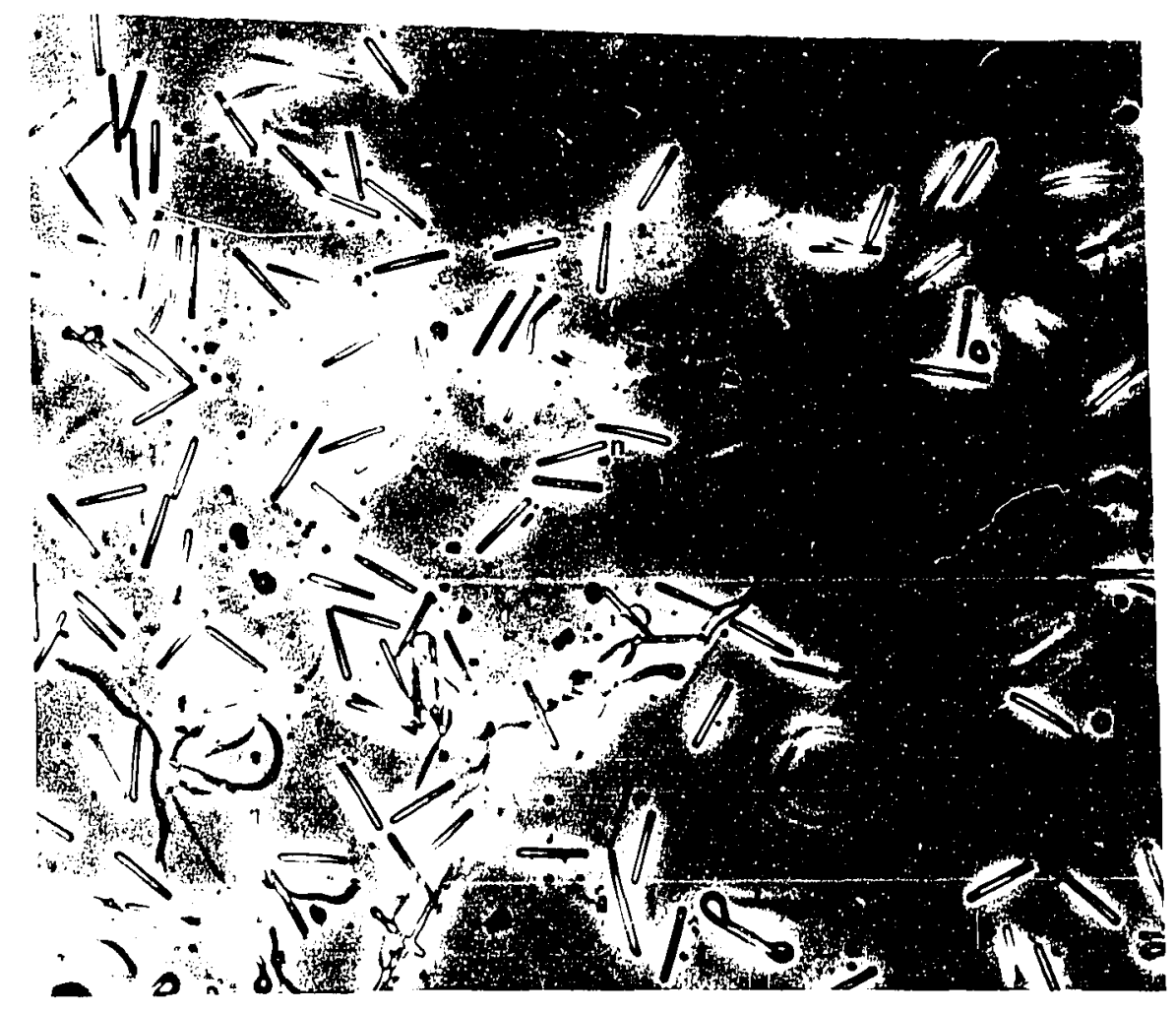


4

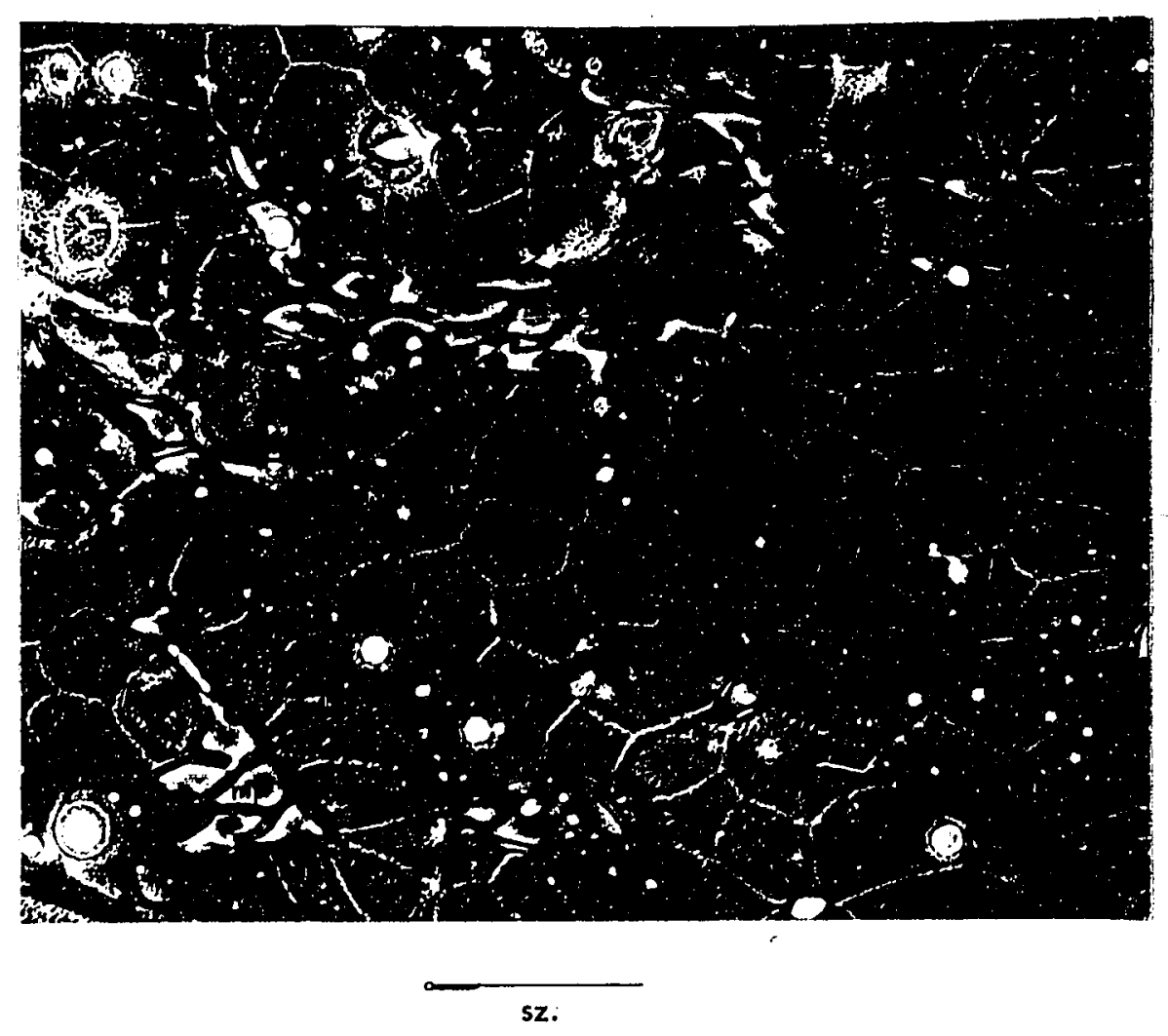

Figure 22. Micropyles in the chorion of the egg (x300). Note the spermatozoon drawn to scale. 


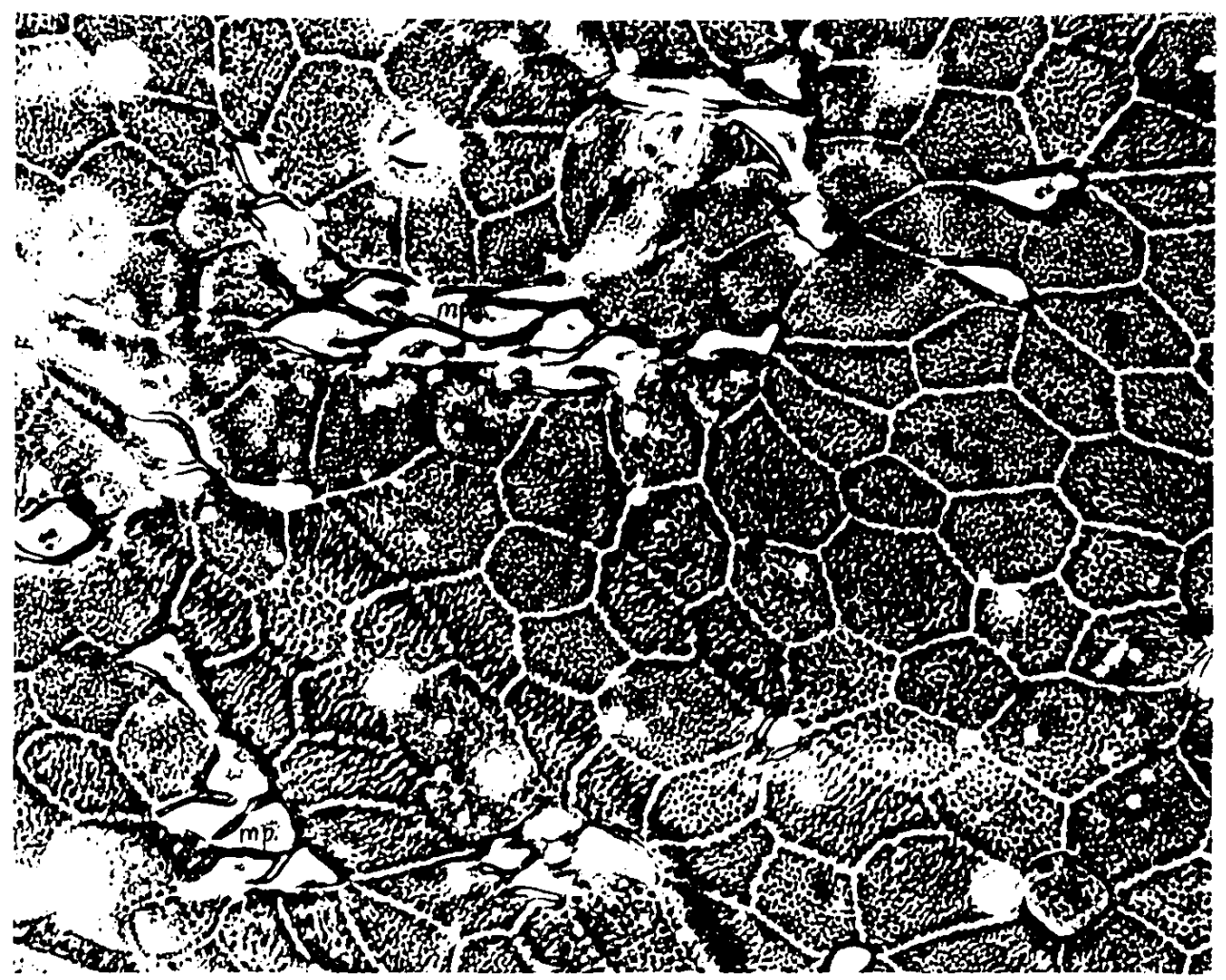

sz. 


\begin{tabular}{|c|c|c|c|c|}
\hline Mating & $\frac{\text { Time after }}{\text { Copulation }}$ & $\begin{array}{l}\text { Acrosome from } \\
\text { Spermatophore }\end{array}$ & $\frac{\text { Acrosome from }}{\text { Spermatheca }}$ & Comments \\
\hline No. 1. & 5 mins & All Male-type & - & \\
\hline No.2. & 10 mins & $1 "$ & - & \\
\hline No. 3. & $5 \mathrm{hrs}$ & $n$ & All Male-type & $\begin{array}{l}\text { Spermatheca part } \\
\text { filled, sperms } \\
\text { active in ducts }\end{array}$ \\
\hline No. 4. & $10.5 \mathrm{hrs}$ & "1 & $\begin{array}{l}\text { Many Male-type } \\
\text { Many reduced } \\
\text { Leaf. } \\
\text { Few. without } \\
\text { Leaf. } \\
\text { Few with Rod } \\
\text { only. }\end{array}$ & $\begin{array}{l}\text { Spermatheca full } \\
\text { of quiescent } \\
\text { sperms }\end{array}$ \\
\hline No. 5 . & 48 hrs. & - & $\begin{array}{l}\text { AlI reduced } \\
\text { Leaf. } \\
\text { Many without. } \\
\text { Leaf. } \\
\text { Some with Rod } \\
\text { only. }\end{array}$ & $\begin{array}{l}\text { Spermatheca full } \\
\text { of quiescent } \\
\text { sperms. }\end{array}$ \\
\hline No.6. & 3 days & - & $\begin{array}{l}\text { AlI without } \\
\text { Leaf } \\
\text { Many Rod only }\end{array}$ & $" n$ \\
\hline No. 7. & 7 days & - & AII Female-type & $n$ \\
\hline Note: & $\begin{array}{l}\text { From the ta } \\
\text { the Rod swe } \\
\text { degree of } r \\
\text { place in th }\end{array}$ & $\begin{array}{l}\text {, and from Fig } \\
\text { to form the F } \\
\text { ganisation wit. } \\
\text { permatheca. }\end{array}$ & $\begin{array}{l}\text { ces } 17 \text { and } 18 \text {, it } \\
\text { aale-type acrosom } \\
\text { in the acrosome } m\end{array}$ & $\begin{array}{l}\text { appears that } \\
\text { e, but a greater } \\
\text { ay possibly take }\end{array}$ \\
\hline
\end{tabular}

Table 17. The reduction in size of the sperm acrosome within the female cockroach. 


\title{
Chapter Eight
}

\section{AN ASSESSMENT}

\author{
"Observation sets the problem; experiment solves it, \\ always assuming that it can be solved." \\ The Insect World of J.Henri Fabre, \\ In the translation of Alexander Teixeira \\ de Mattos \\ Edited by E.W.Teale, 1949. \\ Dodd, Mead and Co., New York.
}

Let us briefly consider what has been observed, the problems posed and the extent to which experiments have answered them. The problems fall roughly into three categories, those associated with sperm transfer, maintenance and utilization, those of the physiology of sperm activity, and those possibly related to capacitation. But of course, from the point of view of the cockroach all details are incidental to the function of the spermatozoan in fertilizing the egg.

How is the semen transferred to the spermatheca? The evidence from Chapter 4 is that the spermatophore did not expel sperms when placed in Ringer, but they were easily squeezed out from it, and that it did become smaller when emptying. Also, the female genital appendages and the walls of the bursa are suitably formed for squeezing the attached spermatophore, although this was not observed. In Chapter 4 we have seen that spermatozoa, although active, were unable to complete their ascent of the spermatheca in vitro. Peristalsis of this organ was observed and the walls are highly secretory. Some exceptionally high activity occurred with sperms removed from copulating pairs.

Reflection on these details suggests that sperm transfer in Periplaneta 
results from sperm activity and peristalsis of the spermatheca muscle layer. The spermatophore may possibly be squeezed in the bursa of the female, and there may be a sperm stimulating secretion released from the spermatheca at this time. Aside from possible stimulation of sperms, active secretion might orientate sperms by rheotaxis. But rheotaxis of sperms was not found; under a raised coverslip, dead or feeble sperms were seen to drift in, and active sperms to effectively ignore a flow of Ringer.

The protocol for elucidating the roles of spermatozoa and spermatheca during sperm transfer in Rhodnius has been set out (Davey, 1958b) and might be adapted for this problem in Periplaneta.

It has been suggested that oxygen is necessary to initiate insect sperm activity (Makielski, 1966, see below) and that in the honey bee seminal hexoses provide for sperm migration to the spermatheca (Blum and Taber, 1965). But these suggestions are misleading for it appears that sperms are passively transported by the spermatheca in the honey bee (Ruttner, 1956) where oxygen may be plentiful (Blum and Taber, 1965); and in Periplaneta spermatozoa show prolonged activity in salt solutions, in dense masses within the spermatheca (Ch. 7 and 4), and even under nitrogen (Davey, 1965). Oxygen and hexoses may well influence sperm motility but not, apparently, with the effect of a switch or simple regulator for activity.

How are the sperms supported in the spermatheca? In mammals the problem of maintenance hardly arises as the semen provides sufficient fructose for sperm energy up to fertilization of the egg. In some insects the sperm may be stored for up to some years and the female must supply some form of exogenous substrate. This problem has been discussed by several authors (Blum and Taber, 1965; Taber and Blum, 1960; Davey, 1965a). Blum and 
Taber found that honey bee sperms can live up to 68 days at room temperatures in vitro without added food, and still be potent. They say that in the spermatheca of the queen bee sperms have access to abundant oxygen (Blum and Taber, 1965).

In Periplaneta the spermatheca is well tracheated (Ch. 4) and sperms do not require hexoses, etc. for prolonged activity (Ch. 7). Therefore, one need not postulate the supply of sustenance by the spermatheca other than oxygen for efficient oxidation of endogenous sperm reserves. The fact that they are quiescent in the female suggests a low storage level of metabolism. Sperm activity in ascending the spermatheca might be supported by seminal hexoses which are known to occur in the honey bee (Blum and Taber, 1.c.) This would protect sperm reserves for the storage period.

This is speculation, and it is quite likely that, for example, the level of sugars in the blood is reflected by a similar level within the spermatheca. This appears to be the case in bee semen (Blum, Glowska and Taber, 1962). Substrates, if present, would surely be used by the sperms of Periplaneta within the spermatheca.

There is evidence that, following insemination, cells of the spermatheca are engaged in secretory activity (Cockroach: Gupta and Smith, 1965; cited by Makielski; Sciara: Makielski, 1966). The endocrinal implications of this were discussed by Davey in 19650 and he has since shown that active secretion does take place after mating in Rhodnius (Davey and Webster, 1967). Another aspect of this problem is the evidence that in some insects the presence of spermatozoa in the spermatheca may result in a stimulus to egg production (Davey, 1965b). This may be the case in Periplaneta. Virgin cockroaches certainly lay fewer eggs than females (Roth and Willis, 1954; 
personal observations). It is just possible that the acrosome may be responsible for initiating the chain of events leading to higher egg production. Speculation is limited until more is known about the nature of the substances within the spermatheca before and after mating and until the structure and contents of the acrosome are more clearly defined. A histochemical and electron microscope study of this problem should prove rewarding.

The problem of the release of sperms from the spermatheca for fertilizing the egg has been discussed in Chapter 4 . The mechanism described by Dewitz in 1886 is plausible. It should be rather simple to check Gupta's contention that females mate again only when their supply of sperms is exhausted (Gupta, 1947).

Dewitz (1.c.) described the movements of the sperms and stressed that their habit of swimming clockwise in circles would further assist their finding and being trapped by a micropyle on the egg. It seems suitable at this point to add a few notes on sperm movements. Nath et al., (1957) found a strong tendency for sperms to stick by their heads to the glass. But I found they are as often stuck by the tips of their tails, indeed, there were suspensions with a pseudo-crystalline appearance due to formation of many clumps of sperms, bound at the centre by their tail-tips and with their heads waving free.

The extent to which sperms circle and show thigmotactic behaviour must be due to the degree of deformation of beat or of sperm structure. By using the stroboscope it was seen that the large acrosome twists through $180^{\circ}$ with each stroke, that is to say it acts like a forward sculling oar, providing lateral purchase for the tailbeat (Fig. 23a). Figure $23 b$ shows the excentric acrosome seen in several sperms swimming close to the glass surface and it 

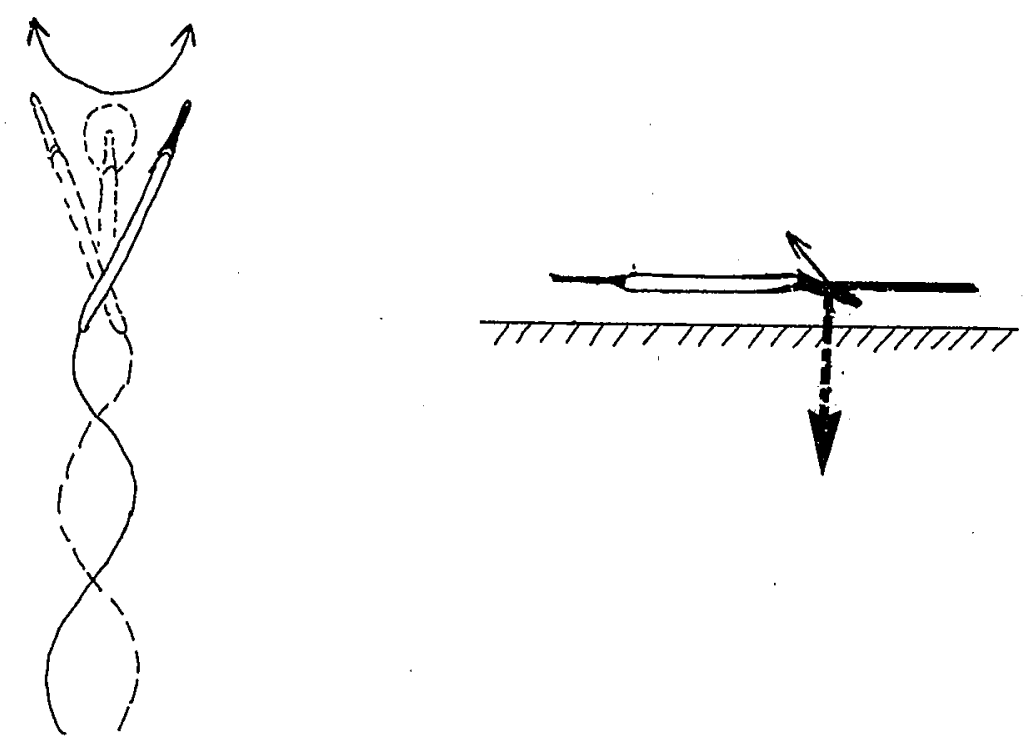

(a)

(b)

Figure 23. Diagram of the position of the sperm acrosome during swimming. 
illustrates the resulting force maintaining the sperm close to the surface. There is, therefore, some direct physical evidence to explain sperm thigmotaxis. However, an increase in circling behaviour did not occur in the presence of an egg.

How does the activity of Periplaneta sperms compare with other species? Activity from the male was about 450 to 700 beats/min. and from the spermatheca about 800 to 1300 beats/min. The value for human sperms in similar conditions was about 700 to 1100 beats/min. (Ch. 5). The insect sperm compares favourably with this and with bull sperms at about 550 beats/min.; but the activity is much slower than the 1,800 beats/min. for sea-urchin sperms (Sleigh, 1962).

How is motility initiated, regulated and maintained? Let us consider the evidence on these questions.

Insect spermatozoa have been reported active in situ in the testes (Aedes: Jones, 1967; Bombyx: Omura, 1936b; Chortophaga: Payne, 1934); in the seminal vesicles (Drosophila: Lefevre and Jonsson, 1962; Rhodnius slight activity: Davey, 1958a); in the bursa of the female (Aedes: Jones and Wheeler, 1965a; Spielman, 1964; Drosophila: De Vries, 1964; Nonidez, 1920); and in the spermatheca (Aedes: Jones and Wheeler, (1.c.); Drosophila: De Vries (1.c.) etc.; Sciara: Phillips, 1966; Makielski, 1966; Rhodnius: Davey, 1958b; Pseudococcus: Nur, 1962; Dahlbominus: Wilkes, 1965; Coleoptera: Surtees, 1961).

Within the above selection of papers, for example Wilkes (1965), there are discussions and also evidence of inactivity within the various organs of the same and other insects. It is clear that sperm activity or quiescence in situ is adjusted to the requirements of each species. 
We have seen that in Periplaneta the spermatozoa and, indeed, the spermatids are inhibited in the testes; as are sperms in the seminal vesicles and in the spermatheca. The fact that in vitro activity occurs under diverse conditions suggests that, in addition to possible restraint by the viscous nature of the semen, some chemical inhibitor is present.

Dopamine produced a reversible inhibition of sperms (Ch. 6). It might prove difficult to demonstrate sufficiently high concentrations of dopamine in the semen in view of its general association with the melanin and tanning processes of the cuticle (Wigglesworth, 1965). Alternative forms of inhibition are equally likely and, indeed, dopamine may prove toxic after pròlonged exposure.

But some serious thought must be given to possible physical inhibition. The acrosome and the tail-tip of sperms tend to stick to glass, and the tailtips to each other; material, also apparently sticky, from the acrosome may be released in the spermatheca; the surface area of a spermatozoon is great in relation to its mass. Taken together, these points could help explain the quiescence and viscous appearance of dense masses of sperms in situ. It is important to know more regarding the exact physical relationships of packed sperms, and the physico-chemical nature of their cell membranes and the surrounding medium.

The dubious roles of oxygen and hexose with respect to sperm activity have been discussed in this chapter. Makielski (1966) assumes too much in stating that initiation of motility depends on energy supply which is not normally available until after sperm leave the testis and which, for insect sperms, consists of an adequate source of oxygen. Anaerobic metabolism supports the motility of sperms of Periplaneta, Rhodnius (Davey, 1965a) and 
of Melolontha (Landa, 1961). Besides, there is no evidence of significant variations in oxygen concentration within the reproductive organs of insects, and on the contrary, the activity in vitro, of cockroach sperms within the spermatheca may have started at lower oxygen levels than occur in vivo.

Oxygen alone cannot be the sole limiting factor, but an accumulation of metabolites might reduce or switch off activity. It would be interesting to test the effect of lactate on sperm activity under various oxygen and substrate concentrations. However, the suggestion by Flanders (1939) of $\mathrm{CO}_{2}$ gradients within the insect is open to serious criticism. Carbon dioxide diffuses rapidly throughout tissue and, moreover, it is dissolved, readily forming bicarbonate. There is a good buffering system within tissues and any tendency towards acidity would be opposed.

There is no evidence of a chemical activator, such as occurs in Bombyx (Omura, 1936a), in Periplaneta but some sort of metabolic inhibitor seems likely. If this is so, the inhibitor might be removed by oxidation or diluted by Ringers or even, perhaps, by spermathecal secretions at copulation. If one accepts that inactivity is maintained by chemical inhibition, then one must postulate the reaccumulation of this or some other chemical within the spermatheca to explain the inactivation of highly active sperms observed in the spermatheca on a slide (Ch. 4). The suggestion that bisulphite inhibits lactate dehydrogenase was considered in Chapter 2 and applying this model to the evidence in Periplaneta we find that oxygen must destroy the inhibition while Ringers wash both bisulphite and lactate away; lactate alone may accumulate after intense, confined activity. These various suggestions require thorough investigation before much more can be concluded. Another problem concerns activity; why are spermatozoa from the female 
so much more active than those from the male? The acrosome is smaller in those from the female but the larger acrosome cannot physically inhibit high activity, for high activity of unmodified sperms occurred in at least one case (Ch. 5). But this activity was after the sperms might have been activated in the spermatophore or in the spermatheca. In Sciara, motility occurs in the spermatheca before sloughing of the nełenkern (Makielski, 1966). High activity is not a simple-physical phenomenon but is probably induced by secretions: of the female.

A simple sperm stimulant is unlikely in view of the negative in vitro results. There may be an enzyme produced which removes or alters say, part of the cell membrane, increasing its permeability to ions. As discussed in Chapter 2, a leaky tail-membrane is a necessary condition for the active sperm model of Steinbach and Dunham (1962). One might expect an increased sensitivity to chemicals in such sperms but, in fact, sperms from the female showed no such sensitivity and were less susceptible to dopamine. The separation and immunological identification (see Tyler et al., 1967) of the acrosome, head and tail of sperms from the male and female of Periplaneta might be feasible (see Fig. 21) and might shed light on the changes which occur in the female.

In addition to the increase in potential activity, the sperms in the female undergo a reduction in the acrosome. The change in the acrosome of Periplaneta bears a striking resemblance to those which occur in mammalian spermatozoa as they ascend the female tract, in particular the fallopian tube, and as they penetrate the cumulus oophorus surrounding the ovum (Austin, 1965; Monroy, 1965). It must be emphasised that in these cases the elevation and complete loss of the acrosome in the region of the vitellus represent 
final stages in the process of fertilization. But the important, earlier phenomenon of capacitation is more subtle. First, there does not appear to be any obvious physical difference between ejaculated and capacitated mammalian sperms (Bedford, 1964) and secondly, capacitation of rabbit sperms appears to be reversible to some extent (Chang, 1957; Bedford and Chang, 1962).

It is possible although very unlikely, that the acrosome material of Periplaneta has a nutritive function, sustaining the spermatozoan activity for the first hours in the spermatheca; or it may be a stimulant producing contractions of the duct muscles. Alternatively, the material, which appears to be sticky, may serve to bind the sperms in a quiescent mass. However, it is difficult to imagine the process of acrosome reduction in Periplaneta as other than a preparatory "unsheathing" before penetration of the egg, that is, as a form of capacitation.

Capacitation in an insect was first suggested by Makielski (1966) who found that sperm maturation took place in the spermatheca of Sciara. It consisted of the aquisition of motility and the elimination of part of the nebenkern. Makielski did not observe an acrosome in any sperms, but Phillips (1966) had described the acrosome in Sciara. The acrosome in the testis appeared to be unmodified in the spermatheca. In Sciara maturation of sperms does not appear to be intrinsically controlled, and factors in the spermathecal fluid may play a role in its completion (Makielski, 1.c.). The same conclusion has been reached for Periplaneta in this work. Sperm maturation and capacitation are not the same thing for fertilizing potency is the criterion for the latter. It is likely, as discussed in Chapter 2, that sperms undergo several maturing processes and 
it may be difficult to decide at which capacitation has occurred. One finds a gradient of conditions in animals generally, from sperms that are released from the male, fully "capacitated", to those which mature that essential bit further in the female when capacitation has occurred. It is very likely that capacitation may include diverse phenomena, peculiar to species or groups of animals. Thus, perhaps, in Periplaneta the acrosome is modified, while in Sciara part of the nebenkern is shed, etc.

Robinson (1965) reported an insect in which scyncytial sperm bundles are passed to the female. These remarkable sperms share a common cytoplasm and membrane. In the female the bundles become motile and release motile spermatozoa. A similar process was reported for Pseudococcus (Nur, 1962) and in Chortophaga the hyaline cap of the pseudo-bundles appears to be digested in the spermatheca (Payne, 1934).

In view of the variety of forms of "precocious" insemination, we may be forced to conclude that capacitation is not a useful general term when applied to insect spermatozoa. However, the variability which defies a general classification should provide rewarding material for specific studies. The lowly echinoderms have provided a disproportionate amount of information on fertilization; but it is with the insects that we may find models of the reproductive systems of higher animals. 


\section{SUMMARY}

1. The large leaf-shaped acrosome of the spermatozoon Periplaneta became smaller and of simpler appearance after some hours within the spermatheca of the female.

2. The activity of Gouldin's solution of sperms from the male rose to about 400 - 700 beats/min., while sperms from the spermatheca were inmediately active and at about $800-1200$ beats/min.

3. The larger acrosome of the sperms from the male could not account for their lower activity. Neither of the above changes could be duplicated in vitro with tissue extracts, chemicals, or modifications to the Ringer.

4. Sperm activity generally was unaffected, or perhaps very slightly, by tissue extracts from the male and female, by the absence of substrate in the Ringer, by pronounced changes in concentration of $\mathrm{K}^{+}, \mathrm{Ca}^{++}, \mathrm{PO}_{4}^{--}, \mathrm{HCO}_{3}^{-}$, or by glucosamine, ATP, seratonin, adrenaline at various concentrations. Strong inhibition occurred with dopamine at $10^{-2} \mathrm{M}$ and $10^{-3} \mathrm{M}$ and some persisted down to about $10^{-5} \mathrm{M}$ or $10^{-6} \mathrm{M}$. Inhibition was reversible to some extent.

5. Spermatozoa were always quiescent in situ except in one case during spermathecal filling. The evidence suggests that sperms may be activated at this time, possibly by secretion from the spermatheca, and that sperm motility and probably peristalsis of the spermatheca are responsible for sperm migration into that organ.

6. The results are discussed and related to literature on the morphology, behaviour, and physiology of spermatozoa of other insects and other groups. 
"Do not attempt to discover anything new - you can do that later on a higher salary.... Always keep in mind the basic purpose of the thesis: to satisfy the graduate school".

A.W. James, How to Write a thesis, Letter to Science, 1967,156:170.

"We shall try to see the scientist with no axe to grind other than the axe of truth and no product to advertise save the product of honest and careful enquiry".

M.J. Moroney,

Facts from Figures, 1951, Penguin Books. 


\section{APPENDIX I}

A stock of a few thousand cockroaches was maintained in three 16 gallon plastic containers at $28 \mathrm{C}$ under normal lighting. They were supplied with fresh water and a diet of dried milk, wheat germ, baby food cereal and mouse chow. Isolated insects were kept in glass bowls or jars, usually in a humid incubator at $28 \mathrm{C}$ in the dark. The insects for experiments were healthy. In one male only, a mild infection of adult gregarines, similar to the Gregarina of the cockroach alimentary canal, was found in the seminal vesicles; the spermatozoa were normal. 
Gouldin's solution (Richards, 1963) is not mentioned in an important review by Lockwood (1962). It has a $\mathrm{pH}$ about 6.4 and a calculated osmolarity of 295 milliosmoles (assuming full dissociation of major ions only) and a measured osmolarity of about 285 milliosmoles (accuracy not high).

\section{Gouldin's Solution}

Part A - $100 \mathrm{ml}$.

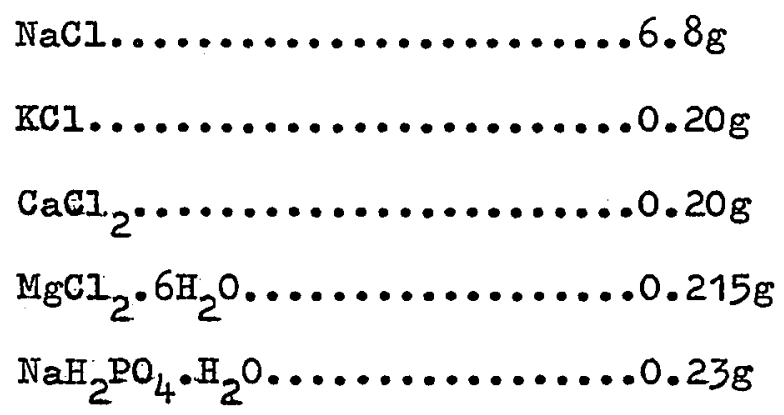

$\underline{\text { Part B }}-100 \mathrm{ml}$

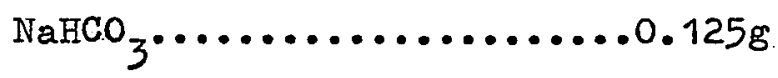

$\underline{\text { Part } \mathrm{C}}-100 \mathrm{ml}$

Glucose (Dextrose)........7.7g

Add $1 \mathrm{ml}$ each of $\mathrm{A}, \mathrm{B}$ and $\mathrm{C}$ to $? \mathrm{mI} \mathrm{H}_{2} \mathrm{O}=10 \mathrm{ml}$ Gouldin's solution. 
(App.II contd)

Substitutes for Gouldin's solution (Ch.6) were as follows: $0.15 \mathrm{M} \mathrm{NaCl}$ (300 milliosmoles), $0.15 \mathrm{M} \mathrm{KCl}$ (300 milliasmoles), $0.15 \mathrm{M} \mathrm{CaCI}_{2}$ (450 milliosmoles.), 0.07. $\mathrm{Na}_{3}$ Citrate (280 milliosmoles).

\section{Chemicals}

The following chemicals were kept refrigerated and generaliy protected from Iight.

$\mathrm{d}(+)$ GIucosamine HCI (Brickman Co.)

Adenosine. 5' - Triphosphate, Disodium salt, plus $4 \mathrm{H}_{2} \mathrm{O}$

(Anhydrous. M.wt.551, Hydrated M.wt.623; From Equine

Muscle) (N.B.C.)

Dopamine ECI (N.B.C.)

Adrenaline (Epinephrine) (N.B.C.)

Seratonin Creatine Sulphate (N.B.C.)

\section{Fixatives}

Neutral Formalin; 5\% with some phosphate buffer to $\mathrm{pH} 7$.

Glutaraldehyde; $\quad 2.5 \%$ with phosphate buffer to $\mathrm{pH} 7.4$ and fixation took place in the cold. 
Alexander, R.D. 1964. The evolution of mating behaviour in arthropods. In 'Insect Reproduction'. K.C. Highnam ed., R.ent.Soc.Lond., Symp. No.2: 78-94.

Amir, D. and Schindler, H. 1967. The effects of high sperm concentrations on the rates of respiration and fructolysis by ram spermatozoa. J. Reprod. Fert. 13: 93-99.

Applegate, A and Nelson, I. 1962. Acetylcholinesterase in Mytilus spermatozoa. Biol. Bull. Woods Hole. 123: 475.

Austin, C.R. 1966. Fertilization. Prentice-Hall Inc., Englewood Cliffs, New Jersey.

Balbiani, E.G. 1869. Sur le mechanisme de la feconoation chez les Lepidopteres. C.R. Acad. Sci. Paris.

Bedford, J.M. 1964. Fine structure of the sperm head in ejaculate and uterine spermatozoa in the rabbit. J. Reprod. Fert. 7: 221-228.

, 1966. Development of fertilizing ability of spermatozoa in the epididymus of the rabbit. J. Exp. Zool. 163: 319.

, 1967. The importance of capacitation for establishing contact between eggs and sperm in the rabbit. J. Reprod. Fert. 13: 365-367.

Bedford, J.M. and Chang, M.C. 1962. Removal of decapacitation factor from seminal plasma by high speed centrifugation. Amer.J. Physiol. 202: 179-181.

Bedford, J.M. and Shalkovsky, R. 1967. Species specificity of sperm capacitation in the rabbit. J. Reprod. Fert. 13: 361-364.

Bishop, D.W. ed. and contributor, 1962. Spermatozoan Motility. Publ. no.72, Amer. Ass. Adv. Sci., Washington.

Bishop, G.H. 1920a. Fertilization in the honej-bee. I. The male sexual organs: their histological structure and physiological function. J. Exp. Zool. 31: 225-258.

, 1920b. Fertilization in the honey-bee. II. Disposal of the sexual fluids in the organs of the female. J. Exp. Zool. 31: $267-286$.

Blandau, R.J. and Rumery R.E. 1964. The relationship of swimming movements of epididymal spermatozoa to their fertilizing capacity. Fertil. Steril. 15: 571-579.

Blum, M.S., Glowska, S. and Taber, S.III. 1962. Chemistry of the drone honey bee reproductive system. II Carbohydrates in the reproductive organs and semen. Ann. Ent. Soc. Amer. 55:135-139. 
BIum, M.S. and Taber, S.III. 1965. Chemistry of the drone honey bee reproductive system. III. Dehydrogenase in washed spermatozor. J. Ins. Physiol. 11: 1489-1501.

Bordas, I. 1909. Recherches anatomiques, histologiques et physiologiques sur les organes appendiculaires de l'appareil reproducteur femelle des Blattes (Periplaneta orientalis $I_{\text {. }}$ ). Ann. Sci. Nat. Paris. ser. 9 Zoo: 9: 71-121.

Brachet, J. 1960. The Biochemistry of Development. Pergamon Press, New York.

Bradfield, J.R.G. 1955. Fibre patterns in animal flagella and cilia. Symp. Soc. Exp. Biol. 9: 306-334.

Brokaw, C.J. 1957. 'Electro-chemical' orientation of braken spermatozaids Nature 179:525.

1967. Adenosine triphosphate usage byflagella.

Science 156: 76-78.

Brown, F.A. Jnr., ed. 1950. Selected Invertebrate Types. John Wiley and Sons Inc., New York.

Brunet, P.C.J. 1951. The formation of the ootheca by $P$. americana. I. The micro-anatomy and histology of the posterior part of the abdomen. Quart. J. Micr. Sci. 92: 1-27.

Carlson, F.D. 1962. A theory of the survival value of motility. In 'Spermatozoan Motility', D.W. Bishop ed., pp. 137-146. (See Bishop, D.W.).

Chang, M.C. 1957. A detrimental factor in seminal plasma on the fertilizing capacity of sperm. Nature, Lond. 179: 258-259.

, 1958. Capacitation of rabbit spermatozoa in the uterus, with special reference to the reproductive phases of the female. J. Endocr. 63: 619-628.

, 1959. Fertilizing capacity of spermatozoa. In 'Recent Progress in the Endocrimology of Reproduction'. C.W. Iloyd ed., pp.131162. Academic Press, New York.

Colwin, A.I. and Colwin, I.H. 1964. Gamete membranes in fertilization. In 'Cellular Membranes in Development'. M. Locke ed., pp.233-279. Symp. no. 2, Soc. for the Study of Development and Growth. Academic Press, New York.

Cragg, F.W. 1920. Further observations on the reproductive system of Cimex with special reference to the behaviour of spermatozoa. Ind. J. Med. Res. 8: 32 . 
Cross, B.A. 1959. Hypothalamic influences on sperm transport in the male and female genital tract. In 'Recent Progress in the Endocrinology of Reproduction'. C.W. Hloyd ed., pp.167-176. Academic Press, New York.

Davey, K.G. 1958a. Physiology of Reproduction in Rhodnius.

D. Phil.Thesis, Cambridge University.

, 1958b. The migration of spermatozoa in the female of Rhodnius prolixus Stahl. J. Exp. Biol. 35: 694-701.

, 1959. Spermatophore production in Rhodnius prolixus Stahl. Quart. J. Micr. Sci. 100: 221-230.

, 1960a. The evolution of spermatophores in insects. Proc. R. ent. Soc. London A 35: 107-113.

, 1960b. A pharmacologically active agent in the reproductive system of insects. Can. J. Zool. 38: 39-45.

1965a. Reproduction in the Insects. University Reviews in Biology, Oliver and Boyd, Edinburgh.

, 1965b. Copulation and egg production in Rhodius prolixus:

The role of the spermatheca. J. Exp. Biol. 42: 373-378.

Davey, K.G. and Webster, J.F. 1967. The structure and secretion of the spermatheca of Rhodnius prolixus Stahl: A histochemical study. Can. J. Zool. 45: 653-658.

Davis, N.T. 1956. The morphology and functional anatomy of the male and female reproductive systems of Cimex lectularius $L$. (Heteroptera, Cimicidae). Ann. Ent. Soc. Amer. 49: 467-493.

1965a. Studies of the reproductive physiology of Cimicidae (Hemiptera). II. Artificial insemination and the function of the seminal fluids. J. Ins. Physiol. 11: 355-366.

1965b. Studies of the reproductive physiology of Cimicidae (Hemiptera). III. The seminal stimulus. J. Ins. Physiol. 2: 1199-1211.

DeVries, J.K. 1964. Insemination and sperm storage in Drosophila melanogaster. Evolution 18: 271-281.

Dewitz, J. 1886. Uber der Setzmussigkeit in der Ortsveranderung der Spermatozoon und in der Vereinigung derselben mit dem Ei. Archiv. ges. Physiol. 38: 358-385.

Fawcett, D.W. 1962. Sperm tail structure in relation to the mechanism of movement. In 'Spermatozoan Motility'. D.W. Bishop ed., pp. 147-170. (See Bishop, D.W.). 
Flanders, S.E. 1939. Environmental control of sex in hymenopterous insects. Ann. Ent. Soc. Amer. 32: 11-16.

, 1946. The mechanism of sex control in the honey bee. J. Econ. Ent. 39: 379-380.

Freund, M., Saphier, A. and Wiederman, J. 1964. In vitro studies of the effect of semen on the motility of the vagina, uterus and uterine horns in the guinea pig. Fertil. Steril. 15: 188-201.

Gibbons, I.R. 1967. The organisation of cilia and flagella. In 'Molecular Organisation and Biological Function'. J.M. Allen ed., Harper and Row, New York.

Gonse, P.H. 1962. Respiration and oxidative phosphorylation in relation to sperm motility. In 'Spermatozoan Motility'. D.W. Bishop ed., pp. 99-132. (See Bishop, D.W.).

Gottschewski, G. 1937. Kunstliche Befruchtung bei Drosophila. Naturwissenschaften 25: 650.

Gupta, P.D. 1947. On copulation and insemination in the cockroach Periplaneta americana (Iinn.). Proc. Nat. Inst. Sci. Ind. 8: 65-104.

Hartree, E.F. and Srivastava, P.W. 1965. Chemical composition of the acrosomes of ram spermatozoa. J. Reprod. Fert. 9: 47-60.

Hamner, C.E. and Williams, W.I. 1963. Effect of the female reproductive tract on sperm metabolism in the rabbit and fowl. J. Reprod. Fert. 5: 143-150.

-. 1964. Identification of sperm stimulating factor of rabbit oviduct fluid. Proc. Soc. Exp. Biol. Med. 117: 240-243.

Hayashi, T. 1962. Muscle research and flagellar movement. In 'Spermatozoan Motility', D.W. Bishop ed., pp. 279-284. (See Bishop, D.W.).

Heberdey, R.F. 1931. Zur Entwicklungsgeschichte vergleichenden Anatomie und Physiologie der weiblichen Geschlechtsausfurwege der Insekten. Zeits. Morph. Okol. Tiere. 22: 416-586.

Heller, J. and Piechowska, M. 1956. Pyrophosphate in the hawk-moth, C. euphorbiae. Bull. Acad. Polonaise Sci. Cl. II. 4: 345-349.

Hewer, H.R. 1934. Studies in Zygaena (Lepidoptera). Part II. The mechanism of copulation and the passage of the sperm in the female. Proc. Zool. Soc. London 104: 513-527.

Hinton, H.E. 1963. Sperm transfer in insects and the evolution of haemocoelic insemination. In 'Insect Reproduction'. K.G. Highnam ed., R. ent. Soc. London, Symp. 2: 95-107. 
Hoffmann-Berling, H. 1955. Geisselmodelle und Adenosintriphosphat. Biochim. et Biophys. Acta. 16: 146-154.

Imms, A.D. 1957. A General Textbook of Entomology, 9th ed. (Revised by 0.W. Richards and R.G. Davies). Methuen and Co. Itd., Iondon.

Ito, H. 1924. Contribution histologique et physiologique a l'etude des annexes des organes genitaux des Orthopteres. Arch. d'Anat. Micr. 20: $343-460$.

Jones, J.C. 1967. Spermatocytes in Aedes aegypti (Iinnaeus). Biol. Bull. 132: 23-33.

Jones, J.C. and Wheeler, R.E. 1965a. Studies on spermathecal filling in Aedes aegypti (Linnaeus). I. Description. Biol. Bull. 129: $134-150$.

-1965b. Studies on spermathecal filling in Aedes aegypti (I innaeus). II. Experimental. Biol. Bull. 129: 532-545.

Jurecka, B. 1950. Morphology of mushroom shaped gland of Blatta orientalis. Sprawozdania z Posiedzen, Wydzialu IV, Nauk Biologicznych, Warszawa 41: 81-102 (English Summaxy).

Kaye, J.S. 1962. Acrosome formation in the house cricket. J. Cell. Biol. 12: $411-431$.

Khalifa, A. 1949. The mechanism of insemination and the mode of action of the spermatophore in Gryllus domesticus. Quart. J. Micr. Sci. 90: $281-292$.

, 1950. Spermatophore production in Blattella germanica $L$. (Orth: Blattidae). Proc. R. ent. Soc. Iondon A 25: 53-61.

Kinoshita, S. 1959. On the identity of the motility inducing factor of flagella and relaxing factor of muscle. J. Fac. Sci. Tokyo Univ., Sect. 4, Zool., 8: 427-437.

Kirton, K.T. Desjardins, C. and Hafs, H.D. 1966. Levels of some normal constituents of rabbit semen during repetitive ejaculation. Fertil. Steril. 17: 204-211.

Kirton, K.T. and Hafs, H.D. 1965. Sperm capacitation by uterine fIuid or beta-amylase in vitro. Science 150: 6j8-619.

Kurzrok, R. and Birnberg, C. 1958. A study of semen mucus penetration and its relation to a test for ovulation. Internat. J. Fertil. 3: 134-138.

Landa, V. 1961. Use of an artificial spermatophore in the study of the activation of the spermatozoa and development of the spermatophores in the cockchafer. Nature 190: 935-936. 
Lardy, H.A., Ghosh, D. and Plant, G.W.E. 1949. A metabolic regulator in mammation spermatozoa. Science 109: 365-367.

Lefevre, G. and Jonsson, U.B. 1962. Sperm transfer, storage displacement and utilization in Drosophila melanogaster. Genetics 47: 1719-1736.

Lockwood, A.P.M. 1961. Ringer solutions and some notes on the physiological. basis of their ionic composition. Comp. Biochem. Physiol. 2: 241-289.

Makielski, S.K. 1966. The structure and maturation of the sperm of Sciaris coprophila. J. Morph. 118: 11-42.

Mann, T. 1964. Biochemistry of Semen and of the Male Reproductive Tract. Methuen and Co. Itd., Iondon.

Metz, C.B. and Monroy, A. eds., 1967. Fertilization Vol.I. Comparative Morphology, Biochemistry and Immunology. Academic Press, New York.

Miall, I.C. and Denny, A. 1886. The Structure and Iife History of the Cockroach. LovelI Reeve and Co., Iondon.

Moghissi, K.S., Dabuh, D. Levine, J. and Neuhaus, 0.W. 1964. Mechanism of sperm migration. Fertil. Steril. 15: 15-23.

Monroy, A. 1965. Chemistry and Physiology of Fertilization. Holt, Rinehart and Winston Inc., New York.

Moses, M.J. 1966. Cytoplasmic and intra-nuclear microtubules in relation to development, chromosome morphology and motility of an aflagellate spermatozoon. Science 154: 424.

Nath, V., Gupta, B.I. and Mittal, I.C. 1960. Position of the proximal centriare in flagellate spermatozoa. Nature 186: 899-900.

Nath, V., Gupta, B.I. and Sehgal, P. 1957. Mitochondria and Golgi bodies in the spermatogenesis of Periplaneta americana as studied under the phase-contrast microscope. Res. Bull. Panjab. Univ. 112: 317-326.

Nelson, I. 1955. Adenosinetriphosphatase of Mytilus sperm. I. Effects of pH, Calcium and magnesium and concentration of enzyme and substrate. Biol. Bull. Woods Hole, 109: 295-305.

1962. Cytochemical aspects of spermatozoan motility. In 'Spermatozoan Motility', D.W. Bishop ed., pp. 171-188. (See Bishop, D.W.).

_. 1964. Acetylcholinesterase in bull spermatozoa. J. Reprod. Fert. ?: 65-71. 
Nelson, Olm E. 1953. Comparative Embryology of the Vertebrates. The Blakiston Co. Inc.,. New York.

Nevo, A.C. 1965. Dependence of sperm motility and respiration on oxygen consumption. J. Reprod. Fert. 9: 103-107.

Nonidez, J.F. 1920. Internal phenomena of reproduction in Drosophila. Biol. Bull. 39: 210-230.

Noyes, R.W., Watton, A. and Adams, C.E. 1958. Capacitation of rabbit spermatozoa. J. Endocr. 17: 347-380.

Nornis, M.J. 1932. Contributions towards the study of insect fertility. I. The structure and operation of the reproductive organs of the genera Ephestia and Plodia. Proc. Zool. Soc. Lond. 102: 595-611.

Novak, A.F., BIum, M.S., Taber, S. and Iiuzzo, J.A. 1960. Separation and determination of seminal plasma and sperm amino acids of the honey bes Apico mellifera. Ann. Ent. Soc. Amer. 53: $841-843$.

Nunez, A. 1963. On the fine structure of the sperm tails of Culex pipiens. Biologisches Zentralblatt 82: 1-7.

Nur, U. 1962. Sperm, sperm bundles and fertilization in a mealy bug Pseudococcus obscura Essig (Homoptera: Coccoidea). J. Morph. 111: 173-199.

Ogasawara, F.X. and Iorenz, F.W. 1964. Respiratory rate of cock spermatozoa as affected by oviduct extracts. J. Reprod. Fert. 7: $281-288$.

Omura, S. 1936a. Artificial insemination of Bombyx mori. J. Fac. Agric. Hokkaido Imp. Univ. 38: 135-150.

, 1936b. Studies on the reproductive system of Bombyx mori. I. Structure of the testis and the intra-testicular behaviour of the spermatozoa. J. Fac. Agric. Hokkaido Imp. Univ. 38: 151-181.

, 1938a. Structure and function of the female fenital system of Bombyx mori, with special reference to the mechanism of fertilization. J. Fac. Agric. Hokkaido Imp. Univ. 40: 111-128.

, 1938b. Post-testicular organs and post-testicular behaviour of the spermatozoa in Bombyx mori. J. Fac. Agric. Hokkaido Inp. Univ. 40: $129-170$.

Pantel, J. and De Sinety, R. 1906. Les cellules de la la lignee male chez le Notonecta glauca $L_{.}$, avec les details plus etendus sur la periode d'accroissement et sur celle de transformation. La Cellule 23: 87-303. 
Parkes, A.S. ed., 1956. Marshall's Physiology of Reproduction. 3rd ed. Longmans, Green and Co., London.

Payne, M.A. 1933. The structure of the testis and movement of sperms in Chortophaga viridifasciata as demonstrated by intravitam technique. J. Morph. 54: 321-346.

, 1934. Intravitam studies on the Hemipteran, Leptocoris trivitatus. A description of the male reproductive system and turning of the sperms. J. Miorph. 56: 513-532.

Phillips, D.M. 1966. Fine structure of Sciara coprophila sperm. J. Cell Biol. 30: 499-517.

Proudfoot, F.G. and Stewart, D.K.R. The effect of oxygen and type of container on the retention of fertilizing capacity of fowl spermatozoa stored in vitro. J. Reprod. Fert. 13: 251-257.

Quin, P.J. and White, I.G. 1966. Variations in semen cations in relation to semen quality and methods of collections. Fertil. Steril. 17: $815-825$.

Richards, A.G. 1963. The rate of sperm locomotion in the cockroach as a function of temperature. J. Ins. Physiol. 9: 545-549.

Robbins, W.G. 1965. Ultrastructure and motility of a scyncytial bundle in an armored scale insect. Notes from Symp. III, Fifth Ann. Meeting of the Amer. Soc. for Cell Biology, no. 171.

Rorie, D.K. and Newton, M. 1964. Oxytocic factors in the plasma of the human male. Fertil. Steril. 15: 135-142.

Roth, L.M. and Willis, E.R. 1954. The reproduction of cockroaches Smithsonian Misc. ColI. 122: 1-49.

Rothschild, Lord 1948a. The physiology of sea-urchin spermatozoa. Lack of movement in semen. J. Exp. Biol. 25: 344-352.

, 1948b. The physiology of sea-urchin spermatozoa. Senescence and the dilution effect. J. Exp. Biol. 25: 353-368.

, 1950. The respiration of sea-urchin spermatozoa.

J. Exp. Biol. 27: 420-436.

, 1955. The spermatozoa of the honey bee. Trans. R. ent. Soc. London 107: 289-294.

, 1962. Sperm movement: problems and observations. In 'Spermatozoan Motility', D.W. Bishop ed., pp. 13-30. (See Bishop, D.W.).

Ruttner, F. 1956. The mating of the honeybee. Bee World, 37: 3-22. 
Salisbury, G.W. 1962. Ionic and osmotic conditions in relation to metabolic control. In 'Spermatozoan Motility', D.W. Bishop ed., pp. 59-88. (See Bishop, D.W..).

Sleigh, M.A. 1962. The Biology of Cilia and Flagella.

Pergamon Press, Maciililion Co., New York.

Snodgrass, R.E. 1931. Morphology of the insect abdomen. I. General structure of the abdomen and its appendages. Smithsonian Misc. Coll. 85: 1-26.

, 1933. Morphology of the insect abdomen. II. The genital ducts and the ovipositor. Smithsonian Misc. Coll. 89: 1-48.

1936. Morphology of the insect abdomen. III. The male genitalia (including arthropods other than insects). Smithsonian Misc. Coll. 95: $1-96$.

$\therefore$ 1940. Male genitalia of orthopteroid insects. Smithsonian Misc. ColI. 96: 1-107.

Soupart., P. and Clewe, T.H. Sperm penetration of rabbit zona pellucida inhibited by treatment of ova with neuraminidase. Fertil. Steril. 16: 677-689.

Soupart, P. and Orgebin-Crist, M. 1966. Capacition of rabbit spermatozoa delayed in vivo by double ligation of uterine horn. J. Exp. Zool. 163: $\overline{311} \overline{318}$.

Spielman, A. 1964. The mechanism of copulation in Aedes aegyptii. Biol. Bull. 127: 324-344.

Steinbach, H.B. and Dunham, P.B. 1962. Ionic balance of sperm cells. In 'Spermatozoan Motility', D.W. Bishop ed., pp. 55-58. (See Bishop, D.W.).

Surtees, G. 1961. Spermathecal structure in some Coleoptera associated with stored products. Proc. Roy. Ent. Soc. Iondon A 36: 144-152.

Taber, S. and Blum, M.S. 1960. Preservation of honeybee semen. Science 131: 1734-1735.

Terner, C. 1962. Oxidative and biosynthetic reactions in spermatozoa. In 'Spermatozoan Motility', D.W. Bishop ed., pp. 89-98. (See Bishop, D.W.).

Tibbs, J. 1962, Adenosine triphosphatase and acetylcholin-esterase in relation to sperm motility. In 'Spermatozoan Motility', D.W. Bishop ed. pp. 233-250. (See Bishop, D.W.).

Tyier, A. 1953. Prolongation of life-span of sea urchin spermatozoa, and improvement of the fertilization-reaction, by treatment of spermatozoa and eggs with metal-chelating agents (amino-acids, versene, dedtc, oxine, cupron). Biol. Bull. 104: 224-239. 
Tyler, A., Tyler, E.T. and Denny, P.C. 1967. Concepts and experiments in immunoreproduction. Fertil. Steril. 18: 153-166.

Van Wyk, I.E. 1952. The morphology and histology of the genital organs of Ieucophaea maderae (Fabr.) (Blattidae, Orthoptera). J. Ent. Soc. S. Africa 15: 3-62.

Voy, A. 1949. Contribution a l'etude anatomique et histologique des organs accessoires de l'appareil genital femelle chez quelques especes d'Orthopteroides. Ann. Sci. Nat. ser. 11 2: 269-349.

Wales, R.G., Wallace, J.C. and White, I.G. 1966. Composition of bull epididymal and testicular fluid. J. Reprod. Fertil. 12: 139-144.

Weidner, H. 1934. Beitrage zur Morphologie and Physiologie des. Genitalapparates des weiblichen Iepidopteren. Z. angew. Ent. 21: 239-290.

Wigglesworth, V.B. 1965. The Principles of Insect Physiology. Sixth Ed., Methuen and Co. Itd., Iondon.

Wilkes, A. 1965. Sperm transfer and utilization by the arrhenotokous wasp Dahlbominus fascipennis (Zett.) Hymenoptera: Eulophidae). 